WORKING PAPER - NO. 2020-02

\title{
Monetary Policy, Redistribution, and Risk Premia
}

Rohan Kekre and Moritz Lenel

JANUARY 2020

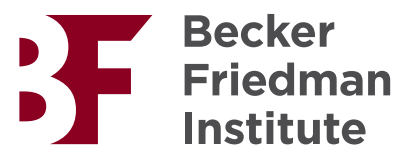




\title{
Monetary Policy, Redistribution, and Risk Premia*
}

\author{
Rohan Kekre` $\quad$ Moritz Lenel ${ }^{\ddagger}$
}

January 2020

\begin{abstract}
We study the transmission of monetary policy through risk premia in a heterogeneous agent New Keynesian environment. Heterogeneity in households' marginal propensity to take risk (MPR) summarizes differences in portfolio choice on the margin. An unexpected reduction in the nominal interest rate redistributes to households with high MPRs, lowering risk premia and amplifying the stimulus to the real economy. Quantitatively, this mechanism rationalizes the role of news about future excess returns in driving the stock market response to monetary policy shocks.
\end{abstract}

JEL codes: E44, E63, G12

Keywords: monetary policy, risk premia, heterogeneous agents

${ }^{*}$ We thank Fernando Alvarez, Adrien Auclert, Markus Brunnermeier, Emmanuel Farhi, Gita Gopinath, Francois Gourio, Veronica Guerrieri, Zhiguo He, Erik Hurst, Anil Kashyap, Nobu Kiyotaki, Stefan Nagel, Brent Neiman, Stavros Panageas, Juan Passadore, Greg Phelan, Monika Piazzesi, Martin Schneider, Alp Simsek, Ludwig Straub, Gianluca Violante, Ivan Werning, Tom Winberry, and Moto Yogo for discussions. We thank Menglu Xu for excellent research assistance.

${ }^{\dagger}$ University of Chicago Booth School of Business. Email: rohan.kekre@chicagobooth.edu.

†Princeton University. Email: lenel@princeton.edu. 


\section{Introduction}

A growing literature finds that expansionary monetary policy lowers risk premia. This has been established for the equity premium in stock markets, the term premium in nominal bonds, and the external finance premium on risky corporate debt. ${ }^{1}$ The basic New Keynesian framework as in Woodford (2003) and Gali (2008) does not capture this aspect of monetary policy transmission. As noted by Kaplan and Violante (2018), this is equally true for emerging heterogeneous agent New Keynesian models in which heterogeneity in the marginal propensity to consume enriches the transmission mechanism but still cannot explain the associated movements in risk premia.

This paper demonstrates that a New Keynesian model with heterogeneous households differing instead in risk-bearing capacity can quantitatively rationalize the observed effects of policy on risk premia, amplifying the transmission to the real economy. An expansionary monetary policy shock lowers the risk premium if it redistributes to households with a high marginal propensity to take risk (MPR), defined as the marginal propensity to save in capital relative to save overall. With heterogeneity in risk aversion, portfolio constraints, rules of thumb, background risk, or beliefs, high MPR households borrow in the bond market from low MPR households to hold leveraged positions in capital. By generating unexpected inflation, raising profit income relative to labor income, and raising the price of capital, an expansionary monetary policy shock redistributes to high MPR households and thus lowers the market price of risk. In a calibration matching portfolio heterogeneity in the U.S. economy, this rationalizes the observed role of news about lower future excess returns in driving the increase in the stock market. The real stimulus is amplified relative to a representative agent economy without heterogeneity in monetary policy exposures and MPRs.

Our baseline environment enriches a standard New Keynesian model with Epstein and Zin (1991) preferences and heterogeneity in risk aversion. Households consume, supply labor subject to adjustment costs in nominal wages, and choose a portfolio of nominal bonds and capital. Production is subject to aggregate TFP shocks. Monetary policy follows a Taylor (1993) rule. Heterogeneity in risk aversion generates heterogeneity in MPRs and exposures to a monetary policy shock. Epstein-Zin preferences allow us to flexibly model this heterogeneity as distinct from households' intertemporal elasticities of substitution. We begin by analytically characterizing the effects of a monetary policy shock in a simple two-period version of this environment, providing an

\footnotetext{
${ }^{1}$ See Bernanke and Kuttner (2005), Hanson and Stein (2015), and Gertler and Karadi (2015).
} 
organizing framework for the quantitative analysis of the infinite horizon which follows.

An expansionary monetary policy shock lowers the risk premium by redistributing wealth to households with a high marginal propensity to save in capital relative to save overall - that is, a high MPR. Redistribution to high MPR households lowers the risk premium because of asset market clearing: if households on aggregate wish to increase their portfolio share in capital, its expected return must fall relative to that on bonds. An expansionary monetary policy shock redistributes across households by revaluing their initial balance sheets: it deflates nominal debt, raises the profits earned using capital, and raises the price of capital. More risk tolerant households hold leveraged positions in capital and have a higher MPR. Hence, an expansionary monetary policy shock will redistribute to these households and lower the risk premium.

These insights are robust to heterogeneity beyond risk aversion. We consider a richer environment in which households may also face portfolio constraints or follow rules-of-thumb; households may be subject to idiosyncratic background risk; and households may have subjective beliefs regarding the value of capital. In this general environment, the MPR continues to summarize the relevant cross-sectional heterogeneity to evaluate the risk premium effects of redistributive shocks. Moreover, because each of these forms of heterogeneity imply that households holding more levered positions in capital will be the ones with a high MPR, they continue to imply that expansionary monetary policy will lower the risk premium through redistribution.

The reduction in the risk premium affects the real economy depending on the monetary feedback rule. Absent nominal rigidity, the investment effect of a shock lowering the risk premium depends on households' intertemporal elasticities of substitution, which control the relative strength of income and substitution effects and thus the equilibrium response of the safe real interest rate to the shock. With nominal rigidity, the response of the real interest rate also depends on the endogenous reaction of monetary policy. This logic applies to the risk premium effects of the primitive monetary shock itself: provided that the central bank's feedback rule limits the rise in the real interest rate following this shock, the decline in the risk premium will be reflected in lower required returns to capital, amplifying the stimulus to investment. The associated increase in household wealth, both due to an increase in labor income and an increase in the price of capital, amplifies the stimulus to consumption.

Accounting for the risk premium effects of monetary policy is important given empirical evidence implying that it may be a key component of the transmission mecha- 
nism. We refresh this point from Bernanke and Kuttner (2005) using the structural vector autoregression instrumental variables (SVAR-IV) approach in Gertler and Karadi (2015). We find that a monetary policy shock resulting in a roughly $25 b p$ reduction in the 1-year Treasury yield leads to a $2 p p$ increase in the real S\&P 500 return. Using a Campbell and Shiller (1988) decomposition and accounting for estimation uncertainty, $20 \%-100 \%$ of this increase is driven by lower future excess returns, challenging existing New Keynesian frameworks where essentially all of the effect on the stock market operates instead through higher dividends or lower risk-free rates.

Extending the model to the infinite horizon, we investigate whether a calibration to the U.S. economy is capable of rationalizing these facts. We match the heterogeneity in wealth, labor income, and financial portfolios in the Survey of Consumer Finances, together disciplining the exposures to a monetary policy shock and MPRs. We use global solution methods to solve the model. To make the computational burden tractable, we model three groups of households: two groups corresponding to the small fraction with high wealth relative to labor income, but differing in their risk tolerance and thus portfolio share in capital, and one group corresponding to the large fraction holding little wealth relative to labor income. In the data, the high-wealth, high-leverage group is disproportionately composed of households with private business wealth, while the high-wealth, low-leverage group is disproportionately composed of retirees.

We find that the redistribution across households with heterogeneous MPRs can quantitatively explain the risk premium effects of an expansionary monetary policy shock. Notably, the redistribution relevant for this result is between wealthy households holding heterogeneous portfolios, rather than between the asset-poor and asset-rich. Using the same Campbell-Shiller decomposition as was used on the data, $38 \%$ of the return on equity in our baseline parameterization arises from news about lower future excess returns, compared to $0 \%$ in a representative agent counterfactual. Consistent with the analytical results, the effect on the risk premium is amplified with a more persistent shock and thus larger debt deflation; higher stickiness and thus a larger increase in profit income relative to labor income; or higher investment adjustment costs and thus a larger increase in the price of capital.

The reduction in the risk premium through redistribution in turn amplifies the effect of policy on the real economy. In both our baseline and counterfactual representative agent economies, we solve for monetary policy shocks which match the roughly $25 b p$ decline in the 1-year Treasury yield which we estimate in the data. Given these shocks, 
our model amplifies the response of quantities by 1.3-1.5 times: the peak investment, consumption, and output responses are $2.2 p p, 0.5 p p$, and $0.9 p p$, while the counterparts in the representative agent economy are $1.7 p, 0.4 p p$, and $0.6 p p$.

Related literature Our paper contributes to the rapidly growing literature on heterogeneous agent New Keynesian (HANK) models by studying the transmission of monetary policy through risk premia. We build on Doepke and Schneider (2006) in our measurement of household portfolios, informing the heterogeneity in exposures to a monetary policy shock. The redistributive effects of monetary policy in our framework follow Auclert (2019). We demonstrate that it is the covariance of these exposures with MPRs rather than MPCs which matters for policy transmission through risk premia. Like Kaplan, Moll, and Violante (2018) and Luetticke (2018), we study a two-asset environment with bonds and capital. And like Alves, Kaplan, Moll, and Violante (2019) and Auclert, Rognlie, and Straub (2019), we study the effects of monetary policy shocks on asset prices. Unlike these models, in our framework assets differ in their exposure to aggregate risk rather than in their liquidity, allowing us to account for the important role of risk premia in driving the change in asset prices.

In doing so, we bring to the HANK literature many established insights from heterogeneous agent and intermediary-based asset pricing. The wealth distribution is a crucial determinant of the market price of risk as in other models with heterogeneous risk aversion (e.g., Garleanu and Panageas (2015)), segmented markets (e.g., He and Krishnamurthy (2013)), rules-of-thumb (e.g., Chien, Cole, and Lustig (2012)), background risk (e.g., Constantinides and Duffie (1996)), or heterogeneous beliefs (e.g., Geanakoplos (2009)). ${ }^{2}$ We build on this literature by focusing on the changes in wealth induced by a monetary policy shock in a production economy with nominal rigidities. In studying this question we follow Alvarez, Atkeson, and Kehoe (2009) and Drechsler, Savov, and Schnabl (2018), who study the effects of monetary policy on risk premia in an exchange economy with segmented markets and in a model of banking, respectively. ${ }^{3}$ We instead study these effects operating through the revaluation of

\footnotetext{
${ }^{2}$ In recent work, Panageas (2019) studies the common structure and implications of these models, and Toda and Walsh (2019) emphasize portfolio heterogeneity as a summary statistic to evaluate the effects of redistribution with incomplete markets, as in our analysis.

${ }^{3}$ More recently, Bhandari, Evans, and Golosov (2019) construct a segmented markets model in the spirit of Alvarez et al. (2009) in which monetary policy also has effects on risk premia. Chen and Phelan (2019) integrate the effects of monetary policy on risk premia in Drechsler et al. (2018) with the macroeconomic framework of Brunnermeier and Sannikov (2014) to study the effects of monetary policy on financial stability. Coimbra and Rey (2019) study the effects of changes in interest rates on
} 
heterogeneous agents' balance sheets in a conventional New Keynesian setting.

Indeed, our paper most directly builds on prior work focused on risk premia in New Keynesian economies. We clarify the sense in which Bernanke, Gertler, and Gilchrist (1999) served as a seminal HANK model focused on heterogeneity in MPRs rather than MPCs. ${ }^{4}$ As we demonstrate, however, heterogeneity in MPRs need not rely on market segmentation, justifying its relevance even in markets which may not be intermediated by specialists. In relating movements in the risk premium to the real economy, we make use of the insight in Ilut and Schneider (2014), Caballero and Farhi (2018), and Caballero and Simsek (2018) that an increase in the risk premium will induce a recession if the safe interest rate does not sufficiently fall in response. ${ }^{5}$ We build especially on the latter two papers, as well as Brunnermeier and Sannikov (2012, 2016), in emphasizing the effects of heterogeneity in asset valuations on risk premia. Relative to these papers, we explore the importance of such heterogeneity for monetary transmission in a calibration to the U.S. economy.

Outline In section 2 we characterize our main insights in a two-period environment, characterizing the mechanisms through which a monetary easing will endogenously redistribute to high MPR households in a wide variety of settings. This provides an organizing framework for our quantitative analysis in the infinite horizon in section 3. Calibrated to the U.S. economy, the redistribution toward high MPR households rationalizes the empirical evidence on the effect of a monetary policy easing on the equity premium and amplifies the stimulus to the real economy.

\section{Analytical insights in a two-period environment}

We first characterize our main conceptual insights in a two-period environment allowing us to obtain simple analytical results. An expansionary monetary policy shock lowers the risk premium on capital if it redistributes to households with relatively high MPRs. Heterogeneity in risk aversion induces a joint distribution of MPRs and monetary policy

risk premia and financial stability in a model with heterogeneous intermediaries.

${ }^{4}$ In Bernanke et al. (1999), households can only trade bonds while entrepreneurs can trade bonds and capital. In equilibrium, households have a zero MPR while entrepreneurs have a positive MPR. Changes in net worth across these agents thus affects credit spreads and economic activity.

${ }^{5}$ While these authors make this point in the case of a time-varying price of risk (as in our model), a similar result obtains with a time-varying quantity of risk as in Fernandez-Villaverde, GuerronQuintana, Kuester, and Rubio-Ramirez (2015), Basu and Bundick (2017), and DiTella (2019). 
exposures such that an expansionary shock lowers the risk premium. A similar result obtains with heterogeneity in portfolio constraints, rules-of-thumb, background risk, or beliefs. The transmission to the real economy is amplified by the decline in the risk premium if the monetary feedback rule limits the rise in the real interest rate.

\subsection{Baseline environment and equilibrium}

There are two periods, 0 and 1 . While we later relax a number of the specific features to demonstrate the generality of our results, this baseline environment is the one we will study quantitatively in the infinite horizon in section 3 of the paper.

Households A unit measure of households indexed by $i \in[0,1]$ is comprised of a continuum of members $j \in[0,1]$ supplying a differentiated variety of labor. There is full consumption insurance within each household. Household $i$ has Epstein-Zin preferences over consumption in each period $\left\{c_{0}^{i}, c_{1}^{i}\right\}$ and labor supply $\left\{\ell_{0}^{i}(j)\right\}_{j=0}^{1}$

$$
v_{0}^{i}=\left(\left(1-\beta^{i}\right)\left(c_{0}^{i} \Phi^{i}\left(\int_{0}^{1} \ell_{0}^{i}(j) d j\right)\right)^{1-1 / \psi^{i}}+\beta^{i}\left(\mathbb{E}_{0}\left[\left(c_{1}^{i}\right)^{1-\gamma^{i}}\right]\right)^{\frac{1-1 / \psi^{i}}{1-\gamma^{i}}}\right)^{\frac{1}{1-1 / \psi^{i}}}
$$

with discount factor $\beta^{i}$, intertemporal elasticity of substitution $\psi^{i}$, relative risk aversion $\gamma^{i}$, and (dis)utility of labor given by the function $\Phi^{i}(\cdot)$. We assume for simplicity that households exogenously supply one unit of non-differentiated labor in period 1, though of course this assumption will be relaxed in the infinite horizon environment.

In addition to consuming and supplying labor, the household chooses its position in a nominal bond $B_{0}^{i}$ and in capital $k_{0}^{i}$ subject to the resource constraints

$$
\begin{aligned}
P_{0} c_{0}^{i}+B_{0}^{i}+Q_{0} k_{0}^{i} \leq & (1-\tau) \int_{0}^{1} W_{0}(j) \ell_{0}^{i}(j) d j-\int_{0}^{1} A C_{0}^{W}(j) d j+ \\
& \left(1+i_{-1}\right) B_{-1}^{i}+\left(\Pi_{0}+\left(1-\delta_{0}\right) Q_{0}\right) k_{-1}^{i}+T_{0}^{i} \\
P_{1} c_{1}^{i} \leq & W_{1}+\left(1+i_{0}\right) B_{0}^{i}+\Pi_{1} k_{0}^{i} .
\end{aligned}
$$

$B_{-1}^{i}$ and $k_{-1}^{i}$ are its endowments in these same assets. In terms of the nominal unit of account ("dollars"), ${ }^{6}$ the consumption good trades at $P_{t}$ dollars at $t$, member $j$ earns an after-tax wage $(1-\tau) W_{0}(j)$ dollars in period 0 and $W_{1}$ dollars in period 1 , one dollar

\footnotetext{
${ }^{6}$ Following Woodford (2003), we model the economy at the cashless limit.
} 
in bonds purchased at $t$ yields $1+i_{t}$ dollars at $t+1$, and one unit of capital purchased for $Q_{t}$ dollars at $t$ yields a dividend $\Pi_{t+1}$ plus non-depreciated value $\left(1-\delta_{t+1}\right) Q_{t+1}$ at $t+1$. We assume that capital fully depreciates after period $1\left(\delta_{1}=1\right)$. Following Rotemberg (1982), in period 0 the household pays a cost of setting its wage for $j$

$$
A C_{0}^{W}(j)=\frac{\chi^{W}}{2} W_{0} \ell_{0}\left(\frac{W_{0}(j)}{W_{-1}}-1\right)^{2},
$$

where $\chi^{W}$ controls the magnitude of adjustment costs, the aggregate wage bill $W_{0} \ell_{0}$ is defined below, and $W_{-1}$ is a reference wage taken as given. Wage adjustment costs are paid to the government and then rebated back through the $i$-specific transfers $T_{0}^{i}$.

Supply-side A union representing each variety $j$ chooses $W_{0}(j), \ell_{0}(j)$ to maximize the social welfare of union members given Pareto weights $\left\{\mu^{i}\right\}$ and the allocation rule

$$
\ell_{0}^{i}(j)=\ell^{i}\left(\ell_{0}(j)\right)
$$

where the functions $\left\{\ell^{i}(\ell)\right\}_{i=0}^{1}$ satisfy $\int_{0}^{1} \ell^{i}(\ell) d i=\ell$ for all $\ell .^{7}$ A representative labor packer purchases varieties supplied by each union and combines them to produce a CES aggregate with elasticity of substitution $\epsilon$ and sold at $W_{0}$, earning

$$
W_{0}\left[\int_{0}^{1} \ell_{0}(j)^{(\epsilon-1) / \epsilon}\right]^{\epsilon /(\epsilon-1)}-\int_{0}^{1} W_{0}(j) \ell_{0}(j) d j .
$$

The representative producer hires $\ell_{0}$ units of the labor aggregate in period 0 and $\ell_{1}$ units of labor directly from households in period 1 , and combines these with $k_{t-1}$ units of capital rented from households each period $t$ to produce the final good with TFP $z_{t}$. In period 0 the producer also uses $\left(\frac{k_{0}}{k_{-1}}\right)^{\chi^{x}} x_{0}$ units of the consumption good to produce $x_{0}$ new capital, where $\chi^{x}$ indexes adjustment costs and we assume the representative producer takes $k_{0}$ as given. Taken together, the producer earns

$$
\begin{aligned}
\Pi_{0} k_{-1} & =P_{0} z_{0} \ell_{0}^{1-\alpha} k_{-1}^{\alpha}-W_{0} \ell_{0}+Q_{0} x_{0}-P_{0}\left(\frac{k_{0}}{k_{-1}}\right)^{\chi^{x}} x_{0}, \\
\Pi_{1} k_{0} & =P_{1} z_{1} \ell_{1}^{1-\alpha} k_{0}^{\alpha}-W_{1} \ell_{1} .
\end{aligned}
$$

\footnotetext{
${ }^{7}$ We demonstrate the robustness of our analytical results to individually-supplied labor in appendix A. In our quantitative analysis, we find the computation of the equilibrium more robust with a union because it reduces the dimension of the fixed point, so we assume the same structure here.
} 
Future TFP is uncertain in period 0, following

$$
\log z_{1} \sim N\left(\log \bar{z}_{1}-\frac{1}{2} \sigma^{2}, \sigma^{2}\right) .
$$

Policy The government sets $\tau=-\frac{1}{\epsilon-1}$ to undo the effects of monopolistic competition in the labor market. The government sets lump-sum transfers $T_{0}^{i}$ so that

$$
T_{0}^{i}=\int_{0}^{1} A C_{0}^{W}(j) d j+\tau \int_{0}^{1} W_{0}(j) \ell_{0}^{i}(j) d j
$$

reflecting the rebating of wage adjustment costs and the payroll tax. Finally, the government sets monetary policy $\left\{i_{0}, P_{1}\right\}$ by committing to a fixed $P_{1}=\bar{P}_{1}$, eliminating inflation risk in the nominal bond, ${ }^{8}$ and setting $i_{0}$ according to the Taylor rule

$$
1+i_{0}=(1+\bar{i})\left(\frac{P_{0}}{P_{-1}}\right)^{\phi} m_{0}
$$

with reference price $P_{-1}$, where $m_{0}$ is the shock of interest. In this two-period setting, the equilibrium can be locally unique even when $\phi \leq 1$, including the useful benchmark where $\phi=-1$ and hence the real interest rate between periods 0 and 1 is

$$
1+r_{1} \equiv\left(1+i_{0}\right) \frac{P_{0}}{P_{1}}=\frac{(1+\bar{i}) P_{-1}}{\bar{P}_{1}} m_{0}
$$

so a shock to the nominal rate translates one-for-one into a shock to the real rate. ${ }^{9}$

Market clearing Market clearing in goods is

$$
\int_{0}^{1} c_{0}^{i} d i+\left(\frac{k_{0}}{k_{-1}}\right)^{\chi^{x}} x_{0}=z_{0} \ell_{0}^{1-\alpha} k_{-1}^{\alpha}, \quad \int_{0}^{1} c_{1}^{i} d i=z_{1} \ell_{1}^{1-\alpha} k_{0}^{\alpha},
$$

in labor is

$$
\left[\int_{0}^{1} \ell_{0}(j)^{(\epsilon-1) / \epsilon} d j\right]^{\epsilon /(\epsilon-1)}=\ell_{0}, \quad 1=\ell_{1},
$$

\footnotetext{
${ }^{8}$ We do so for expositional simplicity but demonstrate the robustness of our analytical results to the case of inflation risk in the nominal bond in appendix A. Our quantitative analysis in the next section features such risk.

${ }^{9}$ Between periods $t$ and $t+1$ we denote $i_{t}$ the nominal interest rate known in period $t$ and $r_{t+1}$ the realized real interest rate depending on the price level in period $t+1$.
} 
in the capital rental market is

$$
\int_{0}^{1} k_{-1}^{i} d i=k_{-1}, \quad \int_{0}^{1} k_{0}^{i} d i=k_{0}
$$

in the capital claims market is

$$
\left(1-\delta_{0}\right) \int_{0}^{1} k_{-1}^{i} d i+x_{0}=\int_{0}^{1} k_{0}^{i} d i
$$

and in bonds is

$$
\int_{0}^{1} B_{0}^{i} d i=0
$$

Equilibrium Given the state variables $\left\{W_{-1}, P_{-1},\left\{B_{-1}^{i}, k_{-1}^{i}\right\}, i_{-1}, z_{0}, m_{0}\right\}$ and a stochastic process for $z_{1}$ in (8), the definition of equilibrium is then standard:

Definition 1. An equilibrium is a set of prices and policies such that: (i) each household $i$ chooses $\left\{c_{0}^{i}, B_{0}^{i}, k_{0}^{i}, c_{1}^{i}\right\}$ to maximize (1) subject to (2)-(3), (ii) each union $j$ chooses $\left\{W_{0}(j), \ell_{0}(j)\right\}$ to maximize the social welfare of its members subject to the allocation rule (4), (iii) the labor packer chooses $\left\{\ell_{0}(j)\right\}$ to maximize profits (5), (iv) the representative producer chooses $\left\{\ell_{0}, x_{0}\right\}$ and $\ell_{1}$ to maximize profits (6)-(7), (v) the government sets $\left\{T_{0}^{i}\right\}$ according to (9) and $\left\{i_{0}, P_{1}\right\}$ according to $P_{1}=\bar{P}_{1}$ and (10), and (vi) the goods, labor, capital, and bond markets clear according to (11)-(15).

Since varieties and unions $j$ are symmetric, $\ell_{0}(j)=\ell_{0}$ and we drop $j$ going forward.

We will analytically study this economy around the point with zero aggregate risk $\left(\sigma=0\right.$ and $\left.z_{1}=\bar{z}_{1}\right)$ and the monetary policy shock $m_{0}$ at a particular value $\bar{m}_{0}$. For any variable $n$, we denote $\bar{n}$ to be its value at the point of approximation, and $\hat{n}$ its log/level deviation from this point (except for $\sigma$, which is a perturbation parameter but will not be denoted as $\hat{\sigma}$ ). For expositional simplicity we do not treat $z_{0}$ as a perturbation parameter of interest, but we discuss this case in appendix A. Like monetary policy shocks, TFP shocks redistribute across households, generating state-dependence in the risk premium and affecting the transmission of TFP shocks to economic activity.

\subsection{Limiting portfolios and MPRs}

To understand the effects of monetary policy shocks through risk premia, it will prove useful to first understand the determinants of households' portfolios in equilibrium as 
well as their marginal portfolio choices given an additional unit of income.

To do so, it is helpful to re-write households' micro-level optimization problem as

$$
\begin{array}{r}
\max \left(\left(1-\beta^{i}\right)\left(c_{0}^{i} \Phi^{i}\left(\ell_{0}^{i}\right)\right)^{1-1 / \psi^{i}}+\beta^{i}\left(\mathbb{E}_{0}\left[\left(c_{1}^{i}\right)^{1-\gamma^{i}}\right]\right)^{\frac{1-1 / \psi^{i}}{1-\gamma^{i}}}\right)^{\frac{1}{1-1 / \psi^{i}}} \text { s.t. } \\
c_{0}^{i}+b_{0}^{i}+q_{0} k_{0}^{i}=y_{0}^{i}\left(w_{0} \ell_{0}^{i}, P_{0}, \pi_{0}, q_{0}\right), \\
c_{1}^{i}=w_{1}+\left(1+r_{1}\right) b_{0}^{i}+\pi_{1} k_{0}^{i},
\end{array}
$$

where we have denominated in lower-case the real analogs to the nominal variables introduced earlier, we have made use of the definition of the real interest rate

$$
1+r_{1} \equiv\left(1+i_{0}\right) \frac{P_{0}}{P_{1}}
$$

and we have collected households' income in period 0 - which they take as exogenous along with $\left\{\ell_{0}^{i}, q_{0}, w_{1}, r_{1}, \pi_{1}\right\}$ - as a function of non-predetermined variables

$$
y_{0}^{i}\left(w_{0} \ell_{0}^{i}, P_{0}, \pi_{0}, q_{0}\right) \equiv w_{0} \ell_{0}^{i}+\frac{1}{P_{0}}\left(1+i_{-1}\right) B_{-1}^{i}+\left(\pi_{0}+\left(1-\delta_{0}\right) q_{0}\right) k_{-1}^{i} .
$$

Defining the real savings of household $i$ chosen in period 0 as

$$
a_{0}^{i} \equiv b_{0}^{i}+q_{0} k_{0}^{i},
$$

its equilibrium portfolio share in capital is given by $\frac{q_{0} k_{0}^{i}}{a_{0}^{i}}$ and its policy functions imply the marginal propensities to consume, save in bonds, save in capital, and save overall

$$
\left\{\frac{\partial c_{0}^{i}}{\partial y_{0}^{i}}, \frac{\partial b_{0}^{i}}{\partial y_{0}^{i}}, \frac{\partial k_{0}^{i}}{\partial y_{0}^{i}}, \frac{\partial a_{0}^{i}}{\partial y_{0}^{i}}\right\}
$$

where these partial derivatives hold fixed all prices and other variables which the household takes as given in (16), namely $\ell_{0}^{i}=\ell^{i}\left(\ell_{0}\right)$, which enters its utility, as well as $q_{0}$, $r_{1}$, and the probability distributions over $w_{1}$ and $\pi_{1}$. We then define a useful summary of the household's portfolio choice on the margin:

Definition 2. Household $i$ 's marginal propensity to take risk (MPR) is given by

$$
m p r_{0}^{i} \equiv \frac{q_{0} \partial k_{0}^{i} / \partial y_{0}^{i}}{\partial a_{0}^{i} / \partial y_{0}^{i}}
$$


The MPR summarizes how much of the marginal dollar of savings the household allocates to capital. As we show in appendix A, the following results hold even when inflation risk renders the nominal bond risky. We give the MPR its name because under any realistic calibration the payoff on capital is more risky than on bonds.

We can better understand the structural determinants of households' portfolios and MPRs by taking their limits as aggregate risk falls to zero. In doing so, we apply techniques developed by Devereux and Sutherland (2011) in the context of open-economy macroeconomics to the present heterogeneous agent New Keynesian environment and our particular statistics of interest. These authors take the difference across countries of a second-order approximation to optimal portfolio choice for each country, and then make use of the method of undetermined coefficients, to characterize crosscountry portfolio shares as aggregate risk falls to zero. Analogous steps can be used to characterize households' portfolio shares in the present environment. Moreover, a second-order approximation to the partial derivatives of the first-order conditions of (16) with respect to $y_{0}^{i}$ can be used to characterize the marginal portfolio responses to income as aggregate risk falls to zero. These steps lead to the first result of the paper, the proof of which (along with all other proofs) is in supplement $\mathrm{A}:{ }^{10}$

Proposition 1. At the limit of zero aggregate risk, $i$ 's portfolio share in capital is

$$
\frac{\bar{q}_{0} \bar{k}_{0}^{i}}{\bar{a}_{0}^{i}}=\left(\frac{\bar{c}_{1}^{i}}{\left(1+\bar{r}_{1}\right) \bar{a}_{0}^{i}}\right) \frac{\gamma}{\gamma^{i}}-\frac{\bar{w}_{1}}{\left(1+\bar{r}_{1}\right) \bar{a}_{0}^{i}},
$$

and its $M P R$ is

$$
\overline{m p r}_{0}^{i}=\frac{\gamma}{\gamma^{i}}
$$

where

$$
\gamma=\left[\int_{0}^{1} \frac{\bar{c}_{1}^{i}}{\int_{0}^{1} \bar{c}_{1}^{i^{\prime}} d i^{\prime}} \frac{1}{\gamma^{i}} d i\right]^{-1}
$$

is the harmonic average of risk aversion weighted by households' period 1 consumption.

Intuitively, a household's portfolio share in capital and its MPR are higher the less risk averse it is relative to other households in the economy. Even though we are asking how the individual household allocates wealth both in equilibrium and when given a marginal dollar, the risk aversion of all other households is relevant because

\footnotetext{
${ }^{10}$ Supplemental material excluded from the main text and appendix for brevity are available on our websites here or here.
} 
this controls the prices faced by the household in general equilibrium.

Proposition 1 further clarifies two useful points regarding the MPR. First, it captures a dimension of heterogeneity in principle orthogonal to the marginal propensity to consume which has been emphasized in prior work: while in the limit of zero aggregate risk the latter is fully determined by households' attitudes towards consumption across dates (discount factors and intertemporal elasticities of substitution), MPRs are governed by attitudes towards consumption across states (relative risk aversion). Second, the MPR is distinct from observed portfolios because it captures portfolio allocation on the margin. Indeed, a household's portfolio share in capital depends not only on risk aversion but its motive to hedge labor income also subject to TFP shocks, captured by $\frac{\bar{w}_{1}}{\left(1+\bar{r}_{1}\right) \bar{a}_{0}^{i}}$ in (18). This hedging motive is irrelevant on the margin.

\subsection{Monetary policy, redistribution, and risk premia}

The joint distribution of portfolios and MPRs determines the effect of a monetary policy shock on the expected excess returns on capital, to which we now turn.

Let $1+r_{1}^{k}$ denote the gross real returns on capital

$$
1+r_{1}^{k} \equiv \frac{\Pi_{1}}{Q_{0}} \frac{P_{0}}{P_{1}}=\frac{\pi_{1}}{q_{0}}
$$

Household $i$ 's first-order conditions with respect to bonds and capital imply

$$
\mathbb{E}_{0}\left[\left(c_{1}^{i}\right)^{-\gamma^{i}}\left(r_{1}^{k}-r_{1}\right)\right]=0 .
$$

Approximating this condition up to third order in the perturbation parameters, and using market clearing in bonds and capital, we obtain:

Proposition 2. Up to third order in the perturbation parameters $\left\{\sigma, \hat{z}_{1}, \hat{m}_{0}\right\}$, the risk premium on capital is

$$
\mathbb{E}_{0} \hat{r}_{1}^{k}-\hat{r}_{1}+\frac{1}{2} \sigma^{2}=\gamma \sigma^{2}+\zeta_{m_{0}} \hat{m}_{0} \sigma^{2}+o\left(\|\cdot\|^{4}\right),
$$

where $\gamma$ was defined in (20) and

$$
\zeta_{m_{0}}=\gamma \int_{0}^{1} \bar{\xi}_{m_{0}}^{i}\left(\overline{m p r}_{0}-\overline{m p r}_{0}^{i}\right) d i
$$


where $\bar{\xi}_{m_{0}}^{i} \equiv \overline{\overline{d\left[c_{1}^{i} / \int_{0}^{1} c_{1}^{i^{\prime}} d i^{\prime}\right]}} \frac{d m_{0}}{d s}$ the effect of a monetary shock on $i$ 's consumption share in period 1, and $\overline{m p r}_{0} \equiv \int_{0}^{1} \frac{\bar{c}_{1}^{i}}{\int_{0}^{1} \bar{c}_{1}^{\prime} d i^{\prime}} \overline{m p r}_{0}^{i} d i=1$ is the weighted average MPR in (19).

$\zeta_{m_{0}}$ summarizes the effect of a monetary policy shock on the risk premium. In this simple two-period model a monetary policy shock affects the risk premium only through redistribution. ${ }^{11}$ If monetary policy does not redistribute $\left(\bar{\xi}_{m_{0}}^{i}=0\right.$ for all $\left.i\right)$ or households have identical MPRs $\left(\overline{m p r}_{0}^{i}=\overline{m p r}_{0}=1\right.$ for all $\left.i\right)$, there is no effect on the risk premium. Away from this case, redistributing wealth to households with relatively high MPRs lowers the risk premium. Intuitively, such redistribution raises the relative demand for capital, lowering the required excess returns to clear asset markets.

The relevant measure of redistribution toward household $i$ is the (endogenous) change in its future consumption share

$$
\begin{aligned}
\bar{\xi}_{m_{0}}^{i} & \equiv \frac{\overline{d\left[c_{1}^{i} / \int_{0}^{1} c_{1}^{\left.i^{\prime} d i^{\prime}\right]}\right.}}{d m_{0}}, \\
& =\frac{1}{\int_{0}^{1} \bar{c}_{1}^{i^{\prime}} d i^{\prime}}\left[\overline{\frac{d c_{1}^{i}}{d m_{0}}}-\frac{\bar{c}_{1}^{i}}{\int_{0}^{1} \bar{c}_{1}^{i^{\prime}} d i^{\prime}} \int_{0}^{1} \overline{\frac{d c_{1}^{i^{\prime}}}{d m_{0}}} d i^{\prime}\right]
\end{aligned}
$$

Using standard tools from price theory, we demonstrate in appendix A that the redistribution following a monetary shock reflects heterogeneity in substitution effects, in the marginal propensity to save, and in changes in wealth. The latter in turn reflects the revaluation of households' financial wealth, the change in the households' non-traded labor income, and income effects induced by the change in the real interest rate. These heterogeneous exposures to a monetary shock have been previously exposited in the HANK literature, as by Auclert (2019). Proposition 2 implies that it is their covariance with MPRs which matters for transmission through risk premia.

In a benchmark case we can isolate the redistribution operating through the revaluation of households' financial wealth. This drives our quantitative results later in the paper and allows us to sign the effect of a monetary shock on the risk premium:

Proposition 3. Suppose that households differ in risk aversion $\left\{\gamma^{i}\right\}$ and that their initial endowments in bonds and capital are identical to their choices in period 0 at the point of approximation $\left(\left\{B_{-1}^{i}=\bar{P}_{0} \bar{b}_{0}^{i}, k_{-1}^{i}=\bar{k}_{0}^{i}\right\}\right)$. Suppose households are otherwise

${ }^{11}$ This is no longer the case in the infinite horizon where, for instance, monetary policy affects the future path of real interest rates and thus the intertemporal hedging demand for capital. 
fully identical, including in their other preference parameters and initial wealth. Then

$$
\bar{\xi}_{m_{0}}^{i} \propto-\frac{\left(1+i_{-1}\right) B_{-1}^{i}}{\bar{P}_{0}} \frac{1}{\bar{P}_{0}} \frac{\overline{d P_{0}}}{d m_{0}}+\left(k_{-1}^{i}-k_{-1}\right)\left(\overline{\frac{d \pi_{0}}{d m_{0}}}+\left(1-\delta_{0}\right) \frac{\overline{d q_{0}}}{d m_{0}}\right) .
$$

For $\chi^{W}$ sufficiently big and with zero wage inflation at the point of approximation $\left(W_{-1}=\bar{W}_{0}\right), \zeta_{m_{0}}>0$ and hence a lower nominal interest rate lowers the risk premium.

The first part of the claim characterizes the components of balance sheet revaluation following a monetary shock, the only source of redistribution when households only differ in risk aversion and initial endowments. If a lower nominal interest rate generates unexpected inflation $\left(\frac{\overline{d P_{0}}}{d m_{0}}<0\right)$, it will redistribute toward debtors in the nominal bond. If it raises short-run profits $\left(\frac{\overline{d \pi_{0}}}{d m_{0}}<0\right)$ or raises asset prices capitalizing future profits $\left(\frac{d q_{0}}{d m_{0}}<0\right)$, it will redistribute to those with disproportionate claims on capital. By Proposition 1, more risk tolerant households will choose levered positions in capital; by the assumption in the claim, households' endowments are consistent with these portfolios. ${ }^{12}$ Hence, provided that inflation, profits, and the price of capital respond as conjectured here, a monetary expansion will redistribute to the relatively risk tolerant.

The second part of the claim demonstrates that with sufficiently high nominal rigidity in wages, a lower nominal interest rate will indeed redistribute to the risk tolerant in this way. ${ }^{13}$ By Proposition 1, the relatively risk tolerant also have relatively high MPRs. Hence, by Proposition 2, the risk premium on capital falls.

\subsection{Generalizations to other sources of heterogeneity}

The preceding results do not rely on heterogeneity in risk aversion alone.

Binding constraints or rules-of-thumb Suppose a measure of households are not at an interior optimum in their portfolio choice because of the additional constraint

$$
q_{0} k_{0}^{i}=\omega_{0}^{i} a_{0}^{i},
$$

\footnotetext{
${ }^{12}$ In the infinite horizon, this is the case around the deterministic steady-state.

${ }^{13}$ Intuitively, consider the effects of an increase in the nominal price level $\bar{P}_{0}$ induced by the monetary policy shock on aggregate labor $\bar{\ell}_{0}$. First, by lowering the real wage, the increase in $\bar{P}_{0}$ will stimulate $\bar{\ell}_{0}$ through labor demand. Second, by raising the real interest rate, putting downward pressure on investment and thus (through the resource constraint) upward pressure on consumption, the increase in $\bar{P}_{0}$ will lower $\bar{\ell}_{0}$ through the wealth effect on labor supply. A sufficiently high $\chi^{W}$ allows us to unambiguously sign the effects of a monetary expansion by lowering the importance of labor supply relative to labor demand. The assumption $W_{-1}=\bar{W}_{0}$ is only made to simplify the proof.
} 
reflecting either a binding leverage constraint or a rule-of-thumb in portfolios. When $\omega_{0}^{i}=0$ in particular, this means the household cannot participate in the capital market. Such constraints are consistent with prior asset pricing models with segmented markets or rules-of-thumb as well as macro models of the financial accelerator.

Background risk Suppose households are subject to idiosyncratic risk beyond the aggregate risk already described: their labor productivity and quality of capital together are subject to a shock $\epsilon_{1}^{i}$ in period 1 , modeled as a multiplicative change in the efficiency units of each factor. ${ }^{14} \epsilon_{1}^{i}$ is iid across households and independent of the aggregate TFP shock $z_{1}$, and $\eta^{i}$ controls the degree of background risk according to

$$
\log \epsilon_{1}^{i} \sim N\left(-\frac{1}{2} \eta^{i} \sigma^{2}, \eta^{i} \sigma^{2}\right)
$$

This environment captures features of the large literatures in macroeconomics and asset pricing with uninsurable labor income risk and/or entrepreneurial income risk.

Subjective beliefs Suppose household $i$ believes that TFP follows

$$
\log z_{1} \sim N\left(\log \bar{z}_{1}-\frac{1}{2} \varsigma^{i} \sigma^{2}, \varsigma^{i} \sigma^{2}\right)
$$

even though the objective (true) probability distribution remains described by (8). As in the large literature on belief disagreements, households with $\varsigma^{i}>1$ are "pessimists" and households with $\varsigma^{i}<1$ are "optimists".

Robustness of the effects of monetary policy In appendix A, we generalize Propositions 1 and 2 to these environments. Households' MPRs remain the relevant statistics to evaluate the effects of redistribution on risk premia. A lower nominal interest rate will lower the risk premium if it redistributes to high MPR households. ${ }^{15}$

In each of these cases, the additional dimension of heterogeneity continues to imply that households with high MPRs also have high portfolio shares in capital: just

\footnotetext{
${ }^{14}$ The assumption that $\epsilon_{1}^{i}$ scales the household's return on capital, not just labor income, differs from Krueger and Lustig (2010) in which idiosyncratic risk is irrelevant for the price of aggregate risk.

${ }^{15}$ The entire distribution of MPRs remains relevant even if some households face binding constraints or a rule-of-thumb. For instance, if wealth transfers to households who cannot trade capital and thus have $\overline{m p r}_{0}^{i}=0$, in equilibrium the remaining households must be induced to hold a more levered position in capital and thus the risk premium must rise.
} 
as both are falling in risk aversion $\gamma^{i}$, they are falling in background risk $\eta^{i}$ and pessimism $\varsigma^{i}$ and are rising in the leverage constraint or rule-of-thumb $\omega^{i}$ (if the household is constrained). Hence, even if households can vary along all of these dimensions, more levered households have higher MPRs. The first part of Proposition 3 summarizing households' exposure to a monetary policy shock remains unchanged. Hence, an expansionary monetary policy shock will redistribute to high MPR households as in the case with heterogeneity in risk aversion alone, lowering the risk premium:

Proposition 4. Suppose households differ in risk aversion $\left\{\gamma^{i}\right\}$, being constrained and (among those that are) constraints $\left\{\omega^{i}\right\}$, background risk $\left\{\eta^{i}\right\}$, and beliefs $\left\{\varsigma^{i}\right\}$. Futher suppose that their endowments are identical to their choices in period 0 at the point of approximation $\left(\left\{B_{-1}^{i}=\bar{P}_{0} \bar{b}_{0}^{i}, k_{-1}^{i}=\bar{k}_{0}^{i}\right\}\right)$ and households are otherwise identical. Then for $\chi^{W}$ sufficiently big and with zero wage inflation at the point of approximation $\left(W_{-1}=\bar{W}_{0}\right), \zeta_{m_{0}}>0$ and hence a lower nominal rate lowers the risk premium.

While our quantitative analysis focuses on differences in risk aversion, we therefore expect that our insights are robust to these other potential sources of heterogeneity generating the same distribution of MPRs and exposures to a monetary policy shock.

\subsection{Monetary policy, redistribution, and the real economy}

Before turning to our quantitative analysis in the infinite horizon, we conclude our analysis of this environment by asking how the risk premium effects of monetary policy matter for the transmission of policy to the real economy.

We focus on new capital $k_{0}$ and consumption $c_{0} \equiv \int_{0}^{1} c_{0}^{i} d i$, which can be combined to understand the effect on output. In terms of perturbation parameters, we have

$$
\begin{aligned}
& \hat{k}_{0}=\delta_{m_{0}}^{k_{0}} \hat{m}_{0}+\frac{1}{2} \delta_{m_{0}^{2}}^{k_{0}} \hat{m}_{0}^{2}+\frac{1}{6} \delta_{m_{0}^{3}}^{k_{0}} \hat{m}_{0}^{3}+\frac{1}{2} \delta_{\sigma^{2}}^{k_{0}} \sigma^{2}+\frac{1}{2} \delta_{m_{0} \sigma^{2}}^{k_{0}} \hat{m}_{0} \sigma^{2}+o\left(\|\cdot\|^{4}\right), \\
& \hat{c}_{0}=\underbrace{\delta_{m_{0}}^{c_{0}} \hat{m}_{0}+\frac{1}{2} \delta_{m_{0}^{2}}^{c_{0}} \hat{m}_{0}^{2}+\frac{1}{6} \delta_{m_{0}^{3}}^{c_{0}} \hat{m}_{0}^{3}}_{\begin{array}{c}
\text { effects absent } \\
\text { aggregate risk }
\end{array}}+\frac{1}{2} \delta_{\sigma^{2}}^{c_{0}} \sigma^{2}+\underbrace{\frac{1}{2} \delta_{m_{0} \sigma^{2}}^{c_{0}} \hat{m}_{0} \sigma^{2}}_{\begin{array}{c}
\text { effect with } \\
\text { aggregate risk }
\end{array}}+o\left(\|\cdot\|^{4}\right),
\end{aligned}
$$

for some coefficients $\delta$. For each macroeconomic aggregate, the first three terms reflect the effects of a monetary policy shock even absent aggregate risk, and they are well understood. They reflect the standard channels through intertemporal substitution as well as heterogeneity in the marginal propensities to consume versus save. We instead 
focus on the additional effects of a monetary policy shock with aggregate risk, summarized in the terms $\delta_{m_{0} \sigma^{2}}^{k_{0}}$ and $\delta_{m_{0} \sigma^{2}}^{c_{0}}$. Equivalently, we study the quantity responses which accompany a change in the risk premium summarized by $\zeta_{m_{0}}$.

We begin with capital. Since the expected return on capital is

$$
\mathbb{E}_{0}\left[1+r_{1}^{k}\right]=\frac{\mathbb{E}_{0}\left[\pi_{1}\right]}{q_{0}}=\frac{\alpha \bar{z}_{1} k_{0}^{\alpha-1}}{\left(k_{0} / k_{-1}\right)^{\chi^{x}}}
$$

the return on capital falls in the amount of new capital both because the marginal product of capital falls and the price of capital rises. Now consider the case where monetary policy redistributes to high MPR households and thus lowers the risk premium. Then to evaluate the effects on investment we must determine whether the required return on capital falls (and thus new capital rises) or the safe real interest rate simply rises (and thus new capital may remain unchanged or even fall).

Absent nominal rigidity, the equilibrium response of the real interest rate depends crucially on households' intertemporal elasticity of substitution. This reflects the presence of offsetting income and substitution effects in response to the shock. As described in Gourio (2012) and other papers studying time-varying risk premia, the elasticity may in fact be such that the real interest rate varies by exactly the amount to keep investment unchanged. This can explain what Cochrane (2017) calls the "macro-finance separation" in analyses of asset pricing and business cycles such as Tallarini Jr. (2000).

With nominal rigidity, the monetary policy rule also determines the extent to which the real interest rate fluctuates. Caballero and Farhi (2018) and Caballero and Simsek (2018) demonstrate, for instance, that a decrease in the risk premium will stimulate real activity if the nominal rate remains at the zero lower bound. In our environment, these insights apply to the risk premium effect of a primitive monetary policy shock itself. In the useful benchmark in which monetary policy targets a constant real interest rate subject to monetary policy shocks $(\phi=-1)$, we obtain:

Proposition 5. If monetary policy follows the rule (10) with $\phi=-1$, then in (24)

$$
\frac{1}{2} \delta_{m_{0} \sigma^{2}}^{k_{0}}=-\frac{1}{1-\alpha+\chi^{x}} \zeta_{m_{0}}
$$

Hence, if monetary policy lowers the risk premium by redistributing to high MPR households, as in Proposition 4, it will amplify the stimulus to investment.

To understand the implications for consumption and thus output, it is most trans- 
parent to focus on the case with a unitary intertemporal elasticity of substitution $\psi^{i}=1$ and identical discount factor $\beta^{i}=\beta$ for each household $i$. The former delivers a simple form for each household's optimal consumption policy solving (16):

$$
c_{0}^{i}=\underbrace{\left(1-\beta^{i}\right)}_{\text {MPC }}[\underbrace{y_{0}^{i}\left(w_{0} \ell_{0}^{i}, P_{0}, \pi_{0}, q_{0}\right)}_{\text {current income }}+\underbrace{\frac{1-\alpha}{\alpha} q_{0} k_{0}}_{\begin{array}{c}
\text { value of } \\
\text { future } \\
\text { labor income }
\end{array}}],
$$

where the first term in brackets was defined in (17) and the second term in brackets summarizes the value of future labor income because the returns to capital and labor are perfectly correlated. The assumption $\beta^{i}=\beta$ eliminates heterogeneity in marginal propensities to consume so that, together with goods market clearing (11), aggregation yields a simple relationship between consumption and new capital

$$
c_{0}=\frac{1-\beta}{\beta} \frac{1}{\alpha} q_{0} k_{0}=\frac{1-\beta}{\beta} \frac{1}{\alpha}\left(\frac{k_{0}}{k_{-1}}\right)^{\chi^{x}} k_{0} .
$$

We immediately obtain the following result:

Proposition 6. If $\psi^{i}=1$ and $\beta^{i}=\beta$ for all $i$, then in (25)

$$
\frac{1}{2} \delta_{m_{0} \sigma^{2}}^{c_{0}}=\frac{1}{2}\left(\chi^{x}+1\right) \delta_{m_{0} \sigma^{2}}^{k_{0}}
$$

If monetary policy follows the rule (10) with $\phi=-1$, Proposition 5 implies

$$
\frac{1}{2} \delta_{m_{0} \sigma^{2}}^{c_{0}}=-\frac{\chi^{x}+1}{1-\alpha+\chi^{x}} \zeta_{m_{0}} .
$$

Hence, if monetary policy lowers the risk premium by redistributing to high MPR households, it also amplifies the stimulus to consumption. This occurs for two reasons: first, higher investment raises aggregate demand and thus labor income in period 0 and raises the present value of future labor income in period 1; second, the lower risk premium is associated with a higher price of capital and thus higher household wealth in period 0. The latter means that even as $\chi^{x} \rightarrow \infty$, while the response of investment in Proposition 5 falls to zero, the response of consumption does not. ${ }^{16}$

\footnotetext{
${ }^{16}$ While we focus on these positive effects of monetary transmission through risk premia, we also expect that these effects would shape the optimal monetary policy. Indeed, in recent work, Caballero and Simsek (2019) demonstrate that an environment with heterogeneous beliefs features aggregate demand externalities which motivate a macroprudential role for the optimal policy.
} 


\section{Quantitative relevance in the infinite horizon}

We now evaluate the relevance of these insights in an extended infinite horizon setting. We first revisit the empirical evidence on the equity premium response to monetary policy shocks which poses a challenge to workhorse models where risk premia barely move. We then calibrate our model to match standard "macro" moments as well as novel "micro" moments from the Survey of Consumer Finances which discipline the cross-sectional heterogeneity in MPRs and exposures to monetary policy. In response to an unexpected monetary easing in our model economy, wealth endogenously redistributes to relatively high MPR households, rationalizing the equity premium response found in the data and contributing to the stimulus in real activity.

\subsection{Empirical effects of monetary policy shocks in U.S. data}

The effects of an unexpected shock to monetary policy have been the subject of a large literature in empirical macroeconomics. In response to an unexpected loosening, the price level rises and production expands, consistent with workhorse New Keynesian models. But, as found in Bernanke and Kuttner (2005) and a number of subsequent papers using asset pricing data, the evidence further suggests that risk premia fall. ${ }^{17,18}$

We refresh the findings in Bernanke and Kuttner (2005) using the structural vector autoregression instrumental variables (SVAR-IV) approach in Gertler and Karadi (2015). Using monthly data from July 1979 through June 2012, we first run a sixvariable, six-lag VAR using the 1-year Treasury yield, CPI, industrial production, S\&P 500 return relative to the 1 -month T-bill, 1-month T-bill relative to the change in CPI, and smoothed dividend-price ratio on the S\&P 500. ${ }^{19,20}$ Over January 1991 through June 2012 we then instrument the residuals in the 1-year Treasury yield (the monetary policy indicator) with an external instrument: policy surprises constructed using the

\footnotetext{
${ }^{17}$ This effect on risk premia may co-exist with the revelation of information, a channel studied by Nakamura and Steinsson (2018) and others. The analysis of Jarocinski and Karadi (forthcoming) implies that by confounding "pure" monetary policy shocks with such information shocks, our estimates may understate the increase in the stock market following a pure monetary easing.

${ }^{18}$ In addition to this literature, there is also evidence that changes in the monetary policy rule affect risk premia. For instance, using a regime-switching model Bianchi, Lettau, and Ludvigson (2019) find that a more dovish monetary policy rule is associated with a lower equity premium.

${ }^{19}$ The series for the 1-year Treasury yield, CPI, and industrial production are taken from the dataset provided by Gertler and Karadi (2015). The remaining series are from CRSP.

${ }^{20}$ The smoothed dividend-price ratio is the 3-month moving average of dividends divided by the price of the stock at the end of the month, value-weighted over the S\&P 500. We linearly detrend this series given changes in corporate payout policy over the sample period (see Bunn and Shiller (2014)).
} 

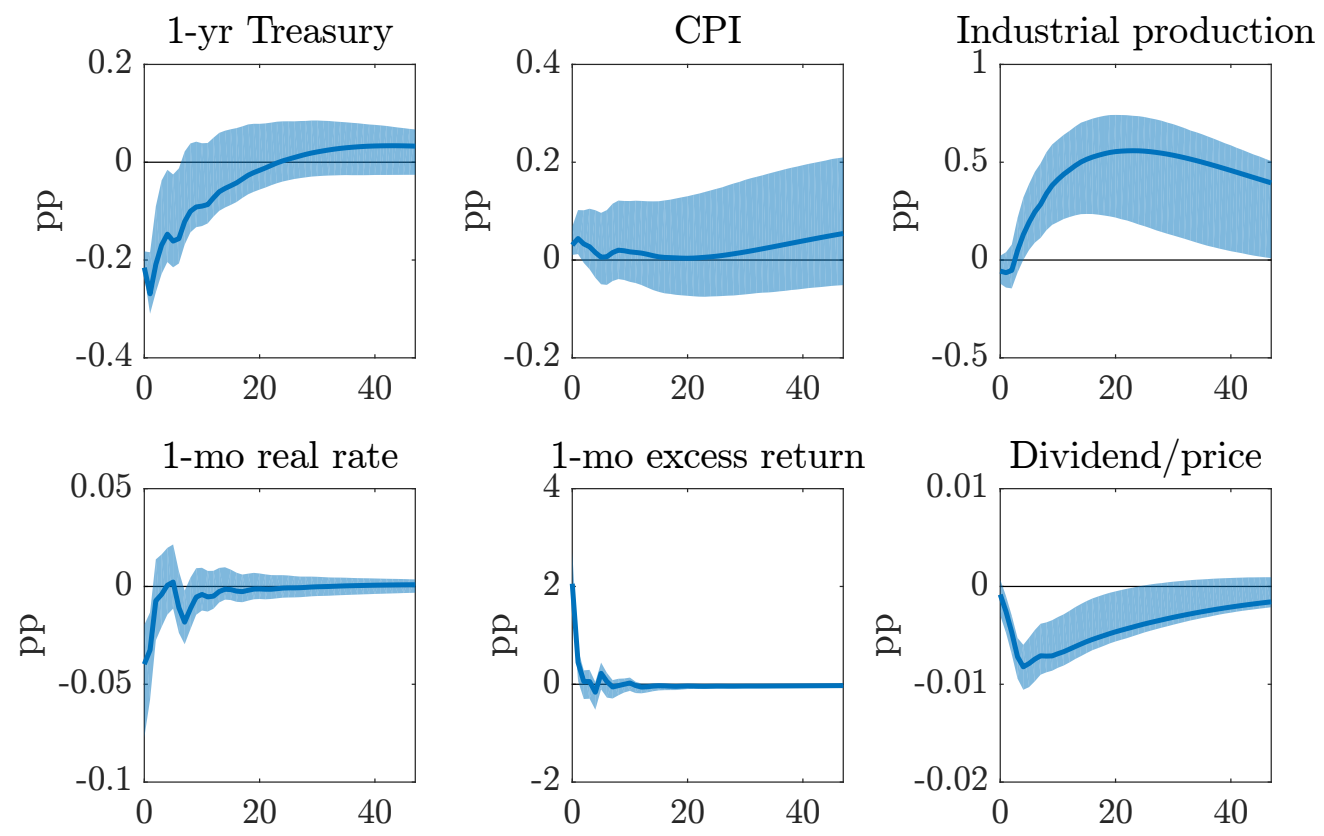

Figure 1: effects of $1 \mathrm{SD}$ monetary shock

Notes: $90 \%$ confidence interval at each horizon is computed using the wild bootstrap (to account for uncertainty in the coefficients of the VAR) with 10,000 iterations, following Mertens and Ravn (2013) and Gertler and Karadi (2015).

current Fed Funds futures contract on FOMC days aggregated to the month level from Gertler and Karadi (2015). The identification assumptions are that the exogenous variation in the monetary policy indicator in the VAR are due to the structural monetary shock and that the instrument is correlated with this structural shock but not the five others. Under these assumptions, a first-stage regression of the monetary policy residual on the surprise, followed by a second-stage regression of all other residuals on the predicted residual, can be used to identify the effects of a monetary policy shock on all variables in the VAR. With a first-stage F statistic of 14.4, this instrument is strong according to the threshold recommended by Stock, Wright, and Yogo (2002).

We then plot the impulse responses to a negative monetary policy shock using this instrument in Figure 1. Since the structural monetary policy shock is not observed, its magnitude should be interpreted through the lens of the $22 b p$ decrease in the 1-year yield on impact. Consistent with the wider literature, industrial production and the price level rise, and the real interest rate falls. Excess returns rise by $2 p p$ on impact; given the comparatively tiny decline in the real interest rate, this means the real return on the stock market is also approximately $2 p p$. Notably, excess returns are small and 
negative in the months which follow, consistent with a decline in the equity premium and the fall in the dividend/price ratio.

Following Bernanke and Kuttner (2005), we can decompose the $2 p p$ real return on the stock market into news about higher dividend growth, lower real risk-free discount rates, and lower future excess returns using a Campbell-Shiller decomposition:

$$
\begin{aligned}
& \left.(\text { real stock return })_{t}-\mathbb{E}_{t-1}\left[(\text { real stock return })_{t}\right]=\left(\mathbb{E}_{t}-\mathbb{E}_{t-1}\right) \sum_{j=0} \kappa^{j} \Delta \text { (dividends }\right)_{t+j} \\
& -\left(\mathbb{E}_{t}-\mathbb{E}_{t-1}\right) \sum_{j=1} \kappa^{j}(\text { real rate })_{t+j}-\left(\mathbb{E}_{t}-\mathbb{E}_{t-1}\right) \sum_{j=1} \kappa^{j}(\text { excess return })_{t+j}
\end{aligned}
$$

where $\kappa=\frac{1}{1+\frac{d}{p}}$ and $\frac{d}{p}$ is the steady-state dividend yield. Using the SVAR-IV to compute the revised expectations in real rates and excess returns given the monetary shock, we obtain the decomposition in Table $1 .^{21} 1.1 p p(58 \%)$ of the initial return on the stock market is due to news about lower future excess returns, $0.1 p p(7 \%)$ is due to news about lower future risk-free rates, and $0.7 p p(34 \%)$ is due to news about higher dividend growth. Accounting for estimation uncertainty, we conclude that at least $21 \%$ and potentially all of the return on the stock market is due to news about lower future excess returns, validating the original message from Bernanke and Kuttner (2005).

The important role of the risk premium in explaining the return on the stock market is robust to details of the estimation approach. In appendix B.1 we modify the estimation approach along a number of dimensions. First, we change the number of lags used in the VAR, ranging from 4 months to 8 months. Second, we change the sample periods over which the VAR and/or first-stage is estimated. Third, we add variables to the VAR, such as the Gilchrist and Zakrajsek (2012) excess bond premium and other credit spreads used in Gertler and Karadi (2015) as well as the term spread and other variables known to predict excess stock market returns used in Bernanke and Kuttner (2005). Fourth, we change the instrument used for the monetary policy shock, using policy surprises constructed using the three-month ahead Fed Funds futures contract

\footnotetext{
${ }^{21}$ As in Bernanke and Kuttner (2005), we use our VAR to compute (excess return) $)_{t}$ $\mathbb{E}_{t-1}\left[(\text { excess return })_{t}\right],\left(\mathbb{E}_{t}-\mathbb{E}_{t-1}\right) \sum_{j=1} \kappa^{j}(\text { real rate })_{t+j}$, and $\left(\mathbb{E}_{t}-\mathbb{E}_{t-1}\right) \sum_{j=1} \kappa^{j}$ (excess return $)_{t+j}$, and we assign to dividend growth the residual implied by (26). As an alternative approach (available on request), we use the estimated impulse responses for the dividend price ratio, real interest rate, and excess return to solve for the news about future dividend growth. The sum of terms on the right-hand side of (26) is slightly different from what the identity should imply, meaning that the estimated IRFs do not exactly satisfy this identity. However, we continue to find that news about future excess returns constitutes more than half of the sum of news from all three components.
} 


\begin{tabular}{lcc}
\hline & $p p$ & $\begin{array}{c}\text { As share of } \\
\text { effect on real } \\
\text { stock return }\end{array}$ \\
\hline Real stock return & 2.02 & \\
Dividend growth news & {$[1.62,2.66]$} & \\
- Future real rate news & 0.69 & $34 \%$ \\
& {$[-0.21,1.54]$} & {$[-11 \%, 71 \%]$} \\
- Future excess return news & 0.15 & $7 \%$ \\
& {$[-0.14,0.41]$} & {$[-6 \%, 21 \%]$} \\
& 1.18 & $58 \%$ \\
\hline
\end{tabular}

Table 1: Campbell-Shiller decomposition following 1 SD monetary shock

Notes: decomposition in (26) uses $\kappa=0.9962$ following Campbell and Ammer (1993). 90\% confidence interval in brackets is computed using the wild bootstrap (to account for uncertainty in the coefficients of the VAR) with 10,000 iterations, following Mertens and Ravn (2013) and Gertler and Karadi (2015).

rather than the current contract. Across these cases we confirm the message of the baseline estimates above: in response to a monetary policy shock which reduces the 1-year Treasury yield by $17-23 b p$, real stock returns rise by $1.5-3.2 p p$, and news about future excess returns explains $35 \%-80 \%$ of this increase.

The dimensionality reduction offered by a VAR enables us to generate the longhorizon forecasts needed for the Campbell-Shiller decomposition, unlike a local projection. As noted by Stock and Watson (2018), we can test the assumption of invertibility implicit in the SVAR-IV both by assessing whether lagged values of the instrument have forecasting power when included in the VAR and by comparing the estimated impulse responses to those obtained using a local projection with instrumental variables (LPIV). We show in appendix B.1 that both of these tests fail to reject the null hypothesis that invertibility in our application is satisfied. ${ }^{22}$

\footnotetext{
${ }^{22}$ Between the SVAR-IV and LP-IV is the approach of including the IV (and its lags) in the VAR and ordering it first as part of a recursive identification strategy. Plagborg-Moller and Wolf (2019) prove that this strategy is robust to non-invertibility, while estimation using a VAR still means that we can implement (26). While the impulse responses using this approach are noisier than our baseline using the SVAR-IV, the point estimates imply that $69 \%$ of the increase in the stock market following a monetary shock is due to news about lower future excess returns. The recursive approach is closely related to the identification strategy used by Paul (2019) in recent work also finding that expansionary monetary policy raises the stock market in part by lowering future excess returns.
} 


\subsection{Infinite horizon environment}

We now investigate whether redistribution can quantitatively rationalize the stock market response to a monetary policy shock and, if so, its implications for policy transmission to the real economy. We first extend the model to the infinite horizon, building on the environment from section 2.1. We describe the necessary changes here and present the complete environment in appendix $\mathrm{C}$.

\subsubsection{Household preferences and constraints}

Household $i$ now maximizes a generalization of (1)

$$
v_{t}^{i}=\left((1-\beta)\left(c_{t}^{i} \Phi\left(\int_{0}^{1} \ell_{t}^{i}(j) d j\right)\right)^{1-1 / \psi}+\beta \mathbb{E}_{t}\left[\left(v_{t+1}^{i}\right)^{1-\gamma^{i}}\right]^{\frac{1-1 / \psi}{1-\gamma^{i}}}\right)^{\frac{1}{1-1 / \psi}}
$$

with endogenous labor supply each period. We assume for simplicity that $\beta, \psi$, and $\Phi(\cdot)$ are identical across households and that the labor allocation rule and Pareto weights are symmetric: $\ell^{i}\left(\ell_{t}\right)=\ell_{t}$ and $\mu^{i}=1$. Following Shimer (2010), we assume

$$
\Phi\left(\ell_{t}^{i}\right)=\left(1+(1 / \psi-1) \bar{\theta} \frac{\left(\ell_{t}^{i}\right)^{1+1 / \theta}}{1+1 / \theta}\right)^{\frac{1 / \psi}{1-1 / \psi}}
$$

where $\theta$ controls the Frisch elasticity of labor supply and $\bar{\theta}$ controls the disutility of labor. Finally, we assume households also face a lower bound on capital

$$
k_{t}^{i} \geq \underline{k} z_{t}
$$

where $z_{t}$ is productivity, discussed below. Such a constraint captures components of capital which households hold for reasons beyond financial returns, such as housing.

\subsubsection{Aggregate productivity}

We now assume that productivity $z_{t}$ follows a unit root process

$$
\log \left(z_{t}\right)=\log \left(z_{t-1}\right)+\sigma \epsilon_{t}^{z}+\varphi_{t}
$$

where $\epsilon_{t}^{z}$ is an iid shock from a standard Normal distribution, $\varphi_{t}$ is a rare disaster equal to zero with probability $1-p_{t}$ and $\underline{\varphi}<0$ with probability $p_{t}$, and $p_{t}$ follows a two-state 
Markov process over $p-\frac{1}{2} \sigma^{p}$ and $p+\frac{1}{2} \sigma^{p}$ with probability of remaining in each state $\rho^{p}$. Following Barro (2006), we introduce the disaster to help match the level of the equity premium. Following Gourio (2012) and Wachter (2013), we introduce a time-varying probability of a disaster to help match the volatility of returns. ${ }^{23}$ We further assume that the disaster destroys capital and reduces the reference wage in households' wage adjustment costs in proportion to the decline in productivity. The first assumption implies that aggregate output is

$$
y_{t} \equiv\left(z_{t} \ell_{t}\right)^{1-\alpha}\left(k_{t-1} \exp \left(\varphi_{t}\right)\right)^{\alpha} \text {, }
$$

where productivity is now labor-augmenting and thus consistent with balanced growth.

\subsubsection{Monetary and fiscal policy}

Finally, monetary policy is now characterized by the Taylor rule (10) each period

$$
1+i_{t}=(1+\bar{i})\left(\frac{P_{t}}{P_{t-1}}\right)^{\phi} m_{t}
$$

where policy shocks follow an $\mathrm{AR}(1)$ process

$$
\log m_{t}=\rho^{m} \log m_{t-1}+\sigma^{m} \epsilon_{t}^{m}
$$

where $\epsilon_{t}^{m}$ is an iid shock from a standard Normal distribution.

Fiscal policy is characterized by a wage subsidy $\tau=-\frac{1}{\epsilon-1}$, government participation in the bond market $B_{t}^{g}$, and household-specific lump-sum transfers

$$
T_{t}^{i}=\int_{0}^{1} A C_{t}^{W}(j) d j+\tau \int_{0}^{1} W_{t}(j) \ell_{t}^{i}(j) d j+\nu^{i}\left(\left(1+i_{t-1}\right) B_{t-1}^{g}-B_{t}^{g}\right)-\mathfrak{T}_{t}^{i}
$$

Relative to (9) in the two-period environment, this adds two new elements of fiscal policy: government debt $-B_{t}^{g}$, where the lump-sum taxes financing it are controlled by the parameters $\left\{\nu^{i}\right\}$ satisfying $\int_{0}^{1} \nu^{i} d i=1$; and a new source of redistribution $\mathfrak{T}_{t}^{i}$.

Accounting for government debt $-B_{t}^{g}$ is important because empirically, the ag-

\footnotetext{
${ }^{23}$ Following Bianchi, Ilut, and Schneider (2018), financial frictions on firms together with uncertainty shocks on operating cost could further improve the model on this dimension. Following Guvenen (2009) and Garleanu and Panageas (2015), heterogeneity in the intertemporal elasticity of substitution could also help lower the volatility of the real interest rate relative to excess returns.
} 
gregate household sector has a positive net position in nominal claims, offset by the government and the rest of the world. We ignore the rest of the world for simplicity, so that the sum of nominal claims held by households and the government equals zero. Because we assume that marginal changes in government debt would be financed by lump-sum taxes and households face no constraints in the bond market, such changes would have no effect on the equilibrium allocation (in the sense that in equilibrium, households effectively choose their position in government debt accounting for that through the government, $\left.B_{t}^{i}+\nu^{i} B_{t}^{g}\right)$. Hence, without loss of generality, we assume time-invariant government debt in real terms: $B_{t}^{g}=P_{t} b^{g}$.

The lump-sum redistributive taxes $\mathfrak{T}_{t}^{i}$ help us match the wealth distribution. They follow

$$
\mathfrak{T}_{t}^{i}=\tau_{t}^{i}\left[\left(1+i_{t-1}\right)\left(B_{t-1}^{i}+\nu^{i} B_{t-1}^{g}\right)+\left(\Pi_{t}+(1-\delta) Q_{t}\right) k_{t-1}^{i} \exp \left(\varphi_{t}\right)\right]
$$

where $\tau_{t}^{i}=\tau^{i}$ for all households except a positive measure, for whom $\tau_{t}^{i}=\tau_{t}$ ensures that $\int_{0}^{1} \mathfrak{T}_{t}^{i} d i=0 .{ }^{24}$ We assume that households fully anticipate these taxes for all households excepts themselves, which they assume to be zero. This ensures that households do not undo the redistributive effects of these taxes in their saving, allowing us to control the wealth distribution. In appendix $\mathrm{C}$, we calibrate an alternative environment featuring fully anticipated, distortionary taxes on wealth and find that our results on monetary policy transmission are robust to this setting. ${ }^{25}$

\subsubsection{Equilibrium and model solution}

The problems facing households, unions, and producers extend to the infinite horizon and are provided in appendix C. The equilibrium generalizes Definition 1.

We solve the model globally using numerical methods. While the perturbation approach used in the two-period environment remains feasible here, we turn to this

${ }^{24}$ Since $\int_{0}^{1} \mathfrak{T}_{t}^{i} d i=0$, it follows from $(34)$ that

$$
B_{t}^{g}+\int_{0}^{1} T_{t}^{i} d i=\int_{0}^{1} A C_{t}^{W}(j) d j+\tau \int_{0}^{1} \int_{0}^{1} W_{t}(j) \ell_{t}^{i}(j) d j d i+\left(1+i_{t-1}\right) B_{t-1}^{g},
$$

so that the government's budget is indeed balanced.

${ }^{25}$ Another approach to control the wealth distribution is to consider an overlapping-generations framework, as in Garleanu and Panageas (2015). In the presence of incomplete markets and endogenous labor supply in our setting, such an approach would break aggregation within groups of households (described further in the next subsection), complicating the computation of the model. 
solution approach for two reasons. First, we find that household portfolios and MPRs solved analytically at the deterministic steady-state have non-trivial differences from their average values in simulations using a global solution. Second, a perturbation solution is ill-suited to handle the addition of a disaster to our driving forces.

Given this global solution approach, we limit the heterogeneity across households to make the computational burden tractable. We divide the continuum of households into a finite number of groups within which households are perfectly symmetric. We choose three groups denoted $i \in\{a, b, c\}$ and where we now understand the index $i$ to refer to groups and the representative household of each group. The fraction of households belonging to group $i$ is denoted $\lambda^{i}$, where $\sum_{i} \lambda^{i}=1$.

We solve a stationary transformation of the economy obtained by dividing all real variables except labor by $z_{t}$ and nominal variables by $P_{t} z_{t}$. As is shown in supplement $\mathrm{B}$, in the transformed economy we obtain a recursive representation of the equilibrium in which the aggregate state in period $t$ is given by the monetary policy shock $m_{t}$, scaled aggregate capital $k_{t-1} / \exp \left(\sigma \epsilon_{t}^{z}\right)$, scaled prior period's real wage $w_{t-1} / \exp \left(\sigma \epsilon_{t}^{z}\right)$, and wealth shares $\left\{s_{t}^{i}\right\}$ of two groups as defined by

$$
\begin{aligned}
s_{t}^{i} & \equiv \lambda^{i} \frac{\left(1+i_{t-1}\right)\left(B_{t-1}^{i}+\nu^{i} B_{t-1}^{g}\right)+\left(\Pi_{t}+(1-\delta) Q_{t}\right) k_{t-1}^{i} \exp \left(\varphi_{t}\right)-\mathfrak{T}_{t}^{i}}{\left(\Pi_{t}+(1-\delta) Q_{t}\right) k_{t-1} \exp \left(\varphi_{t}\right)}, \\
& =\lambda^{i}\left(1-\tau_{t}^{i}\right) \frac{\left(1+i_{t-1}\right)\left(B_{t-1}^{i}+\nu^{i} B_{t-1}^{g}\right)+\left(\Pi_{t}+(1-\delta) Q_{t}\right) k_{t-1}^{i} \exp \left(\varphi_{t}\right)}{\left(\Pi_{t}+(1-\delta) Q_{t}\right) k_{t-1} \exp \left(\varphi_{t}\right)}
\end{aligned}
$$

where the second line uses (35). Productivity shocks inclusive of disasters only govern the transition across states, but do not separately enter the state space itself.

We solve the model over a large grid of the aggregate states, making sure that the solution is robust to larger grid sizes and boundaries. When forming expectations, we use quadrature and linear interpolation over aggregate states, but (for households' value functions) interpolate using cubic splines over individual wealth. The stochastic equilibrium is determined through backward iteration, while dampening the updating of the price of capital and individuals' expectations over the dynamics of the aggregate states. The code is written in Fortran and parallelized using OpenMP, so that convergence can be achieved in less than one hour on a computing system with 16 cores. The computational algorithm is further described in supplement B. 


\subsection{Parameterization, first moments, and second moments}

We now parameterize the model to match micro moments informing the heterogeneity across groups as well as macro moments regarding the business cycle and asset prices.

\subsubsection{Micro: the distribution of wealth, labor income, and portfolios}

We seek to match the distribution of wealth, labor income, and financial portfolios in U.S. data, giving us confidence in the model's MPRs and exposures to a monetary shock. We proceed in three steps with the 2016 Survey of Consumer Finances (SCF).

First, we decompose each household's wealth $\left(A^{i}\right)$ into claims on the economy's capital stock $\left(Q k^{i}\right.$, in positive net supply) and nominal claims ( $B^{i}$, in zero net supply accounting for the government and rest of the world). ${ }^{26}$ We describe this procedure in detail in appendix B.2 and provide a broad overview here. We first add estimates of DB pension wealth for each household since this is the major component of household net worth which is excluded from the SCF. ${ }^{27}$ We then proceed by line item to allocate how much household wealth is held in nominal claims versus claims on capital. ${ }^{28,29}$ In the same spirit as Doepke and Schneider (2006), the key step in doing this is to account for the implicit leverage households have on capital through publicly-traded and privately-held businesses. ${ }^{30}$ In particular, if household $i$ owns $\$ 1$ in equity in a firm which has net leverage

$$
\frac{\text { assets net of nominal assets }}{\text { equity }}=l e v,
$$

then we assign the household $Q k^{i}=l e v$ and $B^{i}=1-l e v$. The aggregate leverage implicit in these equity claims must be consistent with that of the business sectors in the Financial Accounts. We parameterize the dispersion in leverage in these equity

\footnotetext{
${ }^{26}$ Consistent with the traded assets in our model, we do not distinguish between nominal claims having different duration. Extending the model in this direction would be valuable.

${ }^{27}$ We use the estimates of Sabelhaus and Volz (2019) described further in the appendix. We thank John Sabelhaus for generously sharing their estimates with us.

${ }^{28}$ An alternative approach to measuring households' portfolios would be to relate their changes in wealth to changes in asset prices using panel data, as in the recent work of Gomes (2019).

${ }^{29}$ We note in particular that we treat DB pension entitlements as a nominal asset of households, under the interpretation that households have a fixed claim on the pension sponsor which is then the residual claimant on the investment portfolio. In contrast, DC pension assets, as with other mutual fund assets, are decomposed into nominal claims and claims on capital as described here.

${ }^{30}$ This assumes no financial frictions in firms and intermediaries through which households invest. We view this as a natural first step to study the questions of this paper.
} 


\begin{tabular}{|c|c|c|c|}
\hline & \multicolumn{2}{|c|}{$\frac{A^{i}}{W \ell^{i}}$} \\
\hline & & $\geq p 60$ & $<p 60$ \\
\hline \multirow{7}{*}{$\frac{Q k^{i}}{A^{i}}$} & \multirow{5}{*}{$\geq p 90$} & Group $a$ & \multirow{7}{*}{$\begin{array}{l}\text { Group } c \\
\text { Share households: } 60 \% \\
\sum_{i \in c} W \ell^{i} / \sum_{i} W \ell^{i}: 83 \% \\
\sum_{i \in c} A^{i} / \sum_{i} A^{i}: 23 \% \\
\sum_{i \in c} Q k^{i} / \sum_{i \in c} A^{i}: 1.1\end{array}$} \\
\hline & & Share households: $4 \%$ & \\
\hline & & $\sum_{i \in a} W \ell^{i} / \sum_{i} W \ell^{i}: 3 \%$ & \\
\hline & & $\sum_{i \in a} A^{i} / \sum_{i} A^{i}: 18 \%$ & \\
\hline & & $\sum_{i \in a} Q k^{i} / \sum_{i \in a} A^{i}: 2.0$ & \\
\hline & & Group $b$ & \\
\hline & $<p 90$ & $\begin{array}{l}\text { Share households: } 36 \% \\
\sum_{i \in b} W \ell^{i} / \sum_{i} W \ell^{i}: 14 \% \\
\sum_{i \in b} A^{i} / \sum_{i} A^{i}: 59 \% \\
\sum_{i \in b} Q k^{i} / \sum_{i \in b} A^{i}: 0.5\end{array}$ & \\
\hline
\end{tabular}

Table 2: heterogeneity in wealth to labor income and the capital portfolio share

Notes: observations are weighted by SCF sample weights.

claims to match evidence on the cross-sectional dispersion in households' expected rates of return. In appendix B.2, we discuss these features at length and demonstrate that the implied aggregate position of households in nominal claims is consistent with market clearing after accounting for the government and rest of the world.

Second, we stratify households by their wealth to labor income $\left\{\frac{A^{i}}{W \ell^{i}}\right\}$ and capital portfolio share $\left\{\frac{Q k^{i}}{A^{i}}\right\}$, defining subsamples mapping to our three groups. ${ }^{31}$ We sort households on these variables based on Proposition 1, which demonstrated that the capital portfolio share is informative about households' risk aversion and thus MPR only after properly accounting for their non-traded exposure to aggregate risk through labor income. ${ }^{32}$ Group a corresponds to households with high wealth to labor income and a high capital portfolio share, group $b$ corresponds to households with high wealth to labor income but a low capital portfolio share, and group $c$ corresponds to households with low wealth to labor income. We define "high" wealth to labor income as households above the 60th percentile of this measure, and a "high" capital portfolio

\footnotetext{
${ }^{31}$ Labor income is total reported wage and salary income for the previous calendar year.

${ }^{32}$ We sort households by a measure of their capital portfolio share after excluding from both the numerator and denominator assets and liabilities associated with the primary residence and vehicles, even though for each group we report and target the capital portfolio share accounting for all assets and liabilities. We sort households on the former measure since households' decisions regarding their primary residence and consumer durables may reflect considerations beyond risk and return.
} 


\begin{tabular}{lcc}
\hline & $1\left\{\right.$ hbus $\left.^{i}=1\right\}$ & $1\left\{\right.$ age $\left.^{i}>54, l f^{i}=0\right\}$ \\
\hline $1\{i \in a\}$ & 0.38 & 0.36 \\
& $(0.04)$ & $(0.03)$ \\
$1\{i \in b\}$ & 0.05 & 0.55 \\
& $(0.01)$ & $(0.01)$ \\
\hline Observations & 6,229 & 6,229 \\
Adj $R^{2}$ & 0.05 & 0.37 \\
\hline
\end{tabular}

Table 3: indicators for private business wealth or being retired on group indicators

Notes: observations are weighted by SCF sample weights and standard errors adjust for imputation and sampling variability following Pence (2015). Each specification includes a constant term (not shown), capturing the baseline probability of holding private business wealth or being retired among households in group $c$.

share as households above the 90th percentile of this measure. ${ }^{33}$

Third, we summarize the labor income, wealth, and financial portfolios of these three groups, provided in Table 2. Group a households earn $3 \%$ of labor income, hold $18 \%$ of wealth, and have an aggregate capital portfolio share of 2.0. Group $b$ households earn only $14 \%$ of labor income, hold $59 \%$ of wealth, and have an aggregate capital portfolio share of 0.5 . Group $c$ households earn $83 \%$ of labor income, hold only $23 \%$ of wealth, and have an aggregate capital portfolio share of 1.1. To better understand the nature of households in each group, in Table 3 we first project an indicator for the household having private business wealth on households' group indicator. We find that households in group $a$ are especially more likely to have private business wealth. We then project an indicator for the household head being older than 54 and out of the labor force, together capturing a retired household head, on households' group indicator. We find that households in group $b$ are especially more likely to be retired.

\subsubsection{Macro: business cycle dynamics and asset prices}

We also calibrate the model to match standard macro moments regarding the business cycle and asset prices. In terms of the business cycle, we seek to match the volatilities of the growth rates of consumption and investment. We use NIPA data on consumption of non-durables and services as well as investment in durables and capital, together

\footnotetext{
${ }^{33}$ In appendix B.2, we vary these cutoffs. Raising the cutoff in the capital portfolio share in particular means that the wealth share of group $a$ falls, but their capital portfolio share rises. In the context of our model, these changes have offsetting effects on the risk premium effects of a monetary policy shock. The 90th percentile cutoff strikes a balance between capturing the tail of levered households and maintaining a large enough sample size.
} 
with the time series of the working age population from the BLS, to estimate quarterly per capita growth rates in those series over Q3 1979 to Q2 2012 (consistent with our sample period for the VAR). In terms of asset prices, we seek to match the first moments of returns and second moments of the dividend price ratio (informative of second moments of expected returns). In particular, over July 1979 - June 2012 using the data from CRSP described earlier, we estimate the annualized average real interest rate and excess return on the S\&P 500 as well as the quarterly standard deviation and autocorrelation of the smoothed dividend price ratio. ${ }^{34}$ We will compare these moments to those implied by our model assuming that an equity claim (with return $\left.r^{e}\right)$ is a levered claim to capital with a debt to equity ratio of $0.5 .^{35}$

\subsubsection{Parameterization}

A model period corresponds to one quarter. After setting a subset of parameters in accordance with the literature, we calibrate the remaining parameters to be consistent with the macro and micro moments described above. All stochastic properties of the model are estimated using a simulation where no disasters are realized in sample. ${ }^{36}$

Externally set parameters A subset of model parameters summarized in Table 4 are set externally. Among the model's preference parameters, we set $\psi$ to 0.75 . We note that this parameter controls both the intertemporal elasticity of substitution in consumption as well as the complementarity between consumption and labor. A value less than one is consistent with evidence on the consumption responses to changes in interest rates as well as consumption-labor complementarity. ${ }^{37}$ The Frisch elasticity of labor supply is set to $\theta=1$, roughly consistent with the micro evidence for aggregate hours surveyed in Chetty, Guren, Manoli, and Weber (2011). The three types have measure $\lambda^{a}=3 \%, \lambda^{b}=14 \%$ and $\lambda^{c}=83 \%$, consistent with the shares of labor income in our analysis of the SCF micro data in Table 2.

On the production side, we choose $\alpha=0.33$ for the capital share of production and a quarterly depreciation rate of $2.5 \%$, standard values in the literature. The

\footnotetext{
${ }^{34}$ When computing the smoothed dividend price ratio, we smooth dividends over 12 months rather than over 3 months as in the VAR. This is meant to more accurately compare our model (which features no dividend adjustment costs) with the data.

${ }^{35}$ This ratio is commonly used in the literature (e.g., Barro (2006)). It also implies assets to equity of 1.5, very close to our estimate of 1.6 for public equities in appendix B.2.

${ }^{36}$ We make this choice since we compare the model to post-World War II data.

${ }^{37}$ See, for instance, Barsky, Juster, Kimball, and Shapiro (1997), Hall (2009), and Shimer (2010).
} 


\begin{tabular}{clcl}
\hline & Description & Value & Notes \\
\hline$\psi$ & IES & 0.75 & \\
$\theta$ & Frisch elasticity & 1 & Chetty et al. (2011) \\
$\lambda^{a}$ & measure of $a$ households & $3 \%$ & labor income in SCF \\
$\lambda^{b}$ & measure of $b$ households & $14 \%$ & labor income in SCF \\
$\alpha$ & 1 - labor share & 0.33 & \\
$\delta$ & depreciation rate & $2.5 \%$ & \\
$\epsilon$ & elast. of subs. across workers & 10 & \\
$\chi^{W}$ & Rotemberg wage adj costs & 200 & $\approx \mathbb{P}($ adjust) $=5$ qtrs \\
$p$ & disaster probability & $0.5 \%$ & Barro (2006) \\
$\varphi$ & disaster shock & $-15 \%$ & Nakamura et al. (2013) \\
$\phi$ & Taylor coeff. on inflation & 1.5 & Taylor (1993) \\
$\sigma^{m}$ & std. dev. MP shock & $0.25 \% / 4$ & \\
$\rho^{m}$ & persistence MP shock & 0 & \\
$\tau$ & undoes wage markup & -0.11 & \\
$\lambda^{a} \nu^{a}$ & $a$ share of taxes to finance $-B^{g}$ & $18 \%$ & wealth in SCF \\
$\lambda^{b} \nu^{b}$ & $b$ share of taxes to finance $-B^{g}$ & $59 \%$ & wealth in SCF \\
\hline
\end{tabular}

Table 4: externally set parameters

disaster probability is set to $p=0.5 \%$, which follows Barro (2006) and implies that a disaster shock is expected to occur every 50 years. The depth of the disaster is set to $\underline{\varphi}=-15 \%$, consistent with the long-run effects of a disaster estimated by Nakamura, Steinsson, Barro, and Ursua (2013) after accounting for the recovery after an initial disaster. We choose an elasticity of substitution across worker varieties $\epsilon=10$ and Rotemberg wage adjustment costs of $\chi^{W}=200$, which together imply a Calvo (1983)-equivalent frequency of wage adjustment around 5 quarters, consistent with the evidence in Grigsby, Hurst, and Yildirmaz (2019).

Finally, in terms of policy, we set the Taylor coefficient on inflation to $\phi=1.5$, standard in the literature. We assume monetary policy shocks have a standard deviation of $\sigma^{m}=0.25 \% / 4$ with zero persistence. We assume that the wage markup would be offset in the absence of shocks by $\tau=-\frac{1}{\epsilon-1}=-\frac{1}{9}$. We assume that the share of lump-sum taxes financing government debt paid by group $i\left(\lambda^{i} \nu^{i}\right)$ is equal to their wealth share in Table 2. We later compare the average taxes paid by each group (including $\mathfrak{T}^{i}$ ) to the average taxes paid by each group estimated using the NBER Taxsim program. 


\begin{tabular}{clclcc}
\hline & Description & Value & Moment & Target & Model \\
\hline$\sigma$ & std. dev. prod. & $0.4 \%$ & $\sigma(\Delta \log c)$ & $0.5 \%$ & $0.6 \%$ \\
$\chi^{x}$ & capital adj cost & 3.5 & $\sigma(\Delta \log x)$ & $2.1 \%$ & $2.0 \%$ \\
$\beta$ & discount factor & 0.978 & $\mathbb{E} r_{+1}$ & $1.4 \%$ & $1.4 \%$ \\
$\gamma^{b}=\gamma^{c}$ & RRA $b, c$ & 25 & $\mathbb{E}\left[r_{+1}^{e}-r_{+1}\right]$ & $7.1 \%$ & $7.1 \%$ \\
$\sigma^{p}$ & variation dis. prob. & $0.25 \%$ & $\sigma\left(d^{e} / p^{e}\right)$ & $0.2 \%$ & $0.2 \%$ \\
$\rho^{p}$ & persist. dis. prob. & 0.95 & $\rho\left(d^{e} / p^{e}, d_{-1}^{e} / p_{-1}^{e}\right)$ & 0.95 & 0.94 \\
$\gamma^{a}$ & RRA $a$ & 11 & $k^{a} / a^{a}$ & 2.0 & 2.2 \\
$\underline{k}$ & lower bound $k^{i}$ & 6.4 & $k^{c} / a^{c}$ & 1.1 & 0.9 \\
$\tau^{a}$ & controls tax on $a$ & $0.5 \%$ & $\lambda^{a} a^{a} / \sum_{i} \lambda^{i} a^{i}$ & $18 \%$ & $22 \%$ \\
$\tau^{c}$ & controls tax on $c$ & $3.3 \%$ & $\lambda^{c} a^{c} / \sum_{i} \lambda^{i} c^{i}$ & $23 \%$ & $23 \%$ \\
$b^{g}$ & real value govt bonds & -2.6 & $-\sum_{i} \lambda^{i} b^{i} / \sum_{i} \lambda^{i} a^{i}$ & $-11 \%$ & $-11 \%$ \\
$\bar{\theta}$ & $\ell$ disutility & 0.72 & $\ell$ & 1 & 1.0 \\
\hline
\end{tabular}

Table 5: targeted moments and calibrated parameters

Notes: targeted business cycle moments are from Q3/79-Q2/12 NIPA and targeted asset pricing moments are from 7/79-6/12 data underlying the VAR. The equity premium and second moments of the dividend price ratio in the model are calculated assuming a debt/equity ratio of 0.5 on a stock market claim. The first and second moments in the model are estimated over 50,000 quarters after a burn-in period of 5,000 quarters, with no disaster realizations in sample.

Calibrated parameters We calibrate the remaining parameters to target the macro and micro moments described above. Table 5 reports in each line a parameter choice and moment in model and data that this parameter is closely linked to.

The standard deviation of the productivity shock $\sigma$ is set to $0.4 \%$, which is a key determinant of the model's ability to match quarterly consumption growth volatility of $0.5 \%$. The capital adjustment cost is set to $\chi^{x}=3.5$ to dampen the volatility of investment growth in order to match the data. Due to the precautionary savings motive, $\beta=0.978$ is high enough to match the low annualized real rate observed in the data. Households' risk aversion $\left\{\gamma^{i}\right\}$ and the capital constraint $\underline{k}$ are jointly drivers of the risk premium in the economy and households' portfolio choices. $\gamma^{c}$ and $\underline{k}$ are difficult to separately calibrate: for $\gamma^{c}$ not too much lower than $\gamma^{a}$ or $\gamma^{b}$, the relatively high ratio of labor income to wealth among group $c$ households means that they endogenously choose to hedge this exposure to productivity shocks by holding a lower position in capital, consistent with Proposition 1. They are thus more likely to be endogenously constrained by (29). For parsimony we set $\gamma^{c}=\gamma^{b}$ and calibrate $\underline{k}$ to 


\begin{tabular}{lcc}
\hline Moment (ann.) & Data & Model \\
\hline$\sigma(\Delta \log y)$ & $0.8 \%$ & $0.7 \%$ \\
$\sigma(\Delta \log \ell)$ & $0.8 \%$ & $0.6 \%$ \\
$\sigma\left(\mathbb{E} r_{+1}\right)$ & $1.1 \%$ & $1.1 \%$ \\
$\sigma\left(\mathbb{E}\left[r_{+1}^{e}-r_{+1}\right]\right)$ & $5.9 \%$ & $1.4 \%$ \\
\hline$\left(\lambda^{b}\left(-\nu^{b} r b^{g}+\mathfrak{t}^{b}\right)-\lambda^{a}\left(-\nu^{a} r b^{g}+\mathfrak{t}^{a}\right)\right) / y$ & $-0.2 \%$ & $-8.4 \%$ \\
$\left(\lambda^{c}\left(-\nu^{c} r b^{g}+\mathfrak{t}^{c}\right)-\lambda^{a}\left(-\nu^{a} r b^{g}+\mathfrak{t}^{a}\right)\right) / y$ & $12.4 \%$ & $5.6 \%$ \\
\hline$\sum^{i} \lambda^{i} m p r^{i}$ & $\approx 0.2$ & 0.2 \\
$m p r^{a}$ & & 2.0 \\
$m p r^{b}$ & & 0.7 \\
$m p r^{c}$ & & 0.0 \\
\hline
\end{tabular}

Table 6: untargeted macro and micro moments

Notes: see notes accompanying Table 5 on construction of moments in data and model.

target the capital portfolio share of $c$ households in the data, ${ }^{38}$ obtaining $\underline{k}=6.4$ which is $24 \%$ of the average financial wealth of households in the model. The variation $\sigma^{p}$ and persistence $\rho^{p}$ in the disaster probability are chosen to target the standard deviation and autocorrelation of the smoothed dividend price ratio. The redistributive tax rates $\tau^{i}$ are chosen to approximate the measured wealth shares of the three groups. We set $b^{g}$ so that on average, the aggregate bond position of households relative to total wealth is $11 \%$, as in the SCF data underlying Table $2 .{ }^{39}$ Finally we set the disutility of labor to $\bar{\theta}=0.72$, which targets a level of labor $\ell=1.0$ as a normalization.

\subsubsection{Untargeted moments}

Table 6 reports the values of several untargeted moments and their empirical counterparts where available. In terms of macro moments, the model closely matches the quarterly volatilities of output growth and employment growth. It matches the quarterly volatility of (annualized) expected real interest rates and can account for roughly

\footnotetext{
${ }^{38}$ We view this as a realistic description of the data, given that $\underline{k}$ is meant to capture components of the economy's capital stock which households hold for reasons beyond their financial returns. In the SCF, $51 \%$ of the aggregate capital held by group $c$ households is in their primary residence and vehicles, while the same ratio is only $36 \%$ for group $b$ households and $7 \%$ for group $a$ households.

${ }^{39}$ The aggregate household balance sheet is summarized in appendix B.2.
} 
one quarter of the volatility in expected excess returns. ${ }^{40}$ We note that the latter volatility in the data is not directly observed and instead is implied by our VAR, which is on the high end of available estimates. Relative to the average of estimates surveyed in Duarte and Rosa (2015), our model accounts for half of the volatility in expected excess returns, and relative to some estimates, it can account for all of it. We further note that expected excess returns correlate negatively with output in our model, as they do with industrial production in our VAR.

In terms of micro moments, we first compare the average lump-sum taxes on households with counterparts in the data. In the model, Table 6 reports

$$
\frac{\lambda^{i}\left(-\nu^{i} r b^{g}+\mathfrak{t}^{i}\right)-\lambda^{a}\left(-\nu^{a} r b^{g}+\mathfrak{t}^{a}\right)}{y}
$$

for $i \in\{b, c\}$. The numerator summarizes the difference in aggregate taxes assessed on group $i$ relative to group $a$, while the denominator summarizes aggregate income, where all variables are expressed in real terms. We compare this to total federal taxes and transfers for group $i$ less group $a$ in the SCF (estimated using NBER Taxsim) divided by total income exclusive of taxes and transfers. As in the data, group $b$ receives transfers and group $c$ pays additional taxes relative to group $a$ households.

We next discuss the model's predictions for MPRs. The model generates heterogeneity in quarterly MPRs consistent with Proposition 1 in the analytical results. Group $a$ households are the most risk tolerant and have the highest MPR, borrowing $\$ 1$ for every $\$ 1$ of marginal net worth to invest in capital. Group $b$ and $c$ households have higher levels of risk aversion and correspondingly lower MPRs. As noted above, group $c$ households have a higher ratio of labor income to wealth and thus are endogenously constrained by (29). Hence, on the margin their average MPR is zero.

Quasi-experimental evidence is consistent with the MPRs in our calibration. Weighting by the fraction of households, the average MPR in our model is 0.2 . Using data on Norwegian lottery winners, Fagereng, Holm, and Natvik (2019b) estimate an average marginal propensity to save in risky assets relative to save overall of $0.14 .{ }^{41} \mathrm{Using}$ data

\footnotetext{
${ }^{40}$ While we emphasize monetary shocks in the main text given that monetary transmission is our focus in this paper, these shocks contribute little to aggregate fluctuations. Supplement C studies how productivity shocks and changes in disaster probabilities, the drivers of fluctuations in our model, redistribute wealth and amplify the risk premium effects of these shocks. We further provide information on the ergodic distribution of wealth and a simulated sample path.

${ }^{41}$ In their Table 4, the average marginal propensity to save in stocks, bonds, and mutual funds is 0.058 and the marginal propensity to save in these assets, deposits, or repay debt is 0.407 .
} 
on Swedish lottery winners, Briggs, Cesarini, Lindqvist, and Ostling (2015) estimate an analogous ratio of $0.15 .^{42}$ These imply an MPR of roughly 0.2 after accounting for reasonable estimates of the leverage of firms in which households invest. ${ }^{43}$ MPRs further rise with wealth per household in our calibration - recalling that wealth per household is highest among $a$ households and then $b$ households - consistent with the pattern found in these studies. ${ }^{44}$ While the range in estimated MPRs in these studies is smaller than that in our model, estimated MPRs based on lotteries may underestimate the relevant statistic for households in groups $a$ and $b$ of our model. As lottery winnings are paid out as cash or riskless deposits, the estimated MPR may understate the MPR in response to dividends or capital gains, more relevant for the balance sheet revaluation among the wealthy ( $a$ and $b$ households) emphasized in this paper. ${ }^{45}$ Among owners of private businesses, overrepresented in these households, the estimated MPR may particularly understate their true MPR because investment in private businesses is not included in the definition of (traded) risky assets.

\subsection{Impulse responses to a monetary policy shock}

We now simulate the effects of a negative shock to the nominal interest rate. We demonstrate that our model can rationalize the stock market responses to a monetary policy shock in the data, amplifying policy transmission to the real economy.

\subsubsection{Model versus RANK}

Figures 2, 3, and 4 compare the impulse responses to those in a counterfactual representative agent New Keynesian (RANK) economy. In the latter, we set $\gamma^{i}=19.5$ for all groups, equal to the harmonic mean of risk aversion in the model weighted by consumption shares, and we eliminate the redistributive taxes $\mathfrak{T}_{t}^{i}$.

We choose the monetary shock $\epsilon_{0}^{m}$ in our model to match the $22 b p$ reduction in the Treasury yield estimated in Figure 1. We obtain the yield on a 1-year nominal bond

\footnotetext{
${ }^{42}$ In their Table B.8, the average marginal propensity to save in risky assets is 0.085 and the marginal propensity to save in these assets, safe assets, bank accounts, or repay debt is 0.58.

${ }^{43}$ With firm leverage of 1.6 estimated in appendix B.2, these estimates imply an MPR of 0.22-0.24.

${ }^{44}$ See Table 8 of Fagereng et al. (2019b) and Figure 3 of Briggs et al. (2015).

${ }^{45}$ Using the Panel Study of Income Dynamics, Brunnermeier and Nagel (2008) document significant inertia in financial portfolios, with a negative change in the risky share after receiving one dollar of cash or deposits but an increase in the risky share after receiving one dollar of unexpected returns on risky assets. In recent work, Fagereng, Holm, Moll, and Natvik (2019a) also find evidence that households "save by holding" on to nearly $100 \%$ of assets experiencing capital gains.
} 

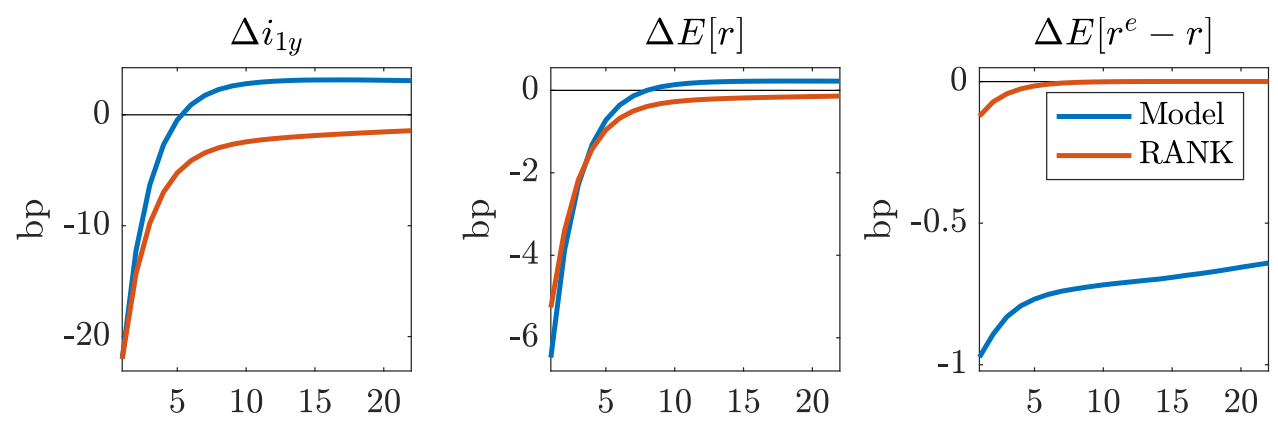

Figure 2: expected returns after negative monetary policy shock

Notes: series are quarterly (non-annualized) measures, except for the 1-year nominal bond yield $\Delta i_{1 y}$. Impulse responses are the average response (relative to no shock) starting at 1,000 different points drawn from the ergodic distribution of the state space, itself approximated using a sample path over 50,000 quarters after a burn-in period of 5,000 quarters. $b p$ denotes basis points $(0.01 \%)$.

by computing, in each state, the price that each household would be willing to pay for the asset. We then set the price to that of the highest-valuation household. We re-calibrate the shock $\epsilon_{0}^{m}$ in the RANK economy to match the same $22 b p$ reduction in the Treasury yield. This implies that the initial path of nominal interest rates in the RANK economy is comparable to that in our model, allowing us to partial out the initial difference in the endogenous response of monetary policy across environments. ${ }^{46}$

Figure 2 summarizes the effect of the monetary policy shock on expected returns. The first panel reports the change in the yield on the 1-year nominal bond. The second and third panels depict the resulting change in the expected real interest rate and the expected excess returns on capital. The decline in the former reflects the monetary non-neutrality in our setting, while the decline in the latter demonstrates that the risk premium declines substantially in our model relative to the representative agent case. It is because of the additional stimulus induced by the fall in the risk premium that monetary policy endogenously tightens by more in our model relative to the RANK economy, evident in the higher 1-year nominal yields after the first quarter.

Figure 3 demonstrates that redistribution drives the decline in the risk premium in our model. The first panel of the first row demonstrates that realized excess returns on capital are substantially positive on impact, followed by small negative returns in the quarters which follow — consistent with the initial decline in expected excess returns and the empirical pattern estimated in Figure 1. The substantially positive excess returns on impact endogenously redistribute to the high MPR a households who hold

\footnotetext{
${ }^{46}$ In supplement C, we consider an alternative comparison with the same shock across environments.
} 

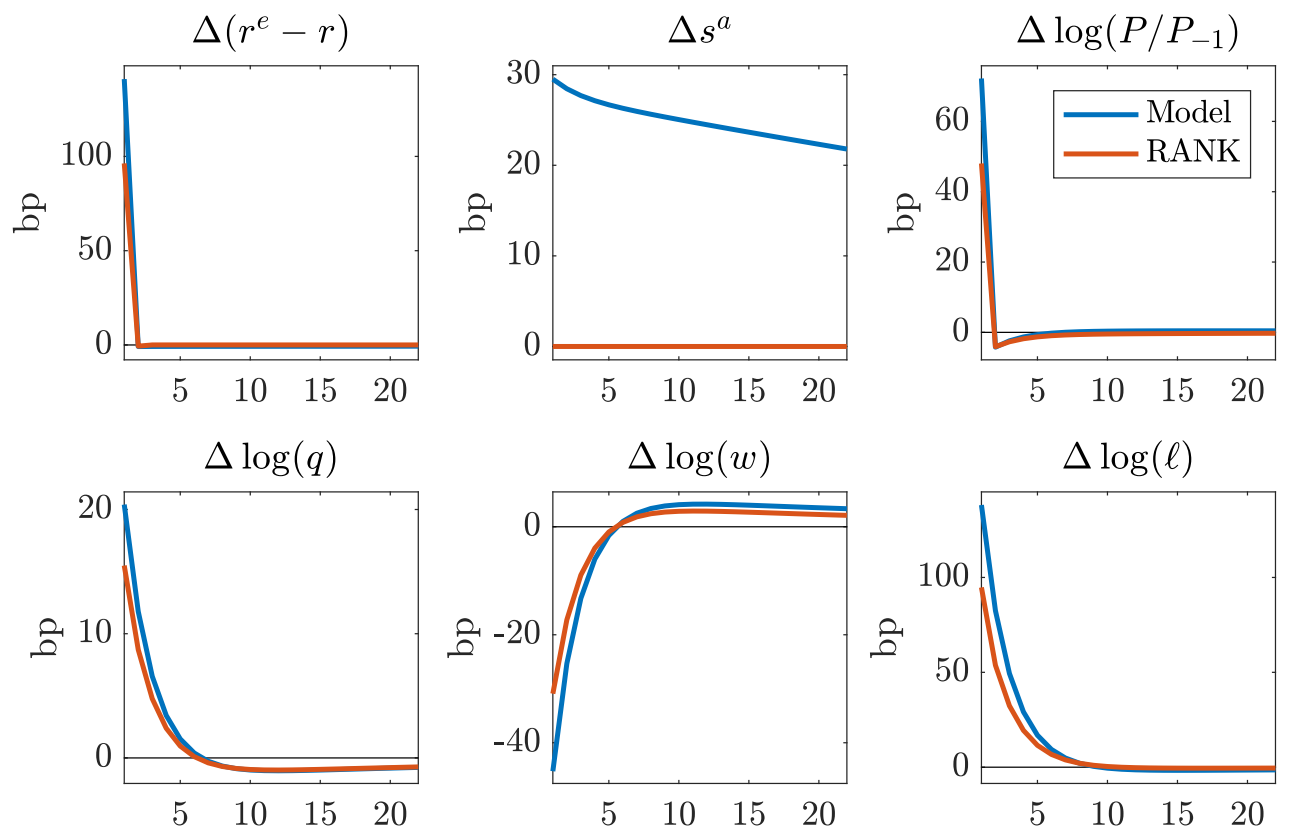

Figure 3: redistribution after negative monetary policy shock

Notes: see notes accompanying Figure 2 on construction of impulse responses.

levered claims on capital, evident from their financial wealth share shown in the second panel in this row. This redistribution in fact occurs at the expense of $b$ households, implying that the redistribution which matters for these effects is among the wealthy who hold heterogeneous portfolios. ${ }^{47,48}$

The positive excess return on impact follows from each of the channels characterized in Proposition A.1. In part it results from unexpected inflation which lowers the realized real interest rate, shown in the third panel. ${ }^{49}$ It also results from an increase in the price of capital, shown in the first panel of the second row. This reflects the increase in short-run profits due to lower real wages and higher employment in this sticky wage environment, shown in the second and third panels of this row.

Figure 4 examines the consequences for policy transmission to the real economy. The impact effects on investment and consumption are 1.3-1.5 times larger versus the

\footnotetext{
${ }^{47}$ The wealth share of the $b$ households falls by $29 b p$, while that of $c$ households falls by $1 b p$.

${ }^{48}$ In light of Table 3, this also accords well with the view that the losers from a monetary expansion are wealthy retirees, as in Doepke and Schneider (2006).

${ }^{49}$ While the response of inflation is more immediate in the model than estimated in the data in Figure 1, we also note that much nominal debt in practice has longer duration than the one-period debt assumed in the model. Hence, we conjecture that enriching the model to feature more sluggish price inflation would not change the redistribution of wealth much if it were also enriched to feature longer duration nominal debt.
} 

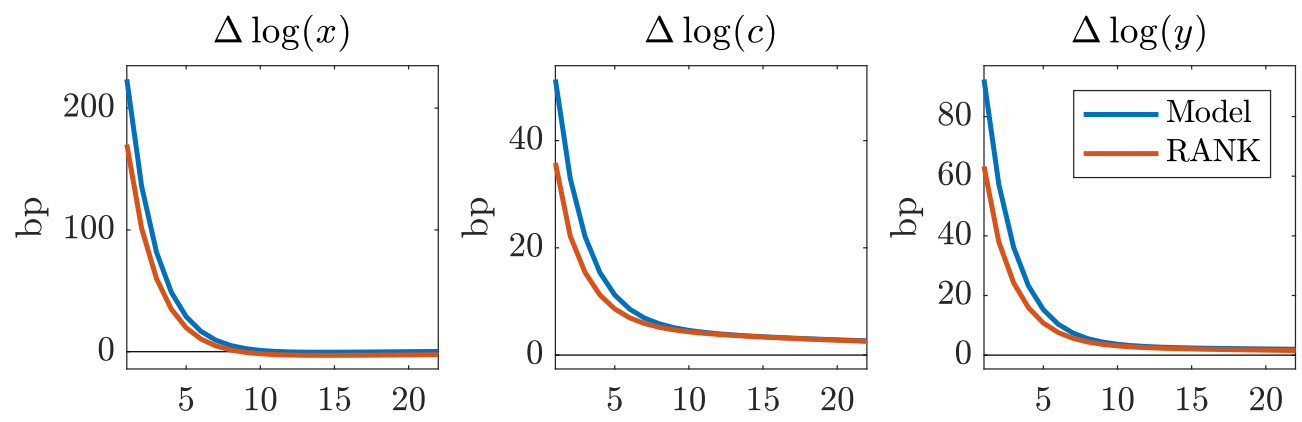

Figure 4: quantities after negative monetary policy shock

Notes: see notes accompanying Figure 2 on construction of impulse responses.

RANK economy. Moreover, the stimulus in our model remains persistently higher than the RANK economy despite the endogenous tightening of monetary policy in subsequent quarters (because the risk premium falls by more than the risk-free rate rises). These patterns are consistent with our discussion of Propositions 5 and 6 . The final panel demonstrates that they are inherited by the response of output as well. ${ }^{50}$

Quantitatively, the price and quantity effects of the monetary policy shock in our model are consistent with the empirical estimates even though these were not targeted in the calibration. First, the impact effect on excess returns of $1.4 p p$ is comparable to the $2 p p$ increase estimated in Figure 1. Second and crucially, a Campbell-Shiller decomposition on the model impulse responses matches the role of news about lower future excess returns in driving the initial stock market return in the data. We summarize this decomposition in Table 7. The performance of our model contrasts starkly with the RANK economy, where essentially none of the transmission to the stock market operates though news about future excess returns. Third, the peak stimulus to output in the model of $0.9 p p$ is only slightly higher than the peak stimulus to industrial production estimated in Figure 1, giving us confidence in the model's predictions for transmission to the real economy. ${ }^{51}$

\footnotetext{
${ }^{50}$ In appendix D, we relatedly show that our results imply state-dependent effects of monetary policy. We partition the state space by the impact effect of a monetary policy shock on output. Comparing states in which the effect is in its top versus bottom quartile, the former is characterized by group $a$ households holding a larger fraction of total wealth. The resulting redistribution and thus risk premium effects of a monetary policy shock are larger, and hence so are its real effects.

${ }^{51}$ We conjecture that adding features such as investment adjustment costs (as opposed to the present capital adjustment costs) could bring the model closer in line with the hump-shapes estimated in the data, following Christiano, Eichenbaum, and Evans (2005).
} 


\begin{tabular}{lccc}
\hline$\%$ Real stock return & Data [90\% CI] & Model & RANK \\
\hline Dividend growth news & $34 \%[-11 \%, 71 \%]$ & $50 \%$ & $65 \%$ \\
-Future real rate news & $7 \%[-6 \%, 21 \%]$ & $12 \%$ & $35 \%$ \\
-Future excess return news & $58 \%[21 \%, 106 \%]$ & $38 \%$ & $0 \%$ \\
\hline
\end{tabular}

Table 7: Campbell-Shiller decomposition of stock market return after monetary shock

Notes: estimates from data correspond to Table 1. Comparable estimates obtained in the model assuming a debt/equity ratio of 0.5 on a stock market claim.

\subsubsection{Inspecting the sources of redistribution}

We seek to further understand the sources of redistribution in the model by varying a set of key parameters. Each column of Table 8 corresponds to a different parameterization, where in each column only a single parameter is changed from our baseline in the first column. The first three rows report the effect on inflation, the price of capital, and the realized excess return on equity in period 0 . The last row then reports the response in the wealth share of group $a$ households.

The second column reports the results for an economy in which monetary policy shocks are persistent, setting $\rho^{m}=0.2$, demonstrating the importance of redistribution through debt deflation. In that case, a monetary policy shock induces a stronger response of the inflation rate relative to the baseline, as can be seen in row 1 . The realized excess return on capital on impact thus rises in row 3 and the change in the wealth share of the levered household group $a$ increases in row 4 .

Eliminating the capital adjustment cost by setting $\chi^{x}=0$, as reported in the third column, mitigates the redistribution through asset prices. In that case a monetary policy shock has no effect on the price of capital and therefore reduces the unexpected return on capital, as reported in rows 2 and 3. Redistribution is slightly smaller in row 4 , but the effect is not especially large because of the countervailing effect of a larger inflation response in row 1: the smaller adjustment cost amplifies quantity responses in the capital market, in turn amplifying the response in the labor market.

The fourth column eliminates nominal wage rigidity by setting $\chi^{W}=0$, demonstrating the role of changes in profit income in inducing redistribution across households. When wage rigidity is zero, the decline in the real wage and the stimulus to employment is mitigated. It follows that the short-run increase in profits is mitigated, which reduces the increase in the price of capital capitalizing future profits in row 2. Redis- 


\begin{tabular}{llrrrr}
\hline Row & & Baseline & $\rho^{m}=0.2$ & $\chi^{x}=0$ & $\chi^{W}=0$ \\
\hline 1 & $\Delta \log \left(P / P_{-1}\right)$ & $72 b p$ & $87 b p$ & $83 b p$ & $80 b p$ \\
2 & $\Delta \log (q)$ & $20 b p$ & $22 b p$ & $0 b p$ & $1 b p$ \\
3 & $\Delta\left(r^{e}-r\right)$ & $143 b p$ & $167 b p$ & $129 b p$ & $120 b p$ \\
4 & $\Delta s^{a}$ & $29 b p$ & $35 b p$ & $28 b p$ & $24 b p$ \\
\hline
\end{tabular}

Table 8: impact effects of negative monetary policy shock across parameterizations

Notes: for each parameterization, each row reports the average change in a variable on impact of the monetary policy shock starting at 1,000 different points drawn from the ergodic distribution of the state space with no disasters ever realized, itself approximated using a sample path over 50,000 quarters after a burn-in period of 5,000 quarters. All rows report quarterly (non-annualized) changes, and $b p$ denotes basis points $(0.01 \%)$.

tribution to $a$ households is thus mitigated in row 4 , even though the redistribution through debt deflation is again amplified in row 1.

\section{Conclusion}

In this paper we revisit monetary transmission in a New Keynesian environment with heterogeneous propensities to bear risk. An expansionary monetary policy shock lowers the risk premium if it redistributes to households with high MPRs. Heterogeneity in risk aversion, portfolio constraints, rules of thumb, background risk, or beliefs imply redistribution in this way. In a calibration matching heterogeneity in the U.S. economy, this mechanism rationalizes the stock market effects of monetary policy which have eluded existing frameworks and amplifies its transmission to the real economy.

The framework of this paper can be further developed along a number of dimensions. First, it seems fruitful to synthesize our perspective emphasizing assets' exposure to aggregate risk with the existing HANK literature emphasizing asset liquidity: in such a setting, an investor's MPR out of liquid versus illiquid wealth will differ, likely a better match to the micro data. Second, while we have focused for concreteness on the equity premium, a natural question is the extent to which our insights can explain the broader effects of monetary policy across asset classes, as in the Treasury market or foreign exchange market. Third, while our analysis has focused on the conditional responses to monetary policy shocks, it would be useful to examine the model's implied comovements when featuring a richer set of business cycle shocks calibrated to the data. We leave these questions for future work. 


\section{References}

Alvarez, F., A. Atkeson, And P. J. Kehoe (2009): "Time-varying risk, interest rates, and exchange rates in general equilibrium," Review of Economic Studies, 76, $851-878$.

Alves, F., G. Kaplan, B. Moll, and G. L. Violante (2019): "A further look at the propagation of monetary policy shocks in HANK," Working paper.

AuClERT, A. (2019): "Monetary policy and the redistribution channel," American Economic Review, 109, 2333-2367.

Auclert, A., M. Rognlie, And L. Straub (2019): "Micro jumps, macro humps: monetary policy and business cycles in an estimated HANK model," Working paper.

BARro, R. J. (2006): "Rare disasters and asset markets in the twentieth century," Quarterly Journal of Economics, 121, 823-866.

Barsky, R. B., F. T. Juster, M. S. Kimball, and M. D. Shapiro (1997): "Preference parameters and behavioral heterogeneity: an experimental approach in the Health and Retirement Study," Quarterly Journal of Economics, 112, 537-579.

BAsu, S. AND B. Bundick (2017): "Uncertainty shocks in a model of effective demand," Econometrica, 85, 937-958.

Bernanke, B. S., M. Gertler, And S. Gilchrist (1999): The financial accelerator in a quantitative business cycle framework, Elsevier, vol. 1 of Handbook of Macroeconomics, 1341-1393.

Bernanke, B. S. And K. N. Kuttner (2005): "What explains the stock market's reaction to Federal Reserve policy?" Journal of Finance, 60, 1221-1257.

Bhandari, A., D. Evans, And M. Golosov (2019): "Risk and asset prices in a monetary model," Working paper.

Bianchi, F., C. Ilut, And M. Schneider (2018): "Uncertainty shocks, asset supply and pricing over the business cycle," Review of Economic Studies, 85, 810-854.

Bianchi, F., M. Lettau, And S. C. Ludvigson (2019): "Monetary policy and asset valuation," Working paper.

Briggs, J., D. Cesarini, E. Lindqvist, and R. Ostling (2015): "Wealth, portfolio allocations, and risk preference," Working paper.

Brunnermeier, M. And Y. SAnnikov (2012): "Redistributive monetary policy," Proceedings of the Symposium at Jackson Hole. 
Brunnermeier, M. K. And S. Nagel (2008): "Do wealth fluctuations generate time-varying risk aversion? Micro-evidence on individuals' asset allocation," American Economic Review, 98, 713-736.

Brunnermeier, M. K. And Y. Sannikov (2014): "A macroeconomic model with a financial sector," American Economic Review, 104, 379-421.

— (2016): "The I theory of money," Working paper.

Bunn, O. D. AND R. J. Shiller (2014): "Changing times, changing values: a historical analysis of sectors within the U.S. stock market 1872-2013," Working paper.

Caballero, R. and E. Farhi (2018): "The safety trap," Review of Economic Studies, 85, 223-274.

Caballero, R. and A. Simsek (2018): "A risk-centric model of demand recessions and monetary policy," Working paper.

(2019): "Prudential monetary policy," Working paper.

Calvo, G. A. (1983): "Staggered prices in a utility-maximizing framework," Journal of Monetary Economics, 12, 383-398.

Campbell, J. Y. and J. Ammer (1993): "What moves the stock and bond markets? A variance decomposition for long-term asset returns," Journal of Finance, 48, 3-37.

Campbell, J. Y. and R. J. Shiller (1988): "The dividend-price ratio and expectations of future dividends and discount factors," Review of Financial Studies, 1, $195-228$.

Chen, W. and G. Phelan (2019): "Dynamic consequences of monetary policy for financial stability," Working paper.

Chetty, R., A. Guren, D. Manoli, And A. Weber (2011): "Are micro and macro labor supply elasticities consistent? A review of evidence on the intensive and extensive margins," American Economic Review, 101, 471-475.

Chien, Y., H. Cole, And H. Lustig (2012): "Is the volatility of the market price of risk due to intermittent portfolio rebalancing?" American Economic Review, 106, 2859-2896.

Christiano, L. J., M. Eichenbaum, and C. L. Evans (2005): "Nominal rigidities and the dynamic effects of a shock to monetary policy," Journal of Political Economy, $113,1-45$.

Cochrane, J. H. (2017): "Macro-Finance," Review of Finance, 21, 945-985. 
Colmbra, N. And H. Rey (2019): "Financial cycles with heterogeneous intermediaries," Working paper.

Constantinides, G. M. And D. Duffie (1996): "Asset pricing with heterogeneous consumers," Journal of Political Economy, 104, 219-240.

Devereux, M. B. And A. Sutherland (2011): "Country portfolios in open economy macro-models," Journal of the European Economic Association, 9, 337-369.

DiTella, S. (2019): "Risk premia and the real effects of money," Working paper.

Doepke, M. And M. Schneider (2006): "Inflation and the redistribution of nominal wealth," Journal of Political Economy, 114, 1069-1097.

Drechsler, I., A. Savov, And P. Schnabl (2018): "A model of monetary policy and risk premia," Journal of Finance, 63, 317-373.

DuARte, F. And C. Rosa (2015): "The equity risk premium: a review of models," FRBNY Economic Policy Review.

Epstein, L. G. AND S. E. ZIN (1991): "Substitution, risk aversion, and the temporal behavior of consumption and asset returns: an empirical analysis," Econometrica, 99, 263-286.

Fagereng, A., M. B. Holm, B. Moll, And G. Natvik (2019a): "Saving behavior across the wealth distribution: the importance of capital gains," Working paper.

Fagereng, A., M. B. Holm, And G. J. Natvik (2019b): "MPC heterogeneity and household balance sheets," Working paper.

Fernandez-Villaverde, J., P. Guerron-Quintana, K. Kuester, And J. Rubio-RAmirez (2015): "Fiscal volatility shocks and economic activity," American Economic Review, 105, 3352-3384.

GALI, J. (2008): Monetary policy, inflation, and the business cycle, Princeton University Press.

Garleanu, N. and S. Panageas (2015): "Young, Old, Conservative, and Bold. The implications of finite lives and heterogeneity for asset pricing," Journal of Political Economy, 123, 670-685.

Geanakoplos, J. (2009): "The leverage cycle," NBER Macroeconomics Annual, 24.

Gertler, M. And P. Karadi (2015): "Monetary policy surprises, credit costs, and economic activity," American Economic Journal: Macroeconomics, 7, 44-76.

Gilchrist, S. AND E. ZAKRAJSEK (2012): "Credit spreads and business cycle fluctuations," American Economic Review, 102, 1692-1720. 
Gomes, M. (2019): "Asset prices and wealth inequality," Working paper.

Gourio, F. (2012): "Disaster Risk and Business Cycles," American Economic Review, $102,2734-2766$.

Grigsby, J., E. Hurst, And A. Yildirmaz (2019): "Aggregate nominal wage adjustments: new evidence from administrative payroll data," Working paper.

Guvenen, F. (2009): "A parsimonious macroeconomic model for asset pricing," Econometrica, 77, 1711-1750.

Hall, R. E. (2009): "Reconciling cyclical movements in the marginal value of time and the marginal product of labor," Journal of Political Economy, 117, 281-323.

Hanson, S. G. And J. C. Stein (2015): "Monetary policy and long-term real rates," Journal of Financial Economics, 115, 429-448.

He, Z. And A. Krishnamurthy (2013): "Intermediary Asset Pricing," American Economic Review, 2, 732-770.

Ilut, C. L. AND M. Schneider (2014): "Ambiguous business cycles," American Economic Review, 104, 2368-2399.

JAROCINSKI, M. AND P. KARADI (forthcoming): "Deconstructing monetary policy surprises - the role of information shocks," AEJ: Macroeconomics.

Kaplan, G., B. Moll, and G. L. Violante (2018): "Monetary policy according to HANK," American Economic Review, 108, 697-743.

Kaplan, G. And G. L. Violante (2018): "Microeconomic heterogeneity and macroeconomic shocks," Journal of Economic Perspectives.

Krueger, D. And H. Lustig (2010): "When is market incompleteness irrelevant for the price of aggregate risk (and when is it not)?" Journal of Economic Theory, 145, $1-41$.

LuetTiCKe, R. (2018): "Transmission of monetary policy with heterogeneity in household portfolios," Working paper.

Mertens, K. And M. O. Ravn (2013): "The dynamic effects of personal and corporate income tax changes in the United States," American Economic Review, 103, $1212-1247$.

Nakamura, E. And J. Steinsson (2018): "High frequency identification of monetary non-neutrality: the information effect," Quarterly Journal of Economics, 133, $1283-1330$. 
Nakamura, E., J. Steinsson, R. Barro, And J. Ursua (2013): "Crises and recoveries in an empirical model of consumption disasters," American Economic Journal: Macroeconomics, 5, 35-74.

Panageas, S. (2019): "The implications of heterogeneity and inequality for asset pricing," Working paper.

PAul, P. (2019): "The time-varying effect of monetary policy on asset prices," Review of Economics and Statistics, forthcoming.

PEnCE, K. (2015): "SCFCOMBO: Stata module to estimate errors using the Survey of Consumer Finances," Tech. rep., Boston College Department of Economics.

Plagborg-Moller, M. And C. K. Wolf (2019): "Local projections and VARs estimate the same impulse responses," Working paper.

Rotemberg, J. J. (1982): "Sticky prices in the United States," Journal of Political Economy, 90, 1187-1211.

Sabelhaus, J. AND A. H. Volz (2019): "Are disappearing employer pensions contributing to rising wealth inequality?" Working paper.

Shimer, R. (2010): Labor markets and business cycles, Princeton University Press.

Stock, J. H. And M. W. Watson (2018): "Identification and estimation of dynamic causal effects in macroeconomics using external instruments," The Economic Journal, 128, 917-948.

Stock, J. H., J. H. Wright, And M. Yogo (2002): “A survey of weak instruments and weak identification in generalized method of moments," Journal of Business and Economic Statistics, 20, 518-529.

TAllarini JR., T. D. (2000): "Risk-sensitive business cycles," Journal of Monetary Economics, 45, 507-532.

TAYlor, J. B. (1993): "Discretion Versus Policy Rules in Practice," CarnegieRochester Conference Series on Public Policy, 39, 195-214.

TodA, A. A. And K. J. WAlsh (2019): "The equity premium and the one percent," Working paper.

WACHTER, J. A. (2013): "Can time-varying risk of rare disasters explain aggregate stock market volatility," Journal of Finance, 68, 987-1035.

WoOdFord, M. (2003): Interest and prices: foundations of a theory of monetary policy, Princeton University Press. 


\title{
Appendix For Online Publication
}

\author{
Monetary Policy, Redistribution, and Risk Premia \\ Rohan Kekre Moritz Lenel
}

\section{A Additional analytical results}

In this section we provide analytical results accompanying section 2. Proofs are included in supplement A, along with all proofs of results in the main text.

\section{A.1 Redistributive effects of a monetary policy shock}

We first characterize the redistributive effects of a monetary policy shock.

As discussed in the main text, the relevant measure of redistribution to evaluate the effect on the risk premium is

$$
\bar{\xi}_{m_{0}}^{i}=\frac{1}{\int_{0}^{1} \bar{c}_{1}^{\prime} d i^{\prime}}\left[\frac{\overline{d c_{1}^{i}}}{d m_{0}}-\frac{\bar{c}_{1}^{i}}{\int_{0}^{1} \bar{c}_{1}^{i^{\prime}} d i^{\prime}} \int_{0}^{1} \frac{\overline{d c_{1}^{i^{\prime}}}}{d m_{0}} d i^{\prime}\right] .
$$

Using standard tools from price theory, we can decompose each household's change in future consumption as follows:

Proposition A.1. A household's change in future consumption in response to a monetary policy shock is given by

$$
\begin{aligned}
& \frac{\overline{d c_{1}^{i}}}{d m_{0}}=\left(1+\bar{r}_{1}\right) \underbrace{\frac{\overline{\partial a_{0}^{i}}}{\partial y_{0}^{i}}}_{M P S}[-\underbrace{\frac{\left(1+i_{-1}\right) B_{-1}^{i}}{\bar{P}_{0}} \frac{1}{\bar{P}_{0}} \frac{\overline{d P_{0}}}{d m_{0}}+k_{-1}^{i}\left(\frac{\overline{d \pi_{0}}}{d m_{0}}+\left(1-\delta_{0}\right) \frac{\overline{d q_{0}}}{d m_{0}}\right)}_{\text {balance sheet revaluation }} \\
& +\underbrace{\left(\overline{\frac{d w_{0} \ell_{0}^{i}}{d m_{0}}}+\frac{1}{1+\bar{r}_{1}} \frac{\overline{d w_{1}}}{d m_{0}}\right)}_{\text {change in non-traded income }}+\underbrace{\bar{a}_{0}^{i} \frac{1}{1+\bar{r}_{1}} \frac{\overline{d\left(1+r_{1}\right)}}{d m_{0}}}_{\text {income effect }} \\
& +\underbrace{\psi^{i} c_{0}^{i} \frac{1}{1+\bar{r}_{1}} \frac{\overline{d\left(1+r_{1}\right)}}{d m_{0}}+\left(\psi^{i}-1\right) \bar{w}_{0}\left(1-\bar{\tau}^{\ell_{0}^{i}}\right) \frac{\overline{d \ell_{0}^{i}}}{d m_{0}}}_{\text {substitution effects }}]
\end{aligned}
$$

given the labor wedge for household $i \bar{\tau}^{\ell_{0}^{i}} \equiv 1-\frac{-\bar{c}_{0}^{i} \Phi^{i^{\prime}}\left(\bar{\ell}_{0}^{i}\right) / \Phi^{i}\left(\bar{\ell}_{0}^{i}\right)}{(1-\alpha) \bar{z}_{0}\left(\ell_{0}\right)^{-\alpha} k_{-1}^{\alpha}}$. 
The resulting redistribution summarized in $\xi_{m_{0}}^{i}$ reflects heterogeneity in the marginal propensity to save; heterogeneity in changes in wealth; and heterogeneity in substitution effects. We further discuss the second here. ${ }^{1}$

First, a cut in the nominal interest rate revalues household balance sheets, the only channel operative under the special conditions of Proposition 3 in the main text. Second, a cut in the nominal interest rate changes the net present value of non-traded labor income. If it lowers the real wage in the short run $\left(\frac{\overline{d w_{0}}}{d m_{0}}>0\right)$, the standard effect with sticky nominal wages rather than prices, it redistributes to households supplying less labor. If it raises the quantity of labor demanded $\left(\overline{\frac{d \ell_{0}}{d m_{0}}}<0\right)$, it redistributes to households whose labor demand is especially sensitive to the aggregate. Third, if a cut in the nominal interest rate lowers the equilibrium real interest rate $\left(\frac{\overline{d\left(1+r_{1}\right)}}{d m_{0}}>0\right)$, it redistributes wealth away from net savers through a Slutsky income effect. These heterogeneous exposures to a monetary shock have been previously exposited in the literature on HANK models, as by Auclert (2019). ${ }^{2}$ Our analysis demonstrates that it is their covariance with MPRs which matters for transmission through risk-premia.

\section{A.2 Generalizations to other sources of heterogeneity}

We next demonstrate that Propositions 1 and 2 generalize to environments with heterogeneity in portfolio constraints, rules-of-thumb, background risk, or beliefs. We describe these richer environments in section 2.4 of the main text.

Binding constraints or rules-of-thumb We have:

Corollary A.1. Letting $C$ denote the set of households with binding constraints or rules-of-thumb, households' limiting portfolios and MPRs are

$$
\begin{aligned}
\frac{\bar{q}_{0} \bar{k}_{0}^{i}}{\bar{a}_{0}^{i}}=\left\{\begin{array}{l}
\omega_{0}^{i} \text { for } i \in C, \\
\left(\frac{\bar{c}_{1}^{i}}{\left(1+\bar{r}_{1}\right) \bar{a}_{0}^{i}}\right) \frac{\gamma}{\gamma^{i}}-\frac{\bar{w}_{1}}{\left(1+\bar{r}_{1}\right) \bar{a}_{0}^{i}} \text { for } i \notin C,
\end{array}\right. \\
\overline{m p r}_{0}^{i}=\left\{\begin{array}{l}
\omega_{0}^{i} \text { for } i \in C, \\
\frac{\gamma}{\gamma^{i}} \text { for } i \notin C,
\end{array}\right.
\end{aligned}
$$

\footnotetext{
${ }^{1}$ The role of the marginal propensity to save and the substitution effect due to a change in the real interest rate is straightforward. The substitution effect due to a change in $\bar{\ell}_{0}^{i}$ reflects the nonseparability of labor from consumption in period 0 when $\psi^{i} \neq 1$.

${ }^{2}$ Since $\bar{q}_{0}=\frac{\bar{\pi}_{1}}{1+\bar{r}_{1}}$ and thus $\frac{\overline{d q_{0}}}{d m_{0}}=\frac{1}{1+\bar{r}_{1}} \frac{\overline{d \pi_{1}}}{d m_{0}}-\frac{\bar{q}_{0}}{1+\bar{r}_{1}} \frac{\overline{d\left(1+\bar{r}_{1}\right)}}{d m_{0}}$, we can re-arrange the terms in Proposition A.1 to obtain a decomposition consistent with Auclert (2019). We find it convenient to explicitly account for the effect on the price of capital to aid the interpretation of our quantitative simulations.
} 
where

$$
\gamma=\left(\int_{i \notin C} \frac{\bar{c}_{1}^{i}}{\int_{i^{\prime} \notin C} \bar{c}_{1}^{i^{\prime}} d i^{\prime}} \frac{1}{\gamma^{i}} d i\right)^{-1}\left(1-\frac{\int_{i \notin C}\left(1+\bar{r}_{1}\right) \bar{b}_{0}^{i} d i}{\int_{i \notin C} \bar{c}_{1}^{i} d i}\right) .
$$

Up to third order in $\left\{\sigma, \hat{z}_{1}, \hat{m}_{0}\right\}$, we obtain (21) with $\gamma$ defined above and

$$
\zeta_{m_{0}}=\left(\int_{i \notin C} \frac{\bar{c}_{1}^{i}}{\int_{0}^{1} \bar{c}_{1}^{i^{\prime}} d i^{\prime}} \frac{1}{\gamma^{i}} d i\right)^{-1} \int_{0}^{1} \bar{\xi}_{m_{0}}^{i}\left(\overline{m p r}_{0}-\overline{m p r}_{0}^{i}\right) d i
$$

where $\bar{\xi}_{m_{0}}^{i} \equiv \overline{\overline{d\left[\left(1+r_{0}\right) a_{0}^{i} / \int_{0}^{1} c_{1}^{i^{\prime}} d i^{\prime}\right]}}$ for $i \in C, \bar{\xi}_{m_{0}}^{i} \equiv \frac{\overline{d\left[c_{1}^{i} / \int_{0}^{1} c_{1}^{i^{\prime}} d i^{\prime}\right]}}{d m_{0}}$ for $i \notin C$, and $\overline{m p r} \bar{p}_{0}=1$.

The risk premium $\gamma$ now depends not only on the weighted average risk aversion of unconstrained households, but also on the leverage which these households must take in aggregate to hold the economy's capital stock after accounting for the positions of constrained households. For this reason, the effect of a monetary policy shock on the risk premium $\zeta_{m_{0}}$ depends on the MPRs of constrained households. For instance, if wealth transfers to households who cannot trade capital and thus have $\overline{m p r}_{0}^{i}=0$, in equilibrium the remaining households must be induced to hold a more levered position in capital and thus the risk premium must rise.

Background risk We have: ${ }^{3}$

Corollary A.2. With background risk, households' limiting portfolios and MPRs are

$$
\begin{aligned}
\frac{\bar{q}_{0} \bar{k}_{0}^{i}}{\bar{a}_{0}^{i}} & =\left(\frac{\bar{c}_{1}^{i}}{\left(1+\bar{r}_{1}\right) \bar{a}_{0}^{i}}\right) \frac{\gamma}{\gamma^{i}\left(1+\eta^{i}\right)}-\frac{\bar{w}_{1}}{\left(1+\bar{r}_{1}\right) \bar{a}_{0}^{i}}, \\
\overline{m p r}_{0}^{i} & =\frac{\gamma}{\gamma^{i}\left(1+\eta^{i}\right)},
\end{aligned}
$$

where

$$
\gamma=\left(\int_{0}^{1} \frac{\bar{c}_{1}^{i}}{\int_{0}^{1} \bar{c}_{1}^{i^{\prime}} d i^{\prime}} \frac{1}{\gamma^{i}\left(1+\eta^{i}\right)} d i\right)^{-1}
$$

Up to third order in $\left\{\sigma, \hat{z}_{1}, \hat{m}_{0}\right\}$, we obtain (21) with $\gamma$ defined above and

$$
\zeta_{m_{0}}=\gamma \int_{0}^{1} \bar{\xi}_{m_{0}}^{i}\left(\overline{m p r}_{0}-\overline{m p r}_{0}^{i}\right) d i
$$

\footnotetext{
${ }^{3}$ We continue to define $1+r_{1}^{k} \equiv \frac{\pi_{1}}{q_{0}}$, a claim on capital aggregating over the idiosyncratic risk, even though each household $i$ faces the set of asset returns $\left\{1+r_{0}, 1+r_{1}^{k, i} \equiv \frac{\pi_{1} \epsilon_{1}^{i}}{q_{0}}\right\}$.
} 
where $\bar{\xi}_{m_{0}}^{i} \equiv \overline{\overline{d\left[c_{1}^{i} / \int_{i^{\prime} \notin C} c_{1}^{i^{\prime}} d i^{\prime}\right]}}$ and $\overline{m p r}_{0} \equiv \int_{0}^{1} \frac{\bar{c}_{1}^{i}}{\int_{0}^{1} \bar{c}_{1}^{i^{\prime}} d i^{\prime}} \overline{m p r}_{0}^{i} d i=1$.

Corollary A.2 is consistent with the empirical finding that households with greater background risk $\eta^{i}$ uncorrelated with the stock market hold a lower portfolio share in stocks (Heaton and Lucas (2000)). It also implies that households with different amounts of background risk will have different MPRs. Redistribution across these households in turn will induce changes in the risk premium.

Subjective beliefs We have:

Corollary A.3. With subjective beliefs, households' limiting portfolios and MPRs are

$$
\begin{aligned}
\frac{\bar{q}_{0} \bar{k}_{0}^{i}}{\bar{a}_{0}^{i}} & =\left(\frac{\bar{c}_{1}^{i}}{\left(1+\bar{r}_{1}\right) \bar{a}_{0}^{i}}\right) \frac{\gamma}{\gamma^{i} \varsigma^{i}}-\frac{\bar{w}_{1}}{\left(1+\bar{r}_{1}\right) \bar{a}_{0}^{i}}, \\
\overline{m p r}_{0}^{i} & =\frac{\gamma}{\gamma^{i} \varsigma^{i}}
\end{aligned}
$$

where

$$
\gamma=\left(\int_{0}^{1} \frac{\bar{c}_{1}^{i}}{\int_{0}^{1} \bar{c}_{1}^{\prime} d i^{\prime}} \frac{1}{\gamma^{i} \varsigma^{i}} d i\right)^{-1}
$$

Up to third order in $\left\{\sigma, \hat{z}_{1}, \hat{m}_{0}\right\}$, we obtain (21) with $\gamma$ defined above and

$$
\zeta_{m_{0}}=\gamma \int_{0}^{1} \bar{\xi}_{m_{0}}^{i}\left(\overline{m p r}_{0}-\overline{m p r}_{0}^{i}\right) d i
$$

where $\bar{\xi}_{m_{0}}^{i} \equiv \overline{\frac{d\left[c_{1}^{i} / \int c_{1}^{i^{\prime}} d i^{\prime}\right]}{d m_{0}}}$ and $\overline{m p r}_{0} \equiv \int_{0}^{1} \frac{\bar{c}_{1}^{i}}{\int_{0}^{1} \bar{c}_{1}^{i^{\prime}} d i^{\prime}} \overline{m p r}_{0}^{i} d i=1$.

Hence, all else equal, optimists (with low $\varsigma^{i}$ ) will hold more levered portfolios and have a higher MPR. Consistent with the theoretical literature exploring the consequences of belief disagreements, redistribution can then have important consequences for the macroeconomy through its effect on asset prices.

\section{A.3 Robustness to features of economic environment}

We next demonstrate the robustness of our analytical results to the specification of labor supply and inflation risk in the nominal bond. 


\section{A.3.1 Individually supplied labor}

We first consider the case with individually-supplied labor rather than the union set-up assumed in the main text.

We dispense with the index $j$ and assume households directly supply distinct varieties of labor to the market at wages $\left\{W_{0}^{i}\right\}$. Household preferences thus can be written

$$
v_{0}^{i}=\left(\left(1-\beta^{i}\right)\left(c_{0}^{i} \Phi^{i}\left(\ell_{0}^{i}\right)\right)^{1-1 / \psi^{i}}+\beta^{i}\left(\mathbb{E}_{0}\left[\left(c_{1}^{i}\right)^{1-\gamma^{i}}\right]\right)^{\frac{1-1 / \psi^{i}}{1-\gamma^{i}}}\right)^{\frac{1}{1-1 / \psi^{i}}}
$$

and the resource constraints become

$$
\begin{aligned}
P_{0} c_{0}^{i}+B_{0}^{i}+Q_{0} k_{0}^{i} \leq & (1-\tau) W_{0}^{i} \ell_{0}^{i}-A C_{0}^{W, i}+ \\
& \left(1+i_{-1}\right) B_{-1}^{i}+\left(\Pi_{0}+\left(1-\delta_{0}\right) Q_{0}\right) k_{-1}^{i}+T_{0}^{i}, \\
P_{1} c_{1}^{i} \leq & W_{1}+\left(1+i_{0}\right) B_{0}^{i}+\Pi_{1} k_{0}^{i}
\end{aligned}
$$

with adjustment costs

$$
A C_{0}^{W, i}=\frac{\chi^{W}}{2} W_{0} \ell_{0}\left(\frac{W_{0}^{i}}{W_{-1}}-1\right)^{2} .
$$

The labor packer directly hires labor from households and combines it using the CES aggregator, earning profits

$$
W_{0}\left[\int_{0}^{1}\left(\ell_{0}^{i}\right)^{(\epsilon-1) / \epsilon}\right]^{\epsilon /(\epsilon-1)}-\int_{0}^{1} W_{0}^{i} \ell_{0}^{i} d i
$$

The notation in the government transfer condition (9) and labor market clearing condition (12) must be changed, and the equilibrium in Definition 1 is otherwise the same.

Even though each household is now characterized by a marginal propensity to work

$\frac{\partial \ell_{0}^{i}}{\partial y_{0}^{i}}$ and marginal propensity to set its wage $\frac{\partial w_{0}^{i}}{\partial y_{0}^{i}}$ in addition to its marginal propensities to consume, save in bonds, save in capital, and save overall, our main results remain unchanged. Proposition 1 is the same. The characterization of the risk premium up to third order in Proposition 2 is also the same. The monetary policy exposures $\bar{\xi}_{m_{0}}^{i}$ now reflect households' alternative adjustment on the supply-side. In particular, Proposition A.1 must be adjusted to reflect the fact that each household is no longer a price-taker in the labor market. However, when households are identical except for risk aversion and their portfolio shares, balance sheet revaluation remains the only source 
of redistribution, so Proposition 3 remains unchanged. The effects of a monetary policy shock on the real economy operating through the change in the risk premium in Propositions 5 and 6 are thus also unchanged.

\section{A.3.2 Inflation risk in the nominal bond}

We next consider the case with inflation risk in the nominal bond.

We assume the monetary authority lets the future price level vary with TFP

$$
P_{1}=\bar{P}_{1} z_{1}^{\iota}
$$

The baseline environment featured $\iota=0$. Beyond this change to monetary policy, the equilibrium in Definition 1 is otherwise unchanged.

Propositions 1 and 2 must be adjusted to reflect the presence of inflation risk in the nominal bond, so that (18), (19), and (21) are replaced by

$$
\begin{gathered}
\frac{\bar{q}_{0} \bar{k}_{0}^{i}}{\bar{a}_{0}^{i}}=\frac{1}{1+\iota}\left[\left(\frac{\bar{c}_{1}^{i}}{\left(1+\bar{r}_{1}\right) \bar{a}_{0}^{i}}\right) \frac{\gamma}{\gamma^{i}}-\frac{\bar{w}_{1}}{\left(1+\bar{r}_{1}\right) \bar{a}_{0}^{i}}+\iota\right], \\
\overline{m p r}_{0}^{i}=\frac{1}{1+\iota}\left[\frac{\gamma}{\gamma^{i}}+\iota\right], \\
\mathbb{E}_{0} \hat{r}_{1}^{k}-\mathbb{E}_{0} \hat{r}_{1}+\frac{1}{2}\left(1-\iota^{2}\right) \sigma^{2}=\gamma(1+\iota) \sigma^{2}+\zeta_{m_{0}} \hat{m}_{0}(1+\iota)^{2} \sigma^{2}+o\left(\|\cdot\|^{4}\right),
\end{gathered}
$$

where $\gamma$ remains characterized by (20) and $\zeta_{m_{0}}$ is defined in (22). While inflation risk in the nominal bond affects households' portfolios and MPRs, it remains the case that exposures and MPRs jointly determine the effect of a monetary shock on the risk premium. Of course, as $\iota \rightarrow-1$ the real payoff to the nominal bond perfectly replicates that of capital, eliminating any excess returns on capital and the effect of a monetary policy shock on those expected excess returns.

Provided $\iota>-1$, we note that despite the presence of inflation risk in the nominal bond it remains the case that more risk tolerant households will hold more levered portfolios and have higher MPRs, all else equal. Hence, the balance sheet revaluation underlying Proposition 3 remains unchanged. The effects of a monetary policy shock on the real economy in Propositions 5 and 6 are thus also unchanged. 


\section{A.4 Effect of TFP shocks}

We finally note that our analytical insights extend beyond monetary policy shocks to any shock which redistributes across households in period 0 or (in expectation) period 1. Here we focus on a TFP shock in period 0 , corresponding to our quantitative analysis of productivity shocks in supplement C.

All of the formulas in the main text generalize to a TFP shock, with $z_{0}$ replacing $m_{0}$ throughout. Hence, for brevity we do not re-state them here. We simply note that in the analog to Proposition 3, a TFP shock can have different effects on prices, profits, and the price of capital than a monetary policy shock. For instance, for $\chi^{W}$

sufficiently large, as is assumed in Proposition 3, we can prove that $\frac{\overline{d P_{0}}}{d z_{0}}<0, \frac{\overline{d q_{0}}}{d z_{0}}>0$, and the sign of $\frac{\overline{d \pi_{0}}}{d z_{0}}$ depends on parameters. It follows that the effect of a positive TFP shock on the risk premium depends on parameters, because it both redistributes away from levered, high MPR households by raising the real value of their debt burden, redistributes toward these same households by raising the price of capital, and has an ambiguous effect on redistribution through short-run profits.

\section{B Empirical appendix}

In this section we provide details on our empirical analysis in section 3.

\section{B.1 The effect of monetary shocks}

\section{B.1.1 Robustness to details of estimation approach}

We first demonstrate that the broad messages of our baseline estimates of the effects of a monetary policy shock in section 3.1 are robust to details of the estimation.

Given a monetary policy shock, Table A.1 summarizes the impact effect on the 1-year Treasury yield, the impact effect on the real S\&P 500 return (implied by the real rate and excess return), and the share of the latter accounted for by news about future excess returns in the Campbell-Shiller decomposition (26). First, we find that the baseline results using 6 lags in the VAR are little affected if 4-8 lags are used instead. Second, we find that the results are broadly robust to using the same January 1991 - June 2012 period for both the VAR and IV regressions, or limiting the analysis of monetary policy shocks to the first half of the IV sample alone (January 1991 September 2001). The expansionary monetary policy shock in fact lowers the stock 


\begin{tabular}{lccc}
\hline & $\begin{array}{c}\text { 1-year } \\
\text { Treasury } \\
\text { yield }(p p)\end{array}$ & $\begin{array}{c}\text { Real stock } \\
\text { return }(p p)\end{array}$ & $\begin{array}{c}\text { Share future } \\
\text { excess return } \\
\text { news }(\%)\end{array}$ \\
\hline Baseline & -0.22 & 2.02 & $58 \%$ \\
Number of lags in VAR & & & \\
4 & -0.21 & 1.93 & $52 \%$ \\
5 & -0.22 & 1.88 & $54 \%$ \\
7 & -0.23 & 1.94 & $62 \%$ \\
8 & -0.23 & & $55 \%$ \\
Sample periods & & 1.99 & $36 \%$ \\
VAR: 1/91-6/12, IV: 1/91-6/12 & -0.14 & 3.15 & $50 \%$ \\
VAR: 7/79-6/12, IV: 1/91-9/01 & -0.21 & -2.01 & $38 \%$ \\
VAR: 7/79-6/12, IV: 10/01-6/12 & -0.17 & & $79 \%$ \\
Variable added to VAR & & 2.30 & $53 \%$ \\
Excess bond premium & -0.21 & 1.62 & $66 \%$ \\
Mortgage spread & -0.24 & 2.26 & $77 \%$ \\
3-month commercial paper spread & -0.19 & 1.64 & $75 \%$ \\
5-year Treasury rate & -0.17 & 1.60 & $64 \%$ \\
10-year Treasury rate & -0.17 & 2.04 & $70 \%$ \\
Term spread & -0.21 & 2.63 & $65 \%$ \\
Relative bill rate & -0.18 & 2.35 & $65 \%$ \\
Change in 3-month Treasury rate & -0.19 & 2.28 & \\
3-month ahead FF as IV & -0.20 & & \\
\hline
\end{tabular}

Table A.1: robustness of 1 SD monetary shock on returns and components

Notes: series for the Gilchrist and Zakrajsek (2012) excess bond premium, mortgage spread, 3-month commercial paper spread, 5-year Treasury rate, and 10-year Treasury rate are taken from the dataset provided by Gertler and Karadi (2015). The term spread (10-year Treasury rate less 1-month Treasury yield), relative bill rate (difference between the 3-month Treasury rate and its 12-month moving average), and change in the 3-month Treasury rate are constructed using CRSP.

market when using the second half of the IV sample alone (October 2001 - June 2012), but we note that the instrument is weak over this sub-sample (having a first-stage $\mathrm{F}$ statistic of 4.7, not shown). Third, we find that news about future excess returns tends to be, if anything, even more important when adding other variables included in the analyses of Bernanke and Kuttner (2005) and Gertler and Karadi (2015) on which we build. Finally, we find similar results when using as the instrument the three-month ahead Fed Funds futures contract instead of the current contract. 


\begin{tabular}{lcccccc}
\hline & $\begin{array}{c}1-\mathrm{yr} \\
\text { Trea- } \\
\text { sury }\end{array}$ & CPI & $\begin{array}{c}\text { Industrial } \\
\text { produc- } \\
\text { tion }\end{array}$ & $\begin{array}{c}\text { 1-mo } \\
\text { real rate }\end{array}$ & $\begin{array}{c}1-\mathrm{mo} \\
\text { excess } \\
\text { return }\end{array}$ & $\begin{array}{c}\text { Dividend/ } \\
\text { price }\end{array}$ \\
\hline SW [2018] test & 0.47 & 0.63 & 0.97 & 0.80 & 0.68 & 0.75 \\
Granger test & 0.07 & 0.15 & 0.88 & 0.12 & 0.44 & 0.93 \\
\hline
\end{tabular}

Table A.2: tests of invertibility assumed in the VAR

Notes: the first row is the bootstrapped p-value for the null hypothesis that the SVAR-IV and LP-IV impulse responses are the same 1,13,25, and 37 months after shock, using the test statistic provided in Stock and Watson (2018). We construct the variance matrix needed for this statistic using the 10,000 iterations of the wild bootstrap used to construct confidence intervals for our SVAR-IV estimates in the main text. The second row is the p-value for the null hypothesis that the coefficients on 6 lags of the instrument are jointly equal to zero when added to the VAR.

\section{B.1.2 Testing invertibility and comparing SVAR-IV and LP-IV}

We now demonstrate that the assumption of invertibility used in the VAR is validated by statistical tests suggested in the literature.

We implement the LP-IV by projecting each outcome variable $h$ months ahead on the 1-year Treasury yield, instrumenting for the latter using the Fed Funds futures surprise also used in our baseline SVAR-IV. Following Stock and Watson (2018), to make this specification comparable with the SVAR-IV and further improve the precision of estimates, we include 6 lags of each of the variables included in the VAR as controls. Moreover, given the serial correlation of the instrument discussed in Ramey (2016) and Stock and Watson (2018), we include a lag of the instrument as an additional control.

Stock and Watson (2018) discuss two tests of the invertibility assumption implicit in the SVAR-IV, the first of which formalizes this comparison of the SVAR-IV and LP-IV estimates. They propose a Hausman-type test statistic of the null hypothesis that invertibility is satisfied by comparing the impulse response at horizon $h$ for a given variable under both approaches. The first row of Table A.2 summarizes the p-value for this test in our setting jointly applied at horizons $h \in\{1,13,25,37\}$ for each variable, demonstrating that we cannot reject the null at standard significance levels. They also recommend the use of the complementary Granger causality test discussed in Forni and Gambetti (2014): if invertibility is satisfied, lagged values of the instrument should not have predictive power given the variables included in the VAR. We include 6 lags of our instrument in the VAR and construct an F statistic associated with the null hypothesis that these coefficients are jointly zero for each variable in the VAR. We again cannot reject the null at standard significance levels. 


\section{B.2 Micro moments from the SCF}

We now provide supplemental details on our measurement of household portfolios using the 2016 SCF described in section 3.3.

\section{B.2.1 Construction of household portfolios}

We first describe how we construct household portfolios. We proceed in five steps.

First, to the SCF data we add an estimate of defined benefit (DB) pension wealth for each household, since this is not included in the SCF measure of net worth. We use the estimates of Sabelhaus and Volz (2019). Their approach involves (1) estimating the present discounted value of DB payments for households who report in the SCF that they are currently receiving a DB pension or expect to receive a known amount from a prior job, (2) subtracting the total DB pension wealth among these households from the total DB pension wealth in the Financial Accounts of the United States (FA) for 2016, and (3) allocating (based on age, earnings, and other characteristics) the remaining DB pension wealth to households who expect to receive a DB pension based on their current job. Together with the other categories of wealth reported in the SCF, we have a comprehensive picture of U.S. household net worth.

Second, we proceed by line item to allocate how much household wealth is in directly held claims on capital, indirect claims on capital through business equity, or nominal claims. Direct claims on capital are non-financial assets (vehicles, primary residence, residential real estate excluding the primary residence, non-residential real estate, and other miscellaneous non-financial assets). Indirect claims on capital through business equity come in two forms: publicly traded stocks or privately-owned businesses. We assume the following line items reported in the SCF summary extract include stocks: ${ }^{4}$

- Savings accounts that may be invested in stocks, included in transaction accounts: these include accounts classified as 529 or state-sponsored education accounts. We use the self-reported fraction of these accounts invested in stocks.

- Stock mutual funds: by definition, $100 \%$ of these accounts are invested in stocks.

- Combination mutual funds: we assume $50 \%$ of these accounts are invested in stocks.

- Other mutual funds: we assume $100 \%$ of these accounts are invested in stocks.

\footnotetext{
${ }^{4}$ Our approach here follows the construction of the EQUITY variable in the summary extract.
} 
- Directly held stocks: by definition, $100 \%$ of these assets are invested in stocks.

- Other managed assets: we use the self-reported fraction of these accounts (which include annuities and trusts) invested in stocks.

- Quasi-liquid retirement assets: we use the self-reported fraction of these accounts (which include IRAs/Keoghs, account-type pensions in the current job, future pensions, and currently received account-type pensions) invested in stocks.

We assume the remaining portion of these line items not invested in stocks, as well as all other line items not mentioned above, are purely nominal assets or liabilities.

Third, we assume a functional form for households' leverage through these equity claims. We assume that the leverage of publicly traded stocks held by household $i$ is

$$
l e v_{\text {public }}^{i}=l e v_{\text {public }} \epsilon^{i}
$$

and the leverage of private businesses owned by household $i$ is

$$
l e v_{\text {private }}^{i}=l e v_{\text {private }} \epsilon^{i},
$$

where the idiosyncratic component $\epsilon^{i}$ is drawn from a $\Gamma\left(\theta^{-1}, \theta\right)$ distribution having mean one. lev public thus reflects the aggregate leverage of the household sector in publicly traded stocks; lev private reflects the aggregate leverage of the household sector in private businesses; and $\theta$ controls the dispersion of household leverage in these claims. The $\Gamma$ distribution is right-skewed, which accords well with the heterogeneity in portfolios studied by Calvet, Campbell, and Sodini (2007) and the recent papers on household returns discussed below.

Fourth, we use the FA to discipline lev public and lev private. We set lev public to the net leverage of the consolidated nonfinancial corporate sector (FA table S.5.a) and financial business sector (FA table S.6.a), net of the central bank (FA table S.61.a), government DB pension funds (FA tables L.119.b and L.120.b), all defined contribution (DC) pension funds (FA tables L.118.c, L.119.c, and L.120.c), and mutual funds (FA table L.122). ${ }^{5}$ We set lev private to the net leverage of the consolidated nonfinancial

\footnotetext{
${ }^{5}$ We exclude the central bank and government DB pension funds because we model these as part of the government sector (the latter consistent with our interpretation of DB pensions in footnote 29). We exclude DC pension funds and mutual funds because we view these as pure pass-through entities whose assets have already been folded into that of households using our approach described so far.
} 


\begin{tabular}{l|c|c}
\hline & $\begin{array}{c}\text { Nonfinancial corporates } \\
\text { and financial businesses }\end{array}$ & $\begin{array}{c}\text { Nonfinancial noncorporates } \\
\text { and nonprofits }\end{array}$ \\
\hline Capital & 23,260 & 18,649 \\
Net equity & 14,754 & 17,445 \\
Leverage & 1.6 & 1.1 \\
\hline
\end{tabular}

Table A.3: business net worth in FA

Notes: capital and net equity values in $\$ 2016 \mathrm{bn}$. Financial businesses exclude the central bank, government DB pension funds, all DC pension funds, and mutual funds. Capital is given by nonfinancial assets. Net equity is given by the sum of corporate equity liabilities, FDI abroad, other equity liabilities, net worth, less corporate equity assets, 0.67 times mutual fund assets, FDI in, and other equity assets. Leverage is capital divided by net equity.

noncorporate sector (FA table S.4.a) and non-profit sector (FA table B.101.n). Table A.3 summarizes our computation of net leverage for each of these consolidated sectors for 2016 using the Q2 2019 release of the FA. We compute net leverage by dividing the aggregate position in capital by net equity issued to other sectors. Capital is given by total assets net of nominal assets and equity assets. Net equity issued to other sectors is given by equity liabilities plus net worth net of equity assets. The resulting measures of leverage we use are $l e v_{\text {public }}=1.6$ and lev private $=1.1$.

Table A.4 provides the resulting decomposition of aggregate net worth of U.S. households into nominal claims and claims on capital using four steps already described. We note that the value of $\theta$ is irrelevant for this aggregate decomposition.

Fifth and finally, we use recent evidence on the heterogeneity in households' expected returns on wealth to discipline $\theta$. Using granular data on the portfolios of the universe of Swedish households, Bach, Calvet, and Sodini (2018) construct householdspecific measures of expected excess returns. Over the 2000-2007 period, the crosssectional standard deviation in expected excess returns on gross assets was $32 \%$ of the expected excess returns of the global market. ${ }^{6}$ We choose $\theta=1.18$ so that the implied cross-sectional standard deviation in leverage on assets in our SCF sample equals $32 \%$ of the aggregate leverage in public equities estimated above $\left(\right.$ lev $\left._{\text {public }}=1.6\right)$. The first panel of Figure A.1 depicts this ratio for our SCF data as we vary $\theta$, illustrating how

\footnotetext{
${ }^{6}$ In their Table VI, these authors report a cross-sectional standard deviation in expected excess returns of 1.9\%. In their section I.D., they report a long-run (1983-2016) average of the global market excess return of $5.8 \%$. The ratio between these is $32 \%$. We use this evidence from Scandinavia because of the absence of comparable data in the United States with exhaustive coverage of households' wealth. We use heterogeneity in expected returns rather than realized returns (as studied by, for instance, Fagereng, Guiso, Malacrino, and Pistaferri (2019)) to avoid ascribing to leverage heterogeneity the effects of idiosyncratic return volatility.
} 


\begin{tabular}{|c|c|c|c|c|}
\hline & & $A$ & $B$ & $Q k$ \\
\hline 1 & Transaction accounts & 4,940 & 4,701 & 239 \\
\hline 2 & $\mathrm{CDs}$ & 620 & 620 & 0 \\
\hline 3 & Stock mutual funds & 5,939 & $-3,563$ & 9,502 \\
\hline 4 & Tax-free bond mutual funds & 1,329 & 1,329 & 0 \\
\hline 5 & Govt bond mutual funds & 276 & 276 & 0 \\
\hline 6 & Other bond mutual funds & 404 & 404 & 0 \\
\hline 7 & Combination mutual funds & 757 & 151 & 605 \\
\hline 8 & Other mutual funds & 1,011 & -606 & 1,617 \\
\hline 9 & Savings bonds & 104 & 104 & 0 \\
\hline 10 & Directly held stocks & 5,742 & $-3,445$ & 9,187 \\
\hline 11 & Directly held bonds & 1,179 & 1,179 & 0 \\
\hline 12 & Cash value life insurance & 914 & 914 & 0 \\
\hline 13 & Other managed assets & 3,231 & 2,253 & 978 \\
\hline 14 & Quasi-liquid retirement assets & 15,001 & 2,366 & 12,635 \\
\hline 15 & Other miscellaneous financial assets & 659 & 659 & 0 \\
\hline 16 & DB pension assets & 17,855 & 17,855 & 0 \\
\hline 17 & Vehicles & 2,717 & 0 & 2,717 \\
\hline 18 & Primary residence & 24,176 & 0 & 24,176 \\
\hline 19 & Residential real estate excl primary residence & 6,301 & 0 & 6,301 \\
\hline 20 & Non-residential real estate & 3,694 & 0 & 3,694 \\
\hline 21 & Actively-managed businesses & 17,015 & $-1,701$ & 18,716 \\
\hline 22 & Non-actively-managed businesses & 2,332 & -233 & 2,566 \\
\hline 23 & Other miscellaneous non-financial assets & 559 & 0 & 559 \\
\hline 24 & Mortgage on primary residence & $-8,310$ & $-8,310$ & 0 \\
\hline 25 & Mortgage excl primary residence & $-1,128$ & $-1,128$ & 0 \\
\hline 26 & Other lines of credit & -127 & -127 & 0 \\
\hline 27 & Credit card balance & -316 & -316 & 0 \\
\hline 28 & Installment loans & $-1,976$ & $-1,976$ & 0 \\
\hline 29 & Other debt & -176 & -176 & 0 \\
\hline 30 & Total & 104,721 & 11,228 & 93,492 \\
\hline
\end{tabular}

Table A.4: aggregate household net worth in SCF

Notes: all values in $\$ 2016$ bn. Observations are weighted by SCF sample weights. 

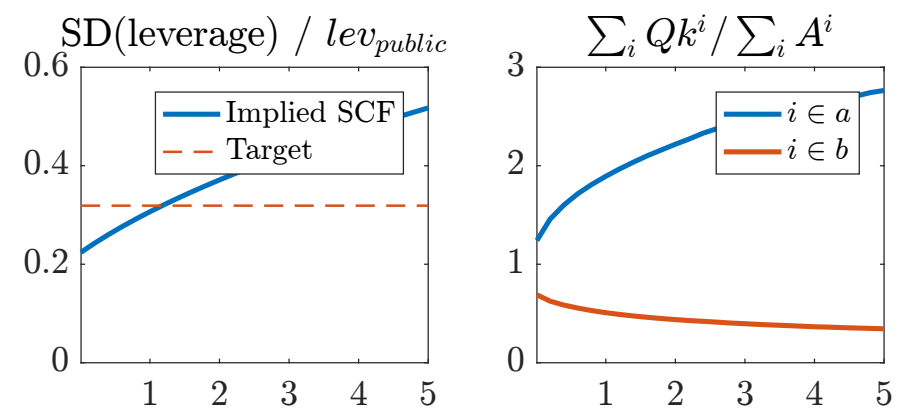

Figure A.1: identification of $\theta$ and variation in capital portfolio shares with $\theta$

Notes: empirical target in first panel is $32 \%$, the cross-sectional standard deviation in expected excess returns on gross wealth relative to the long-run average of the global market excess return reported by Bach et al. (2018). The comparable moment in the SCF is the cross-sectional standard deviation in leverage on gross assets relative to the aggregate leverage on public equities, lev public $=1.6$. Groups in the second panel are defined using a 60th percentile cutoff in wealth to labor income and 90th percentile cutoff in the capital portfolio share, as described in the main text. All moments from the $\mathrm{SCF}$ are computed by weighting observations using sample weights.

identification is achieved. The fact that a positive value of $\theta$ is needed to match the evidence on return heterogeneity is consistent with broader results from the literature that households in fact do not hold identical, diversified equity portfolios. ${ }^{7}$ The second panel of Figure A.1 depicts the implied capital portfolio shares of our group $a$ and $b$ households as we vary $\theta$, illustrating how such heterogeneity amplifies the differences between groups. Nonetheless, even when $\theta \rightarrow 0$, in which case households hold the same, diversified portfolio of equity claims, both panels indicate that there remains heterogeneity in capital portfolio shares (and thus expected returns) because of households' heterogeneous portfolios across nominal claims, capital, and equity.

\section{B.2.2 Consistency of assumptions with market clearing in nominal claims}

We now demonstrate that the aggregate household balance sheet in Table A.4 is consistent with market clearing in the market for nominal claims after accounting for the balance sheets of the government and rest of the world.

We proceed in three steps. First, we summarize the balance sheets of the government and rest of the world for 2016 using the Q2 2019 release of the FA. We construct

\footnotetext{
${ }^{7}$ It is also consistent with the fact that some households invest in equity through levered investment intermediaries such as hedge funds and private equity, which cannot be explicitly identified in the SCF. In their Table 2B, Ang, Gorovyy, and van Inwegen (2011) report that the average leverage of long-only hedge funds is 1.4. In their Table 8, Axelson, Jenkinson, Stromberg, and Weisbach (2013) report that the average leverage of LBO transactions is 4.0 .
} 


\begin{tabular}{l|c|c}
\hline & Government & Rest of world \\
\hline$A$ & $-7,288$ & 7,704 \\
$B$ & $-25,688$ & 8,929 \\
$Q k$ & 18,400 & $-1,225$ \\
\hline
\end{tabular}

Table A.5: government and rest of world net worth in FA

Notes: all values in $\$ 2016 \mathrm{bn}$.

the government balance sheet by adding that of the central bank (table S.61.a), federal government excluding DB funds (table S.7.a), state and local governments excluding DB funds (table S.8.a), federal DB funds (table L.119.b), and state and local DB funds (table L.120.b). ${ }^{8}$ We obtain the rest of the world balance sheet in table S.9.a.

Second, we decompose the net worth of these sectors into nominal claims and claims on capital using assumptions consistent with those used for households in the SCF. We do so for each line item of the sector's assets and liabilities and then aggregate across them, analogous to our approach for the household sector. We map our assumptions for the SCF to the line items in the FA as follows:

- Corporate equities and FDI in/out are indirect claims on capital with leverage 1.6, consistent with $l e v_{\text {public }}$ estimated in Table A.3.

- Mutual fund shares are a portfolio in which $67 \%$ is invested in traded stocks (and the remainder in bonds), where these stocks are again a indirect claim on capital with leverage 1.6. The former is consistent with the portfolio share in corporate equities of the mutual fund sector (table L.224).

- Non-financial assets; monetary gold; and other equity claims (including equity in international organizations; equity in GSEs; equity under the public-private investment program; equity in Federal Reserve Banks; and investment by holding companies) are directly held claims on capital. We treat gold as capital because it is in positive net supply, even though it may not be directly used in production.

We assume all other assets and liabilities are nominal claims. The resulting decomposition of each sector's net worth is provided in Table A.5. We note that while the rest

\footnotetext{
${ }^{8}$ By including the balance sheet of government DB funds with the government sector, we remain consistent with our treatment of DB pensions in footnote 29. We do not include government DC funds because these are pure pass-through entities whose assets will already have been reflected in the household balance sheets constructed in the prior subsection.
} 


\begin{tabular}{ll|c}
\hline & & $B$ \\
\hline 1 & Households (SCF) & 11,228 \\
2 & Reconciliation with FA & 5,524 \\
3 & Time deposits and short-term investments & 4,718 \\
4 & Net worth in private business & 806 \\
5 & Households [=(1)+(2)] & 16,752 \\
6 & Government (FA) & $-25,688$ \\
7 & Rest of world (FA) & 8,929 \\
\hline 8 & Sum [=(5)+(6)+(7)] & -7 \\
\hline
\end{tabular}

Table A.6: net nominal claims by sector (source)

Notes: all values in $\$ 2016$ bn.

of the world's non-financial assets and liabilities are not reported in the FA, this is not of primary interest here since these are claims on capital.

Third, we aggregate over the net position in nominal claims across sectors implied by Tables A.4 and A.5, accounting for the major discrepancies in measuring household wealth between the SCF and FA. Batty, Bricker, Briggs, Holmquist, McIntosh, Moore, Nielsen, Reber, Shatto, Sommer, Sweeney, and Volz (2019) provide an exhaustive accounting of these discrepancies. Aside from the exclusion of DB pensions in the SCF (which we have already addressed), the two other largest sources of discrepancy are in time deposits and short-term investment assets and in wealth in noncorporate businesses. Following Batty et al. (2019), in Table A.6 we adjust the aggregate household position in nominal claims to be consistent with the FA along each of these dimensions:

- We use the value of aggregate time deposits and short-term investment assets reported in the FA, instead of those reported in the SCF. The Q2 2019 FA reports for $2016 \$ 8,864 \mathrm{bn}$ in such assets (table B.101.h), whereas Batty et al. (2019) cumulate such assets in the $2016 \mathrm{SCF}$ and obtain $\$ 4,146 \mathrm{bn}$. The difference is $\$ 4,718 \mathrm{bn}$.

- We adjust households' wealth in actively-managed businesses and non-activelymanaged businesses to reflect the average of the market value and cost basis, whereas our analysis in Table A.4 used just the former. This follows the finding in Batty et al. (2019) that the average of the market value and cost basis in the SCF closely tracks the reported equity in noncorporate businesses (excluding real estate) in the FA. Applying our leverage assumptions outlined in the prior subsection to these revalued wealth positions and computing the difference in 
aggregate nominal claims for these line items versus those reported in Table A.4 results in an adjustment of $\$ 806 \mathrm{bn}$.

The resulting aggregate household position in nominal claims rises from $\$ 11,228 \mathrm{bn}$ to $\$ 16,752 \mathrm{bn}$. Adding these to the position of the government sector and rest of the world computed using the FA, we obtain an net position in nominal claims of $-\$ 7 \mathrm{bn}$. Since these claims should be in zero net supply, we conclude that our assumptions on leverage are remarkably consistent with market clearing in the market for nominal claims.

\section{B.2.3 Sensitivity of targeted moments to cutoffs}

We now characterize the sensitivity of our targeted moments in Table 2 to alternative cutoffs in the distributions of wealth to labor income and the capital portfolio share. Each row of Figure A.2 summarizes the fraction of labor income, fraction of wealth, and ratio of aggregate capital to wealth for each group. The first row presents moments for group $a$, the second for group $b$, and third for group $c$. On the x-axis of each panel we vary the cutoff in the capital portfolio share defining the groups (recalling that the cutoff used to construct targeted moments for the calibration is the 90th percentile). In each panel we plot moments with different cutoffs in the wealth to labor income ratio defining the groups (recalling that the cutoff used to construct targeted moments for the calibration is the 60th percentile).

A higher capital portfolio share cutoff naturally means that group $a$ households are more levered, but conversely have a lower share of total wealth. In the context of our model, these effects have countervailing implications for the effect of monetary policy on the risk premium. Raising the wealth to labor income cutoff changes the shares of labor income and wealth for each group but leaves leverage little changed.

\section{Infinite horizon environment}

In this section we describe the infinite horizon environment studied in section 3 . We follow the exposition of the two-period environment in section 2.1.

Households The unit measure of households is now organized into three groups $i \in\{a, b, c\}$ with measures $\left\{\lambda^{i}\right\}$ such that $\sum_{i} \lambda^{i}=1$, where households are identical within groups. Each household continues to be comprised of a continuum of members $j \in[0,1]$ supplying a differentiated variety of labor, and there remains full consumption 

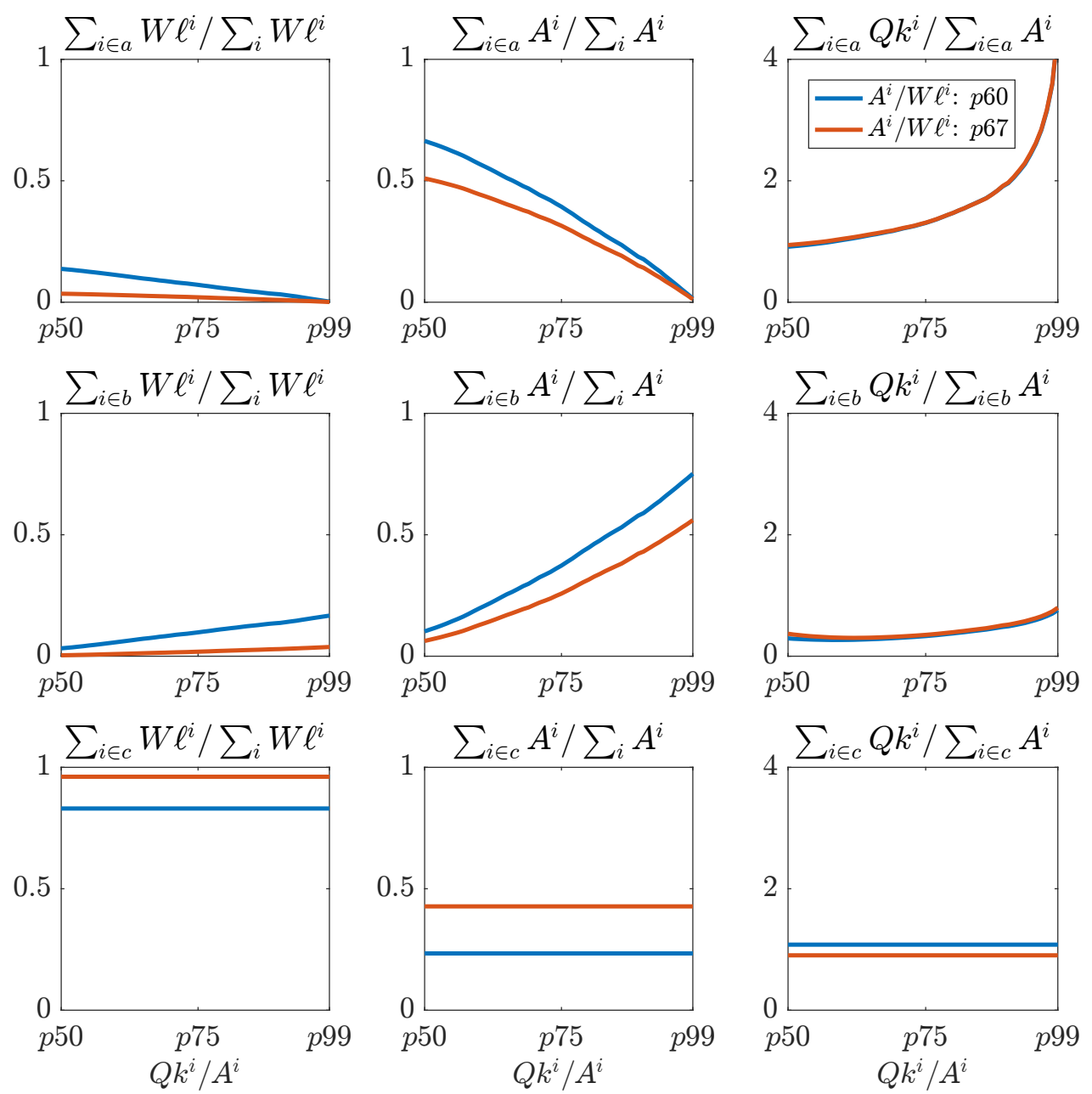

Figure A.2: alternative cutoffs in wealth to labor income and the capital portfolio share

Notes: observations are weighted by SCF sample weights. Targets in the calibration use a 60th percentile cutoff in wealth to labor income and 90th percentile cutoff in the capital portfolio share.

insurance within households. The representative household $i$ has Epstein-Zin preferences (27) with disutility of labor each period (28) following Shimer (2010). Each period, the household faces the resource constraint

$$
\begin{aligned}
P_{t} c_{t}^{i}+B_{t}^{i}+Q_{t} k_{t}^{i} \leq & (1-\tau) \int_{0}^{1} W_{t}(j) \ell_{t}^{i}(j) d j-\int_{0}^{1} A C_{t}^{W}(j) d j+ \\
& \left(1+i_{t-1}\right) B_{t-1}^{i}+\left(\Pi_{t}+(1-\delta) Q_{t}\right) k_{t-1}^{i} \exp \left(\varphi_{t}\right)+T_{t}^{i},
\end{aligned}
$$


where the Rotemberg (1982) cost of setting the wage for member $j$ is

$$
A C_{t}^{W}(j)=\frac{\chi^{W}}{2} W_{t} \ell_{t}\left(\frac{W_{t}(j)}{W_{t-1} \exp \left(\varphi_{t}\right)}-1\right)^{2}
$$

Households further face the capital constraint (29). In our calibration, this constraint will (almost always) only bind for $c$ households.

Supply-side A union continues to represent each labor variety $j$ across households. Each period, it chooses $W_{t}(j), \ell_{t}(j)$ to maximize the social welfare of union members subject to the allocation rule (4) and Pareto weights $\left\{\mu^{i}\right\}$. We now assume for simplicity that the allocation rule and Pareto weights are symmetric: $\ell^{i}\left(\ell_{t}\right)=\ell_{t}$ and $\mu^{i}=1$. The labor packer combines varieties supplied by the union as in the two-period model, earning profits each period

$$
W_{t}\left[\int_{0}^{1} \ell_{t}(j)^{(\epsilon-1) / \epsilon}\right]^{\epsilon /(\epsilon-1)}-\int_{0}^{1} W_{t}(j) \ell_{t}(j) d j .
$$

The representative producer hires $\ell_{t}$ units of the labor aggregator in period $t$ and combines it with $k_{t-1} \exp \left(\varphi_{t}\right)$ units of capital rented from households. It further uses $\left(\frac{k_{t}}{k_{t-1} \exp \left(\varphi_{t}\right)}\right)^{\chi^{x}} x_{t}$ units of the consumption good to produce $x_{t}$ new capital goods, where it again takes $k_{t}$ as given. Taken together, it earns profits

$$
\begin{aligned}
& \Pi_{t} k_{t-1} \exp \left(\varphi_{t}\right)= \\
& \quad P_{t}\left(z_{t} \ell_{t}\right)^{1-\alpha}\left(k_{t-1} \exp \left(\varphi_{t}\right)\right)^{\alpha}-W_{t} \ell_{t}+Q_{t} x_{t}-P_{t}\left(\frac{k_{t}}{k_{t-1} \exp \left(\varphi_{t}\right)}\right)^{\chi^{x}} x_{t} .
\end{aligned}
$$

Productivity follows (30).

Policy The government follows a standard Taylor rule (32) where monetary policy shocks $m_{t}$ follow (33). The government continues to set $\tau=-\frac{1}{\epsilon-1}$ and now sets household-specific lump-sum transfers $T_{t}^{i}$ as in (34) given $B_{t}^{g}=P_{t} b^{g}$ and $\mathfrak{T}_{t}^{i}$ as in (35). We assume that $\tau_{t}^{a}=\tau^{a}$ and $\tau_{t}^{c}=\tau^{c}$ are constant, and $\tau_{t}^{b}$ ensures that $\sum_{i} \lambda^{i} \mathfrak{T}_{t}^{i}=0$. As noted in the main text, we assume that households perfectly anticipate $\mathfrak{T}_{t}^{i}$ for all households except themselves. 
Market clearing Market clearing in goods each period is now

$$
\sum_{i} \lambda^{i} c_{t}^{i}+\left(\frac{k_{t}}{k_{t-1} \exp \left(\varphi_{t}\right)}\right)^{\chi^{x}} x_{t}=\left(z_{t} \ell_{t}\right)^{1-\alpha}\left(k_{t-1} \exp \left(\varphi_{t}\right)\right)^{\alpha},
$$

in labor is

$$
\left[\int_{0}^{1} \ell_{t}(j)^{(\epsilon-1) / \epsilon} d j\right]^{\epsilon /(\epsilon-1)}=\ell_{t}
$$

in the capital rental market is

$$
\sum_{i} \lambda^{i} k_{t-1}^{i}=k_{t-1}
$$

in the capital claims market is

$$
(1-\delta) \sum_{i} \lambda^{i} k_{t-1}^{i} \exp \left(\varphi_{t}\right)+x_{t}=\sum_{i} \lambda^{i} k_{t}^{i}
$$

and in bonds is

$$
\sum_{i} \lambda^{i} B_{t}^{i}+B_{t}^{g}=0
$$

Equilibrium Given initial state variables $\left\{W_{-1},\left\{B_{-1}^{i}, k_{-1}^{i}\right\}, i_{-1}, z_{0}, p_{0}, m_{0}\right\}$ and the stochastic processes (30)-(33), the equilibrium naturally generalizes Definition 1:

Definition C.1. An equilibrium is a sequence of prices and policies such that: (i) each household $i$ chooses $\left\{c_{t}^{i}, B_{t}^{i}, k_{t}^{i}\right\}$ to maximize (27) subject to (A.1) and (29), (ii) each union $j$ chooses $\left\{W_{t}(j), \ell_{t}(j)\right\}$ to maximize the utilitarian social welfare of its members subject to the symmetric allocation rule $\left\{\ell_{t}^{i}(j)=\ell_{t}(j)\right\}$, (iii) the labor packer chooses $\left\{\ell_{t}(j)\right\}$ to maximize profits (A.2), (iv) the representative producer chooses $\left\{\ell_{t}, x_{t}\right\}$ to maximize profits (A.3), (v) the government sets $\left\{T_{t}^{i}\right\}$ and $i_{t}$ according to (34) and (32), and (vi) the goods, labor, capital, and bond markets clear according to (A.4)-(A.8).

Since labor varieties and unions $j$ are symmetric, $\ell_{t}(j)=\ell_{t}$ and we drop $j$.

\section{Additional quantitative results}

In this section we provide quantitative results accompanying section 3. 

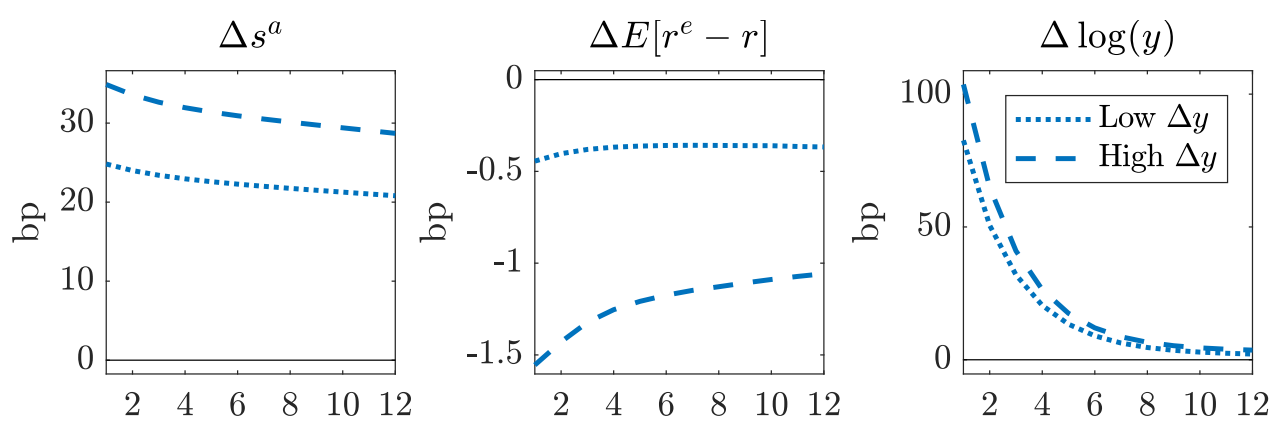

Figure A.3: conditional impulse responses to negative monetary policy shock

Notes: all series are quarterly (non-annualized) measures. Each impulse response is the average response (relative to no shock) starting at 1,000 different points drawn from the ergodic distribution of the state space with no disasters ever realized, conditional on the impact effect on output being in the top or bottom quartile of its marginal distribution. $b p$ denotes basis points $(0.01 \%)$.

\section{D.1 State-dependent effects of monetary policy}

We first demonstrate that the redistribution across households with heterogeneous MPRs implies state-dependent effects of monetary policy.

In particular, the effects of monetary policy are larger when the wealth share of $a$ households is high because the implied redistribution and thus effects on risk premia are larger. Figure A.3 first depicts the average impulses responses to a monetary policy shock (in all cases resulting in a $22 b p$ decline in the 1-year nominal yield) conditional on the impact effect on output being in its top versus bottom quartile. The periods in which the expansionary shock has a larger effect on output are also those in which the redistribution to $a$ households and the resulting effect on risk premia are larger. Table A.7 then characterizes conditional moments of these two sets in the state space. The effect on output is high when the wealth share of $a$ households is high. Notably, this is the case even though the leverage of $a$ households is low. These states are consistent with bull markets - excess returns over the prior year have been especially high, and the economy's capital to output ratio is high - suggesting that monetary policy will be most potent during this part of the cycle.

\section{D.2 Anticipated, progressive wealth taxes}

In the main text we introduced and calibrated redistributive lump-sum taxes $\mathfrak{T}_{t}^{i}$ to match the wealth distribution in the data. To ensure that these taxes were not undone by households' saving decisions, we assumed that each household fully anticipated 


\begin{tabular}{lcc}
\hline$\Delta \log (y):$ & Bottom quartile & Top quartile \\
\hline$s^{a}$ & $20 \%$ & $25 \%$ \\
$k^{a} / a^{a}$ & 2.3 & 2.1 \\
$\sum_{t=0}^{-3}\left[r_{t}^{e}-r_{t}\right]$ & $4.0 \%$ & $9.3 \%$ \\
$k / y$ & 8.0 & 8.3 \\
\hline
\end{tabular}

Table A.7: first moments conditional on impact effect of monetary policy shock

Notes: moments computed using the ergodic distribution of the state space with no disasters ever realized, approximated using a sample path over 50,000 quarters after a burn-in period of 5,000 quarters. Excess return assumes a debt/equity ratio of 0.5 on a stock market claim.

these taxes for all households except themselves. Here we demonstrate that our results are robust to an alternative environment and calibration featuring fully anticipated, progressive wealth taxes. Because these are distortionary, they are not undone by households even though they are fully anticipated; because they are progressive, they can match the distribution of wealth.

The environment is exactly as in the main text except for the following changes. First, we assume that household $i$ faces a wealth $\operatorname{tax} \tau_{t}^{i, w}$ so that the resource constraint (A.1) is replaced by

$$
\begin{aligned}
& P_{t} c_{t}^{i}+B_{t}^{i}+Q_{t} k_{t}^{i} \leq(1-\tau) \int_{0}^{1} W_{t}(j) \ell_{t}^{i}(j) d j-\int_{0}^{1} A C_{t}^{W}(j) d j+ \\
&\left(1-\tau_{t}^{i, w}\right)\left[\left(1+i_{t-1}\right) B_{t-1}^{i}+\left(\Pi_{t}+(1-\delta) Q_{t}\right) k_{t-1}^{i} \exp \left(\varphi_{t}\right)\right]+T_{t}^{i} .
\end{aligned}
$$

Second, we set $\mathfrak{T}_{t}^{i}=0$ and re-define the transfers $T_{t}^{i}$ so that (34) is replaced by

$$
\begin{aligned}
T_{t}^{i}= & \int_{0}^{1} A C_{t}^{W}(j) d j+\tau \int_{0}^{1} W_{t}(j) \ell_{t}^{i}(j) d j+\nu^{i}\left(\left(1-\tau_{t}^{i, w}\right)\left(1+i_{t-1}\right) B_{t-1}^{g}-B_{t}^{g}\right)+ \\
& \sum_{i^{\prime}} \tau_{t}^{i^{\prime}, w}\left[\left(1+i_{t-1}\right)\left(B_{t-1}^{i^{\prime}}+\nu^{i^{\prime}} B_{t-1}^{g}\right)+\left(\Pi_{t}+(1-\delta) Q_{t}\right) k_{t-1}^{i} \exp \left(\varphi_{t}\right)\right] .
\end{aligned}
$$

Relative to (34), the financing of government debt is adjusted so that we may continue to think of households choosing their bond position inclusive of their implicit position through the government, $B^{i}+\nu^{i} B^{g}$. Finally, we parameterize each household's wealth tax rate to itself be a function of the household's wealth, scaled by the economy's 


\begin{tabular}{clclcc}
\hline & Description & Value & Moment & Target & Model \\
\hline$\sigma$ & std. dev. prod. & $0.5 \%$ & $\sigma(\Delta \log c)$ & $0.5 \%$ & $0.6 \%$ \\
$\chi^{x}$ & capital adj cost & 3.5 & $\sigma(\Delta \log x)$ & $2.1 \%$ & $1.9 \%$ \\
$\beta$ & discount factor & 0.987 & $\mathbb{E} r_{+1}$ & $1.4 \%$ & $1.4 \%$ \\
$\gamma^{b}=\gamma^{c}$ & RRA $b, c$ & 24 & $\mathbb{E}\left[r_{+1}^{e}-r_{+1}\right]$ & $7.1 \%$ & $7.2 \%$ \\
$\sigma^{p}$ & variation dis. prob. & $0.25 \%$ & $\sigma\left(d^{e} / p^{e}\right)$ & $0.2 \%$ & $0.2 \%$ \\
$\rho^{p}$ & persist. dis. prob. & 0.95 & $\rho\left(d^{e} / p^{e}, d_{-1}^{e} / p_{-1}^{e}\right)$ & 0.95 & 0.94 \\
$\gamma^{a}$ & RRA $a$ & 14 & $k^{a} / a^{a}$ & 2.0 & 2.2 \\
$\underline{k}$ & lower bound $k^{i}$ & 6.3 & $k^{c} / a^{c}$ & 1.1 & 0.9 \\
$\tau^{a, w}$ & controls tax on $a$ & $0.3 \%$ & $\lambda^{a} a^{a} / \sum_{i} \lambda^{i} a^{i}$ & $18 \%$ & $24 \%$ \\
$\tau^{c, w}$ & controls tax on $c$ & $2.5 \%$ & $\lambda^{c} a^{c} / \sum_{i} \lambda^{i} c^{i}$ & $23 \%$ & $23 \%$ \\
$B^{g}$ & govt bonds & -2.5 & $-\sum_{i} \lambda^{i} b^{i} / \sum_{i} \lambda^{i} a^{i}$ & $-11 \%$ & $-11 \%$ \\
$\bar{\theta}$ & $\ell$ disutility & 0.72 & $\ell$ & 1 & 1.0 \\
\hline
\end{tabular}

Table A.8: targeted moments and calibrated parameters with wealth taxes

Notes: targeted business cycle moments are from Q3/79-Q2/12 NIPA and targeted asset pricing moments are from 7/79-6/12 data underlying the VAR. The equity premium and second moments of the dividend price ratio in the model are calculated assuming a debt/equity ratio of 0.5 on a stock market claim. The first and second moments in the model are estimated over 50,000 quarters after a burn-in period of 5,000 quarters, with no disaster realizations in sample.

aggregate wealth:

$$
\tau_{t}^{i, w}=\tau^{i, w}\left(\frac{\left(1+i_{t-1}\right)\left(B_{t-1}^{i}+\nu^{i} B_{t-1}^{g}\right)+\left(\Pi_{t}+(1-\delta) Q_{t}\right) k_{t-1}^{i} \exp \left(\varphi_{t}\right)}{\left(\Pi_{t}+(1-\delta) Q_{t}\right) k_{t-1} \exp \left(\varphi_{t}\right)}\right) .
$$

We calibrate $\tau^{i, w}$ to target the wealth shares of the three groups of households, and re-calibrate all other parameters to match the same moments as in the main text. The calibrated parameters are provided in Table A.8. The model's untargeted moments (not shown for brevity) are similar to Table 6 in the main text; in particular, group $b$ receives transfers and group $c$ pays additional taxes relative to group $a$.

The effects of a monetary policy shock are robust to this environment and calibration. The impulse responses to a monetary policy shock resulting in a $22 b p$ reduction in the one-year nominal yield are provided in Figure A.4. The signs, magnitudes, and differences between the model and the representative agent counterfactual are comparable to Figures 2-4 in the main text. Moreover, a Campbell-Shiller decomposition of 

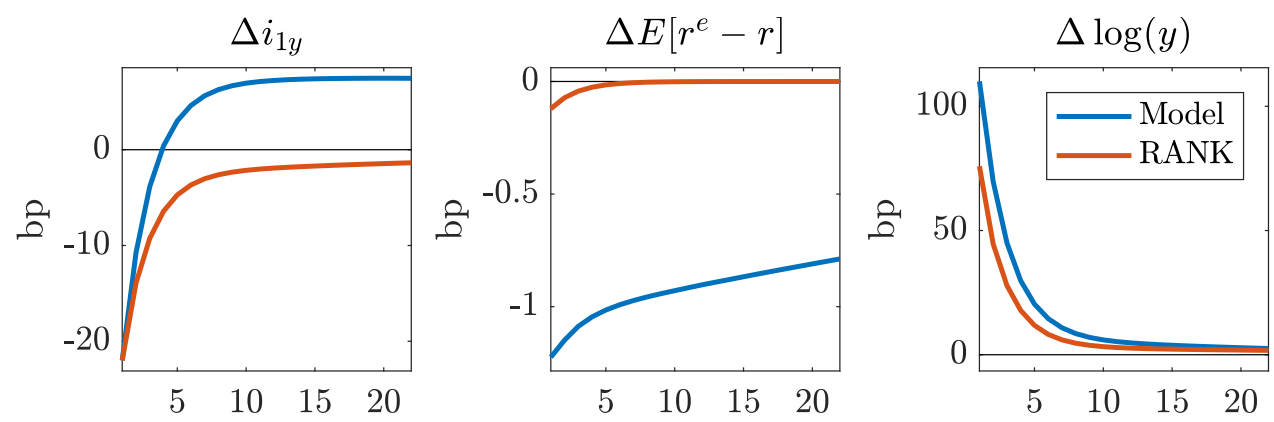

Figure A.4: impulse responses to monetary policy shock with wealth taxes

Notes: series are quarterly (non-annualized) measures, except for the 1-year nominal bond yield $\Delta i_{1 y}$. Impulse responses are the average response (relative to no shock) starting at 1,000 different points drawn from the ergodic distribution of the state space, itself approximated using a sample path over 50,000 quarters after a burn-in period of 5,000 quarters. bp denotes basis points $(0.01 \%)$.

\begin{tabular}{lccc}
\hline \% Real stock return & Data $([90 \% \mathrm{CI}])$ & Model & RANK \\
\hline Dividend growth news & $34 \%([-11 \%, 71 \%])$ & $67 \%$ & $66 \%$ \\
-Future real rate news & $7 \%([-6 \%, 21 \%])$ & $-6 \%$ & $34 \%$ \\
-Future excess return news & $58 \%([21 \%, 106 \%])$ & $39 \%$ & $0 \%$ \\
\hline
\end{tabular}

Table A.9: Campbell-Shiller decomposition with wealth taxes

Notes: estimates from data correspond to Table 1. Comparable estimates obtained in the model assuming a debt/equity ratio of 0.5 on a stock market claim.

the stock market response to the shock, summarized in Table A.9, demonstrates that our model with heterogeneity rationalizes the role of the decline in the equity premium in driving an increase in the stock market. Note that the negative sign on news about future real interest rates reflects the fact that the monetary policy rule implies an even more aggressive increase in future nominal interest rates in this model than in the case with unanticipated lump-sum taxes.

\section{References}

Ang, A., S. Gorovyy, And G. B. van Inwegen (2011): "Hedge fund leverage," Journal of Financial Economics, 102, 102-126.

Auclert, A. (2019): "Monetary policy and the redistribution channel," American Economic Review, 109, 2333-2367.

Axelson, U., T. Jenkinson, P. Stromberg, and M. S. Weisbach (2013): 
"Borrow cheap, buy high? The determinants of leverage and pricing in buyouts," Journal of Finance, 68, 2223-2267.

Bach, L., L. E. CAlvet, And P. Sodini (2018): "Rich pickings? Risk, return, and skill in household wealth," Working paper.

Batty, M., J. Bricker, J. Briggs, E. Holmquist, S. McIntosh, K. Moore, E. Nielsen, S. Reber, M. Shatto, K. Sommer, T. Sweeney, And A. H. Volz (2019): "Introducing the Distributional Financial Accounts of the United States," Working paper.

Bernanke, B. S. And K. N. Kuttner (2005): "What explains the stock market's reaction to Federal Reserve policy?" Journal of Finance, 60, 1221-1257.

Calvet, L. E., J. Y. Campbell, And P. Sodini (2007): "Down or out: assessing the welfare costs of household investment mistakes," Journal of Political Economy, $115,707-747$.

Fagereng, A., L. Guiso, D. Malacrino, and L. Pistaferri (2019): "Heterogeneity and persistence in returns to wealth," Econometrica, forthcoming.

Forni, M. And L. Gambetti (2014): "Sufficient information in structural VARs," Journal of Monetary Economics, 66, 124-136.

Gertler, M. And P. Karadi (2015): "Monetary policy surprises, credit costs, and economic activity," American Economic Journal: Macroeconomics, 7, 44-76.

Gilchrist, S. AND E. ZAKRAJSEK (2012): "Credit spreads and business cycle fluctuations," American Economic Review, 102, 1692-1720.

Heaton, J. And D. LuCAs (2000): "Portfolio choice and asset prices: the importance of entrepreneurial risk," Journal of Finance, 55, 1163-1198.

RAMEY, V. A. (2016): Macroeconomic shocks and their propagation, Elsevier, vol. 2A of Handbook of Macroeconomics, 71-162.

Rotemberg, J. J. (1982): "Sticky prices in the United States," Journal of Political Economy, 90, 1187-1211.

Sabelhaus, J. AND A. H. Volz (2019): "Are disappearing employer pensions contributing to rising wealth inequality?" Working paper.

Shimer, R. (2010): Labor markets and business cycles, Princeton University Press.

Stock, J. H. And M. W. Watson (2018): "Identification and estimation of dynamic causal effects in macroeconomics using external instruments," The Economic Journal, 128, 917-948. 


\section{Supplemental Material \\ Monetary Policy, Redistribution, and Risk Premia \\ Rohan Kekre Moritz Lenel}

\section{A Proofs}

In this section we prove the results stated in section 2 and appendix A.

\section{Proposition 1}

Proof. We first characterize households' portfolio share in capital in the limit of zero aggregate risk. Optimal portfolio choice is given by

$$
\mathbb{E}_{0}\left(c_{1}^{i}\right)^{-\gamma^{i}}\left(r_{1}^{k}-r_{1}\right)=0
$$

Up to first-order, optimal portfolio choice yields

$$
\mathbb{E}_{0} \hat{r}_{1}^{k}-\hat{r}_{1}=o\left(\|\cdot\|^{2}\right)
$$

It follows that given the first-order expansion in terms of the states

$$
\begin{aligned}
& \hat{r}_{1}^{k}=\hat{z}_{1}+\delta_{m_{0}}^{r_{1}^{k}} \hat{m}_{0}+o\left(\|\cdot\|^{2}\right), \\
& \hat{r}_{1}=\delta_{m_{0}}^{r_{1}} \hat{m}_{0}+o\left(\|\cdot\|^{2}\right)
\end{aligned}
$$

with coefficients $\delta$, we can conclude

$$
\delta_{m_{0}}^{r_{1}^{k}}=\delta_{m_{0}}^{r_{1}}
$$

by the method of undetermined coefficients.

Up to second-order, optimal portfolio choice yields

$$
\mathbb{E}_{0} \hat{r}_{1}^{k}-\hat{r}_{1}+\frac{1}{2} \mathbb{E}_{0}\left(\hat{r}_{1}^{k}\right)^{2}-\frac{1}{2} \hat{r}_{1}^{2}=\gamma^{i} \mathbb{E}_{0} \hat{c}_{1}^{i}\left(\hat{r}_{1}^{k}-\hat{r}_{1}\right)+o\left(\|\cdot\|^{3}\right)
$$

Using the above first-order approximations of $\hat{r}_{1}^{k}$ and $\hat{r}_{1}$ in terms of the underlying 
states, and the first-order approximation of $\hat{c}_{1}^{i}$

$$
\hat{c}_{1}^{i}=\delta_{z_{1}}^{c_{1}^{i}} \hat{z}_{1}+\delta_{m_{0}}^{c_{1}^{i}} \hat{m}_{0}+o\left(\|\cdot\|^{2}\right)
$$

it follows that optimal portfolio choice implies

$$
\mathbb{E}_{0} \hat{r}_{1}^{k}-\hat{r}_{1}+\frac{1}{2} \sigma^{2}=\gamma^{i} \delta_{z_{1}}^{c_{1}^{i}} \sigma^{2}+o\left(\|\cdot\|^{3}\right) .
$$

Anticipating the result in Proposition 2 that

$$
\mathbb{E}_{0} \hat{r}_{1}^{k}-\hat{r}_{1}+\frac{1}{2} \sigma^{2}=\gamma \sigma^{2}+o\left(\|\cdot\|^{3}\right)
$$

it follows that

$$
\delta_{z_{1}}^{c_{1}^{i}}=\frac{\gamma}{\gamma^{i}}
$$

Approximating up to first order the period 1 resource constraint and equilibrium wages and profits

$$
\begin{aligned}
& w_{1}=(1-\alpha) z_{1} k_{0}^{\alpha} \\
& \pi_{1}=\alpha z_{1} k_{0}^{\alpha-1}
\end{aligned}
$$

the method of undetermined coefficients implies

$$
\delta_{z_{1}}^{c_{1}^{i}}=\frac{\bar{w}_{1}+\bar{\pi}_{1} \bar{k}_{0}^{i}}{\bar{c}_{1}^{i}}
$$

Substituting in (S.2) and re-arranging, we can conclude that

$$
\frac{\bar{q}_{0} \bar{k}_{0}^{i}}{\bar{a}_{0}^{i}}=\frac{\bar{\pi}_{1} \bar{k}_{0}^{i}}{\left(1+\bar{r}_{1}\right) \bar{a}_{0}^{i}}=\frac{\bar{c}_{1}^{i}}{\left(1+\bar{r}_{1}\right) \bar{a}_{0}^{i}} \frac{\gamma}{\gamma^{i}}-\frac{\bar{w}_{1}}{\left(1+\bar{r}_{1}\right) \bar{a}_{0}^{i}},
$$

where the first equality uses $\bar{q}_{0}=\frac{\bar{\pi}_{1}}{1+\bar{r}_{1}}$ absent aggregate risk.

We now characterize households' marginal responses to a unit of income in the limit of zero aggregate risk. Differentiating households' optimal portfolio choice condition yields

$$
0=\mathbb{E}_{0}^{i} m_{0,1}^{i} \frac{\gamma^{i}}{c_{1}^{i}}\left(r_{1}^{k}-r_{1}\right) \frac{\partial c_{1}^{i}}{\partial y_{0}^{i}}
$$


where the household's stochastic discount factor between periods 0 and 1 is

$$
m_{0,1}^{i} \equiv \frac{\beta^{i}}{1-\beta^{i}}\left(c_{0}^{i}\right)^{\frac{1}{\psi^{i}}} \Phi^{i}\left(l_{0}^{i}\right)^{1-\frac{1}{\psi^{i}}}\left(c e_{0}^{i}\right)^{\gamma^{i}-\frac{1}{\psi^{i}}}\left(c_{1}^{i}\right)^{-\gamma^{i}}
$$

Differentiating households' period 1 resource constraint yields

$$
\frac{\partial c_{1}^{i}}{\partial y_{0}^{i}}=\left(1+r_{1}\right) \frac{\partial b_{0}^{i}}{\partial y_{0}^{i}}+\pi_{1} \frac{\partial k_{0}^{i}}{\partial y_{0}^{i}} .
$$

Combining the previous two equations yields

$$
0=\mathbb{E}_{0} m_{0,1}^{i} \frac{\gamma^{i}}{c_{1}^{i}}\left(r_{1}^{k}-r_{1}\right)\left(\left(1+r_{1}\right) \frac{\partial b_{0}^{i}}{\partial y_{0}^{i}}+\pi_{1} \frac{\partial k_{0}^{i}}{\partial y_{0}^{i}}\right) .
$$

A second-order approximation then implies

$$
\begin{aligned}
0= & \left.\left(1+\bar{r}_{1}\right) \frac{\overline{\partial b_{0}^{i}}}{\partial y_{0}^{i}}+\bar{\pi}_{1} \frac{\overline{\partial k_{0}^{i}}}{\partial y_{0}^{i}}\right)\left(\mathbb{E}_{0} \hat{r}_{1}^{k}-\hat{r}_{1}+\frac{1}{2} \sigma^{2}\right) \\
& -\left(\left(1+\bar{r}_{1}\right) \frac{\overline{\partial b_{0}^{i}}}{\partial y_{0}^{i}}+\bar{\pi}_{1} \frac{\overline{\partial k_{0}^{i}}}{\partial y_{0}^{i}}\right) \frac{\gamma^{i}+1}{\bar{c}_{1}^{i}}\left(\bar{w}_{1}+\bar{\pi}_{1} \bar{k}_{0}^{i}\right) \sigma^{2}+\bar{\pi}_{1} \frac{\overline{\partial k_{0}^{i}}}{\partial y_{0}^{i}} \sigma^{2}+o\left(\|\cdot\|^{3}\right) .
\end{aligned}
$$

Again anticipating the result in Proposition 2 that

$$
\mathbb{E}_{0} \hat{r}_{1}^{k}-\hat{r}_{1}+\frac{1}{2} \sigma^{2}=\gamma \sigma^{2}+o\left(\|\cdot\|^{3}\right)
$$

and the above result that

$$
\frac{\bar{w}_{1}+\bar{\pi}_{1} \bar{k}_{0}^{i}}{\bar{c}_{1}^{i}}=\frac{\gamma}{\gamma^{i}}
$$

it follows from (S.4) that

$$
\bar{q}_{0} \frac{\overline{\partial k_{0}^{i}}}{\partial y_{0}^{i}}=\frac{\gamma}{\gamma^{i}} \frac{\overline{\partial a_{0}^{i}}}{\partial y_{0}^{i}}
$$

using $\bar{q}_{0}=\frac{\bar{\pi}_{1}}{1+\bar{r}_{0}}$ and $\frac{\overline{\partial b_{0}^{i}}}{\partial y_{0}^{i}}+\bar{q}_{0} \frac{\overline{\partial k_{0}^{i}}}{\partial y_{0}^{i}}=\frac{\overline{\partial a_{0}^{i}}}{\partial y_{0}^{i}}$. The expression for $\overline{m p r}_{0}^{i} \equiv \frac{\overline{q_{0}} \frac{\overline{\partial k_{0}^{i}}}{\partial y_{0}^{2}}}{\frac{\partial a_{0}^{i}}{\partial y_{0}^{2}}}$ then follows.

\section{Proposition 2}

Proof. We first derive the result up to second order. Multiplying both sides of (S.1) by $\frac{\bar{c}_{1}^{i}}{\gamma^{i}}$, integrating over all households $i$, and making use of the market clearing conditions 
which imply that

$$
\int_{0}^{1} \bar{c}_{1}^{i} d i=\int_{0}^{1}\left(\bar{w}_{1}+\bar{\pi}_{1} \bar{k}_{0}^{i}\right) d i
$$

we obtain

$$
\mathbb{E}_{0} \hat{r}_{1}\left(z_{1}\right)-\hat{r}_{0}+\frac{1}{2} \sigma^{2}=\left(\frac{\bar{c}_{1}^{i}}{\int_{0}^{1} \bar{c}_{1}^{\prime} d i^{\prime}} \frac{1}{\gamma^{i}}\right)^{-1} \sigma^{2}+o\left(\|\cdot\|^{3}\right),
$$

defining $\gamma$ as in the claim.

We now derive the result up to third order. The third-order approximation of optimal portfolio choice for household $i$ is

$$
\begin{aligned}
\mathbb{E}_{0} \hat{r}_{1}^{k}-\hat{r}_{1}+\frac{1}{2} \mathbb{E}_{0}\left(\hat{r}_{1}^{k}\right)^{2}- & \frac{1}{2} \hat{r}_{1}^{2} \\
=\gamma^{i} & \mathbb{E}_{0} \hat{c}_{1}^{i}\left(\hat{r}_{1}^{k}-\hat{r}_{1}\right)-\frac{1}{2}\left(\gamma^{i}\right)^{2} \mathbb{E}_{0}\left(\hat{c}_{1}^{i}\right)^{2}\left(\hat{r}_{1}^{k}-\hat{r}_{1}\right) \\
& \quad+\frac{1}{2} \gamma^{i} \mathbb{E}_{0} \hat{c}_{1}^{i}\left(\left(\hat{r}_{1}^{k}\right)^{2}-\hat{r}_{1}^{2}\right)-\frac{1}{6}\left(\mathbb{E}_{0}\left(\hat{r}_{1}^{k}\right)^{3}-\hat{r}_{1}^{3}\right)+o\left(\|\cdot\|^{4}\right) .
\end{aligned}
$$

A second-order expansion of $\hat{r}_{1}^{k}$ and $\hat{r}_{1}$ in terms of the underlying states yields

$$
\begin{aligned}
& \hat{r}_{1}^{k}=\hat{z}_{1}+\delta_{m_{0}}^{r_{0}} \hat{m}_{0}+\frac{1}{2} \delta_{m_{0}^{2}}^{r_{0}} \hat{m}_{0}^{2}+\left(-\frac{1}{2}+\gamma+\frac{1}{2} \delta_{\sigma^{2}}^{r_{0}}\right) \sigma^{2}, \\
& \hat{r}_{0}=\delta_{m_{0}}^{r_{0}} \hat{m}_{0}+\frac{1}{2} \delta_{m_{0}^{2}}^{r_{0}} \hat{m}_{0}^{2}+\frac{1}{2} \delta_{\sigma^{2}}^{r_{0}} \sigma^{2}
\end{aligned}
$$

where we have already made use of the fact that, by the method of undetermined coefficients, (S.5) implies

$$
\begin{aligned}
\frac{1}{2} \delta_{m_{0}^{2}}^{r_{1}^{k}} & =\frac{1}{2} \delta_{m_{0}^{2}}^{r_{1}}, \\
\frac{1}{2} \delta_{\sigma^{2}}^{r_{1}^{k}}-\frac{1}{2} \delta_{\sigma^{2}}^{r_{1}}+\frac{1}{2} & =\gamma .
\end{aligned}
$$

A second-order expansion of $\hat{c}_{1}^{i}$ in terms of the underlying states yields

$$
\hat{c}_{1}^{i}=\delta_{m_{0}}^{c_{1}^{i}} \hat{m}_{0}+\delta_{z_{1}}^{c_{1}^{i}} \hat{z}_{1}+\frac{1}{2} \delta_{m_{0}^{2}}^{c_{1}^{i}} \hat{m}_{0}^{2}+\delta_{m_{0} z_{1}}^{c_{1}^{i}} \hat{m}_{0} \hat{z}_{1}+\frac{1}{2} \delta_{z_{1}^{2}}^{c_{1}^{i}} \hat{z}_{1}^{2}+\frac{1}{2} \delta_{\sigma^{2}}^{c_{1}^{i}} \sigma^{2}+o\left(\|\cdot\|^{3}\right) .
$$


Substituting these into (S.6) and collecting terms, we obtain

$$
\begin{aligned}
\mathbb{E}_{0} \hat{r}_{1}^{k}-\hat{r}_{1}+ & \frac{1}{2} \sigma^{2}= \\
\gamma^{i} \delta_{z_{1}}^{c_{1}^{i}} \sigma^{2}+ & {\left[\gamma^{i}\left(\delta_{m_{0}}^{c_{1}^{i}} \gamma+\delta_{m_{0} z_{1}}^{c_{1}^{i}}\right)-\left(\gamma^{i}\right)^{2} \delta_{m_{0}}^{c_{1}^{i}} \delta_{z_{1}}^{c_{1}^{i}}+\gamma^{i} \delta_{z_{1}}^{c_{1}^{i}} \delta_{m_{0}}^{r_{1}}-\gamma \delta_{m_{0}}^{r_{1}}\right] \hat{m}_{0} \sigma^{2}+o\left(\|\cdot\|^{4}\right) }
\end{aligned}
$$

Making use of (S.2) substantially simplifies this to

$$
\mathbb{E}_{0} \hat{r}_{1}^{k}-\hat{r}_{1}+\frac{1}{2} \sigma^{2}=\gamma^{i} \delta_{z_{1}}^{c_{1}^{i}} \sigma^{2}+\gamma^{i} \delta_{m_{0} z_{1}}^{c_{1}^{i}} \hat{m}_{0} \sigma^{2}+o\left(\|\cdot\|^{4}\right)
$$

Again multiplying both sides by $\frac{\bar{c}_{1}^{i}}{\gamma^{i}}$, integrating over all households $i$, and making use of the market clearing conditions, we obtain

$$
\mathbb{E}_{0} \hat{r}_{1}^{k}-\hat{r}_{1}+\frac{1}{2} \sigma^{2}=\gamma \sigma^{2}+\frac{\gamma}{\int_{0}^{1} \bar{c}_{1}^{i} d i}\left(\int_{0}^{1} \bar{c}_{1}^{i} \delta_{m_{0} z_{1}}^{c_{1}^{i}} d i\right) \hat{m}_{0} \sigma^{2}+o\left(\|\cdot\|^{4}\right)
$$

Then, taking a second-order approximation of the period 1 resource constraint and equilibrium wages and profits, the method of undetermined coefficients implies

$$
\bar{c}_{1}^{i} \delta_{m_{0} z_{1}}^{c_{1}^{i}}+\bar{c}_{1}^{i} \delta_{m_{0}}^{c_{1}^{i}} \delta_{z_{1}}^{c_{1}^{i}}=\alpha \bar{w}_{1} \delta_{m_{0}}^{k_{0}}+\bar{\pi}_{1} \delta_{m_{0}}^{k_{0}^{i}}-(1-\alpha) \bar{\pi}_{1} \bar{k}_{0}^{i} \delta_{m_{0}}^{k_{0}}
$$

It follows that

$$
\int_{0}^{1} \bar{c}_{1}^{i} \delta_{m_{0} z_{1}}^{c_{1}^{i}} d i=-\int_{0}^{1} \bar{c}_{1}^{i} \delta_{m_{0}}^{c_{1}^{i}} \delta_{z_{1}}^{c_{1}^{i}} d i+\bar{\pi}_{1} \int_{0}^{1} \delta_{m_{0}}^{k_{0}^{i}} d i
$$

using

$$
\begin{gathered}
\int_{0}^{1} \alpha \bar{w}_{1} \delta_{m_{0}}^{k_{0}} d i=\alpha \bar{w}_{1} \delta_{m_{0}}^{k_{0}}=\alpha(1-\alpha) \bar{z}_{1} \bar{k}_{0}^{\alpha} \delta_{m_{0}}^{k_{0}} \\
\int_{0}^{1}(1-\alpha) \bar{\pi}_{1} \bar{k}_{0}^{i} \delta_{m_{0}}^{k_{0}} d i=(1-\alpha) \bar{\pi}_{1} \bar{k}_{0} \delta_{m_{0}}^{k_{0}}=\alpha(1-\alpha) \bar{z}_{1} \bar{k}_{0}^{\alpha} \delta_{m_{0}}^{k_{0}}
\end{gathered}
$$

implied by market clearing and the definition of equilibrium wages and profits. ${ }^{1}$ Since a first-order approximation to capital claims market clearing implies

$$
\int_{0}^{1} \delta_{m_{0}}^{k_{0}^{i}} d i=\bar{k}_{0} \delta_{m_{0}}^{k_{0}}
$$

\footnotetext{
${ }^{1}$ Note that we linearize rather than log-linearize with respect to $\left\{k_{0}^{i}, b_{0}^{i}, a_{0}^{i}\right\}$ since in principle these may be negative.
} 
it further follows that

$$
\int_{0}^{1} \bar{c}_{1}^{i} \delta_{m_{0} z_{1}}^{c_{1}^{i}} d i=-\int_{0}^{1} \bar{c}_{1}^{i} \delta_{m_{0}}^{c_{1}^{i}} \delta_{z_{1}}^{c_{1}^{i}} d i+\bar{\pi}_{1} \bar{k}_{0} \delta_{m_{0}}^{k_{0}}
$$

Moreover, since a first-order approximation to goods market clearing implies

$$
\int_{0}^{1} \bar{c}_{1}^{i} \delta_{m_{0}}^{c_{1}^{i}} d i=\alpha \bar{z}_{1} \bar{k}_{0}^{\alpha} \delta_{m_{0}}^{k_{0}}
$$

and $\bar{\pi}_{1}=\alpha \bar{z}_{1} \bar{k}_{0}^{\alpha-1}$, it further follows that

$$
\begin{aligned}
\int_{0}^{1} \bar{c}_{1}^{i} \delta_{m_{0} z_{1}}^{c_{1}^{i}} d i & =-\int_{0}^{1} \bar{c}_{1}^{i} \delta_{m_{0}}^{c_{1}^{i}} \delta_{z_{1}}^{c_{1}^{i}} d i+\int_{0}^{1} \bar{c}_{1}^{i} \delta_{m_{0}}^{c_{1}^{i}} d i \\
& =\int_{0}^{1} \bar{c}_{1}^{i} \delta_{m_{0}}^{c_{1}^{i}}\left(1-\delta_{z_{1}}^{c_{1}^{i}}\right) d i \\
& =\int_{0}^{1} \bar{c}_{1}^{i} \delta_{m_{0}}^{c_{1}^{i}}\left(1-\frac{\gamma}{\gamma^{i}}\right) d i
\end{aligned}
$$

where the final line uses (S.2). Hence, we can conclude

$$
\begin{aligned}
\zeta_{m_{0}} & =\frac{\gamma}{\int_{0}^{1} \bar{c}_{1}^{i} d i}\left(\int_{0}^{1} \bar{c}_{1}^{i} \delta_{m_{0} z_{1}}^{c_{1}^{i}} d i\right) \\
& =\frac{\gamma}{\int_{0}^{1} \bar{c}_{1}^{i} d i} \int_{0}^{1} \bar{c}_{1}^{i} \delta_{m_{0}}^{c_{1}^{i}}\left(1-\frac{\gamma}{\gamma^{i}}\right) d i
\end{aligned}
$$

Recall from Proposition 1 that $\overline{m p r}_{0}^{i} \equiv \frac{\gamma}{\gamma^{i}}$. Since the definition of (20) implies

$$
\int_{0}^{1} \bar{c}_{1}^{i} \delta_{m_{0}}^{c_{1}^{i}}\left(1-\frac{\gamma}{\gamma^{i}}\right) d i=\int_{0}^{1}\left(\bar{c}_{1}^{i} \delta_{m_{0}}^{c_{1}^{i}}-\frac{\bar{c}_{1}^{i}}{\int_{0}^{1} \bar{c}_{1}^{i^{\prime}} d i^{\prime}} \int_{0}^{1} \bar{c}_{1}^{i^{\prime}} \delta_{m_{0}}^{c_{1}^{i^{\prime}}} d i^{\prime}\right)\left(1-\frac{\gamma}{\gamma^{i}}\right) d i
$$

and

$$
1=\int_{0}^{1} \frac{\bar{c}_{1}^{i}}{\int_{0}^{1} \bar{c}_{1}^{i^{\prime}} d i^{\prime}} \overline{m p r}_{0}^{i} d i \equiv \overline{m p r}_{0}
$$


and we further have

$$
\begin{aligned}
\overline{\frac{d\left[c_{1}^{i} / \int_{0}^{1} c_{1}^{i^{\prime}}\right]}{d m_{0}}} & =\frac{1}{\int_{0}^{1} \bar{c}_{1}^{i^{\prime}} d i^{\prime}}\left(\frac{\overline{d c_{1}^{i}}}{d m_{0}}-\frac{\bar{c}_{1}^{i}}{\int_{0}^{1} \bar{c}_{1}^{i^{\prime}} d i^{\prime}} \int_{0}^{1} \overline{\frac{d c_{1}^{i^{\prime}}}{d m_{0}}} d i^{\prime}\right), \\
& =\frac{1}{\int_{0}^{1} \bar{c}_{1}^{i^{\prime}} d i^{\prime}}\left(\bar{c}_{1}^{i} \delta_{m_{0}}^{c_{1}^{i}}-\frac{\bar{c}_{1}^{i}}{\int_{0}^{1} \bar{c}_{1}^{i^{\prime}} d i^{\prime}} \int_{0}^{1} \bar{c}_{1}^{i^{\prime}} \delta_{m_{0}}^{i^{\prime}} d i^{\prime}\right),
\end{aligned}
$$

we obtain the expression for $\zeta_{m_{0}}$ given in the claim.

\section{Proposition 3}

Proof. Combining (23) with Proposition A.1 and using

$$
\begin{aligned}
\frac{\bar{c}_{1}^{i}}{\partial \frac{\partial a_{0}^{i}}{\partial y_{0}^{i}}} & =\frac{\bar{c}_{1},}{\partial a_{0}}, \\
\psi^{i} & =\psi, \\
\bar{\tau}_{0}^{i} & =\bar{\tau}^{\ell_{0}}, \\
\frac{\bar{\ell}_{0}^{i}}{d \ell_{0}^{i}} & =\bar{\ell}_{0}, \\
\frac{d m_{0}}{d m_{0}} & =\frac{\overline{d \ell_{0}}}{d m_{0}},
\end{aligned}
$$

as assumed in the claim, we obtain

$$
\bar{\xi}_{m_{0}}^{i}=\frac{1}{\bar{c}_{1}}\left(1+\bar{r}_{1}\right) \frac{\overline{\partial a_{0}}}{\partial y_{0}}\left[-\frac{\left(1+i_{-1}\right) B_{-1}^{i}}{P_{0}} \frac{1}{P_{0}} \frac{\overline{d P_{0}}}{d m_{0}}+\left(k_{-1}^{i}-k_{-1}\right)\left(\overline{\frac{d \pi_{0}}{d m_{0}}}+\left(1-\delta_{0}\right) \frac{\overline{d q_{0}}}{d m_{0}}\right)\right] .
$$

By Proposition 1 and the assumptions in the claim,

$$
\begin{aligned}
k_{-1}^{i}=\bar{k}_{0}^{i} & =\bar{a}_{0}\left[\frac{\bar{c}_{1}}{\left(1+\bar{r}_{1}\right) \bar{a}_{0}} \frac{\gamma}{\gamma^{i}}-\frac{\bar{w}_{1}}{\left(1+\bar{r}_{1}\right) \bar{a}_{0}}\right], \\
& =\frac{\bar{k}_{0}}{\alpha}\left(\frac{\gamma}{\gamma^{i}}-1\right)+\bar{k}_{0}, \\
B_{-1}^{i}=\bar{P}_{0} \bar{b}_{0}^{i} & =\bar{P}_{0}\left[\bar{a}_{0}-\bar{k}_{0}^{i}\right], \\
& =-\bar{P}_{0} \frac{\bar{k}_{0}}{\alpha}\left(\frac{\gamma}{\gamma^{i}}-1\right),
\end{aligned}
$$


where

$$
\gamma=\left[\int_{0}^{1} \frac{1}{\gamma^{i}} d i\right]^{-1}
$$

and we use $\bar{q}_{0}=1$ following the assumption that $k_{-1}=\bar{k}_{0}$. It follows that

$$
\begin{aligned}
-\frac{\left(1+i_{-1}\right) B_{-1}^{i}}{P_{0}} & =\left(1+i_{-1}\right) \frac{\bar{k}_{0}}{\alpha}\left(\frac{\gamma}{\gamma^{i}}-1\right), \\
k_{-1}^{i}-k_{-1} & =\frac{\bar{k}_{0}}{\alpha}\left(\frac{\gamma}{\gamma^{i}}-1\right) .
\end{aligned}
$$

Hence,

$$
\begin{aligned}
\zeta_{m_{0}} & =\gamma \int_{0}^{1} \bar{\xi}_{m_{0}}^{i}\left(\overline{m p r}_{0}-\overline{m p r} r_{0}^{i}\right) d i \\
& =\gamma \int_{0}^{1} \bar{\xi}_{m_{0}}^{i}\left(1-\frac{\gamma}{\gamma^{i}}\right) d i \\
& \propto-\left(1+i_{-1}\right) \frac{1}{P_{0}} \frac{\overline{d P_{0}}}{d m_{0}}-\frac{\overline{d \pi_{0}}}{d m_{0}}-\left(1-\delta_{0}\right) \frac{\overline{d q_{0}}}{d m_{0}}
\end{aligned}
$$

where the second line uses Proposition 1 and the third line uses the above results.

To sign (S.9), we now compute $\left\{\frac{d P_{0}}{d m_{0}}, \frac{d \pi_{0}}{d m_{0}}, \frac{d q_{0}}{d m_{0}}\right\}$ at the limit of $\sigma=0$. Assuming these derivatives are continuous in $\sigma$, their values at the limit of $\sigma=0$ will be equal to $\left\{\frac{d P_{0}}{d m_{0}}, \frac{d \pi_{0}}{d m_{0}}, \frac{d q_{0}}{d m_{0}}\right\}$. The limiting Euler equation

$$
\left(\bar{c}_{0}^{i}\right)^{-\frac{1}{\psi}} \Phi\left(\bar{\ell}_{0}\right)^{1-\frac{1}{\psi}}=\beta\left(1+\bar{r}_{1}\right)\left(\bar{c}_{1}^{i}\right)^{-\frac{1}{\psi}}
$$

implies

$$
-\frac{1}{\psi} \frac{1}{\bar{c}_{0}} \frac{d \bar{c}_{0}^{i}}{d \bar{m}_{0}}+\left(1-\frac{1}{\psi}\right) \epsilon \frac{\Phi}{\bar{\ell}_{0}} \frac{1}{\bar{\ell}_{0}} \frac{d \bar{\ell}_{0}}{d \bar{m}_{0}}=\frac{1}{1+\bar{r}_{1}} \frac{d\left(1+\bar{r}_{1}\right)}{d \bar{m}_{0}}-\frac{1}{\psi} \frac{1}{\bar{c}_{1}} \frac{d \bar{c}_{1}^{i}}{d \bar{m}_{0}},
$$

where we write the elasticity of $\Phi\left(\ell_{0}\right)$ with respect to $\ell_{0}$ evaluated at $\bar{\ell}_{0}$

$$
\epsilon_{\bar{\ell}_{0}}^{\Phi} \equiv \frac{\Phi^{\prime}\left(\bar{\ell}_{0}\right) \bar{\ell}_{0}}{\Phi\left(\bar{\ell}_{0}\right)}
$$

The union's limiting labor supply condition

$$
\int_{0}^{1}\left(\bar{v}_{0}^{i}\right)^{\frac{1}{\psi}}\left(\bar{c}_{0}^{i}\right)^{-\frac{1}{\psi}} \Phi\left(\bar{\ell}_{0}\right)^{1-\frac{1}{\psi}}\left[\frac{\bar{W}_{0}}{\bar{P}_{0}}+\bar{c}_{0}^{i} \frac{\Phi^{\prime}\left(\bar{\ell}_{0}\right)}{\Phi\left(\bar{\ell}_{0}\right)}+\frac{\bar{W}_{0}}{\bar{P}_{0}} \frac{\chi^{W}}{\epsilon} \frac{\bar{W}_{0}}{W_{-1}}\left(\frac{\bar{W}_{0}}{W_{-1}}-1\right)\right] d i=0
$$


implies

$$
\frac{1}{\bar{W}_{0}} \frac{d \bar{W}_{0}}{d \bar{m}_{0}}-\frac{1}{\bar{P}_{0}} \frac{d \bar{P}_{0}}{d \bar{m}_{0}}-\frac{1}{\bar{c}_{0}}\left(\int_{0}^{1} \frac{d \bar{c}_{0}^{i}}{d \bar{m}_{0}} d i\right)-\left(\epsilon_{\bar{\ell}_{0}}^{-\Phi^{\prime}}-\epsilon_{\bar{\ell}_{0}}^{\Phi}\right) \frac{1}{\bar{\ell}_{0}} \frac{d \bar{\ell}_{0}}{d \bar{m}_{0}}+\frac{\chi^{W}}{\epsilon} \frac{1}{\bar{W}_{0}} \frac{d \bar{W}_{0}}{d \bar{m}_{0}}=0
$$

where we have used the symmetry across households and $W_{-1}=\bar{W}_{0}$ at the point of approximation, and further defined the elasticity of the marginal disutility of labor

$$
\epsilon_{\bar{\ell}_{0}}^{-\Phi^{\prime}} \equiv \frac{-\Phi^{\prime \prime}\left(\bar{\ell}_{0}\right) \bar{\ell}_{0}}{-\Phi^{\prime}\left(\bar{\ell}_{0}\right)}
$$

The limiting labor demand condition in period 0

$$
\frac{\bar{W}_{0}}{\bar{P}_{0}}=(1-\alpha) z_{0} \bar{\ell}_{0}^{-\alpha} k_{-1}^{\alpha}
$$

implies

$$
\frac{1}{\bar{W}_{0}} \frac{d \bar{W}_{0}}{d \bar{m}_{0}}-\frac{1}{\bar{P}_{0}} \frac{d \bar{P}_{0}}{d \bar{m}_{0}}=-\alpha \frac{1}{\bar{\ell}_{0}} \frac{d \bar{\ell}_{0}}{d \bar{m}_{0}}
$$

The limiting optimal investment condition

$$
\bar{q}_{0}=\left(\frac{\bar{k}_{0}}{k_{-1}}\right)^{\chi^{x}}
$$

implies

$$
\frac{d \bar{q}_{0}}{d \bar{m}_{0}}=\chi^{x} \frac{1}{\bar{k}_{0}} \frac{d \bar{k}_{0}}{d \bar{m}_{0}}
$$

where we have used $k_{-1}=\bar{k}_{0}$ at the point of approximation. The limiting goods market clearing condition in period 0

$$
\int_{0}^{1} \bar{c}_{0}^{i} d i+\bar{q}_{0}\left(\bar{k}_{0}-\left(1-\delta_{0}\right) k_{-1}\right)=z_{0} \bar{\ell}_{0}^{1-\alpha} k_{-1}^{\alpha}
$$

implies

$$
\int_{0}^{1} \frac{d \bar{c}_{0}^{i}}{d \bar{m}_{0}} d i+\frac{d \bar{k}_{0}}{d \bar{m}_{0}}+\delta \bar{k}_{0} \frac{d \bar{q}_{0}}{d \bar{m}_{0}}=(1-\alpha) z_{0} \bar{\ell}_{0}^{-\alpha} k_{-1}^{\alpha} \frac{d \bar{\ell}_{0}}{d \bar{m}_{0}}
$$

where we use $\bar{q}_{0}=1$ and $\bar{k}_{0}=k_{-1}$ at the point of approximation. The limiting goods market clearing condition in period 1

$$
\int_{0}^{1} \bar{c}_{1}^{i} d i=\bar{z}_{1} \bar{k}_{0}^{\alpha}
$$


implies

$$
\int_{0}^{1} \frac{d \bar{c}_{1}^{i}}{d \bar{m}_{0}} d i=\alpha \bar{z}_{1} \bar{k}_{0}^{\alpha-1} \frac{d \bar{k}_{0}}{d \bar{m}_{0}} .
$$

The limiting definition of the returns

$$
1+\bar{r}_{1}=\frac{\alpha \bar{z}_{1} \bar{k}_{0}^{\alpha-1}}{\bar{q}_{0}}
$$

implies

$$
\frac{1}{1+\bar{r}_{1}} \frac{d\left(1+\bar{r}_{1}\right)}{d \bar{m}_{0}}=(\alpha-1) \frac{1}{\bar{k}_{0}} \frac{d \bar{k}_{0}}{d \bar{m}_{0}}-\frac{d \bar{q}_{0}}{d \bar{m}_{0}},
$$

where we again use $\bar{q}_{0}=1$ at the point of approximation. Finally, the limiting Fisher equation together with the monetary policy rules $(10)$ and $P_{1}=\bar{P}_{1}$,

$$
1+\bar{r}_{1}=\frac{(1+\bar{i})}{\left(P_{-1}\right)^{\phi}} \frac{\left(\bar{P}_{0}\right)^{1+\phi}}{\bar{P}_{1}} \bar{m}_{0},
$$

implies

$$
\frac{1}{1+\bar{r}_{1}} \frac{d\left(1+\bar{r}_{1}\right)}{d \bar{m}_{0}}=(1+\phi) \frac{1}{\bar{P}_{0}} \frac{d \bar{P}_{0}}{d \bar{m}_{0}}+\frac{1}{\bar{m}_{0}} .
$$

Combining (S.13), (S.16), and (S.17) yields

$$
\frac{1}{\bar{k}_{0}} \frac{d \bar{k}_{0}}{d \bar{m}_{0}}=-\frac{1}{1-\alpha+\chi^{x}}\left((1+\phi) \frac{1}{\bar{P}_{0}} \frac{d \bar{P}_{0}}{d \bar{m}_{0}}+\frac{1}{\bar{m}_{0}}\right) .
$$

Combining (S.10), (S.13), (S.14), (S.15), and (S.17) yields

$$
\begin{aligned}
\frac{1}{\bar{c}_{0}}\left(z_{0} \bar{\ell}_{0}^{-\alpha} k_{-1}^{\alpha}(1-\alpha) \frac{d \bar{\ell}_{0}}{d \bar{m}_{0}}-\left(\delta_{0} \chi^{x}+1\right) \frac{d \bar{k}_{0}}{d \bar{m}_{0}}\right)+(1-\psi) \epsilon_{\bar{\ell}_{0}}^{\Phi} \frac{1}{\bar{\ell}_{0}} \frac{d \bar{\ell}_{0}}{d \bar{m}_{0}}= \\
-\psi\left((1+\phi) \frac{1}{\bar{P}_{0}} \frac{d \bar{P}_{0}}{d \bar{m}_{0}}+\frac{1}{\bar{m}_{0}}\right)+\alpha \frac{1}{\bar{k}_{0}} \frac{d \bar{k}_{0}}{d \bar{m}_{0}} .
\end{aligned}
$$

Since by assumption $W_{-1}=\bar{W}_{0}$, it follows from the union's optimal labor supply and the representative producer's optimal labor demand that each household's labor wedge is zero at the point of approximation:

$$
\bar{\tau}_{0}^{\ell_{0}^{i}}=\bar{\tau}_{0}^{\ell_{0}}=1-\frac{-\bar{c}_{0} \Phi^{\prime}\left(\bar{\ell}_{0}\right) / \Phi\left(\bar{\ell}_{0}\right)}{(1-\alpha) z_{0} \bar{\ell}_{0}^{-\alpha} k_{-1}^{\alpha}}=0 .
$$


Hence we can further simplify the above as

$$
-\psi \epsilon_{\bar{\ell}_{0}}^{\Phi} \frac{1}{\bar{\ell}_{0}} \frac{d \bar{\ell}_{0}}{d \bar{m}_{0}}=-\psi\left((1+\phi) \frac{1}{\bar{P}_{0}} \frac{d \bar{P}_{0}}{d \bar{m}_{0}}+\frac{1}{\bar{m}_{0}}\right)+\left(\alpha+\left(\delta_{0} \chi^{x}+1\right) \frac{\bar{k}_{0}}{\bar{c}_{0}}\right) \frac{1}{\bar{k}_{0}} \frac{d \bar{k}_{0}}{d \bar{m}_{0}}
$$

Combining (S.11), (S.12), (S.13), and (S.14) yields

$$
\frac{\frac{\chi^{W}}{\epsilon}}{1+\frac{\chi^{W}}{\epsilon}} \frac{1}{\bar{P}_{0}} \frac{d \bar{P}_{0}}{d \bar{m}_{0}}=\left(\alpha+\frac{1}{1+\frac{\chi^{W}}{\epsilon}}\left(\epsilon_{\bar{\ell}_{0}}^{-\Phi^{\prime}}-2 \epsilon_{\bar{\ell}_{0}}^{\Phi}\right)\right) \frac{1}{\bar{\ell}_{0}} \frac{d \bar{\ell}_{0}}{d \bar{m}_{0}}-\frac{1}{1+\frac{\chi^{W}}{\epsilon}}\left(\delta_{0} \chi^{x}+1\right) \frac{1}{\bar{c}_{0}} \frac{d \bar{k}_{0}}{d \bar{m}_{0}},
$$

where we have again used the result that each household's labor wedge is zero at the point of approximation. Then (S.18)-(S.20) are 3 equations in the 3 unknowns $\left\{\frac{d \bar{\ell}_{0}}{d \bar{m}_{0}}, \frac{d \bar{k}_{0}}{d \bar{m}_{0}}, \frac{d \bar{P}_{0}}{d \bar{m}_{0}}\right\}$. Solving this system yields

$$
\begin{aligned}
& \frac{\bar{m}_{0}}{\bar{\ell}_{0}} \frac{d \bar{\ell}_{0}}{d \bar{m}_{0}}=-\frac{\left(\psi+\frac{\alpha+\left(\delta_{0} \chi^{x}+1\right) \frac{\bar{k}_{0}}{\bar{c}_{0}}}{1-\alpha+\chi^{x}}\right) \frac{1}{1-\frac{\epsilon}{\chi^{W}}\left(\delta_{0} \chi^{x}+1\right) \frac{\bar{k}_{0}}{\bar{c}_{0}} \frac{1+\phi}{1-\alpha+\chi^{x}}}}{-\psi \epsilon \epsilon_{\bar{\ell}_{0}}^{\Phi}+\left(\psi+\frac{\alpha+\left(\delta_{0} \chi^{x}+1\right) \frac{k_{0}}{c_{0}}}{1-\alpha+\chi^{x}}\right)(1+\phi)\left(\frac{\alpha\left(1+\frac{\epsilon}{\chi^{W}}\right)+\frac{\epsilon}{\chi^{W}}\left(\epsilon_{\bar{\ell}_{0}}^{-\Phi^{\prime}}-2 \epsilon_{\bar{\ell}_{0}}^{\Phi}\right)}{1-\frac{\epsilon}{\chi^{W}}\left(\delta_{0} \chi^{x}+1\right) \frac{\bar{k}_{0}}{\bar{c}_{0}} \frac{1+\phi}{1-\alpha+\chi^{x}}}\right)}, \\
& \frac{\bar{m}_{0}}{\bar{P}_{0}} \frac{d \bar{P}_{0}}{d \bar{m}_{0}}=\frac{1}{1-\frac{\epsilon}{\chi^{W}}\left(\delta_{0} \chi^{x}+1\right) \frac{\bar{k}_{0}}{\bar{c}_{0}} \frac{1+\phi}{1-\alpha+\chi^{x}}} \times \\
& {\left[-\frac{\left(\psi+\frac{\alpha+\left(\delta_{0} \chi^{x}+1\right) \frac{\bar{k}_{0}}{\bar{c}_{0}}}{1-\alpha+\chi^{x}}\right) \frac{\alpha\left(1+\frac{\epsilon}{\chi^{W}}\right)+\frac{\epsilon}{\chi^{W}}\left(\epsilon_{\bar{\ell}_{0}}^{-\Phi^{\prime}}-2 \epsilon_{\bar{\ell}_{0}}^{\Phi}\right)}{1-\frac{\epsilon}{\chi^{W}}\left(\delta_{0} \chi^{x}+1\right) \frac{\bar{k}_{0}}{\bar{c}_{0}} \frac{1+\phi}{1-\alpha+\chi^{x}}}}{-\psi \epsilon_{\overline{\ell_{0}}}^{\Phi}+\left(\psi+\frac{\alpha+\left(\delta_{0} \chi^{x}+1\right) \frac{\bar{k}_{0}}{\bar{c}_{0}}}{1-\alpha+\chi^{x}}\right)(1+\phi)\left(\frac{\alpha\left(1+\frac{\epsilon}{\chi^{W}}\right)+\frac{\epsilon}{\chi^{W}}\left(\epsilon_{\overline{\bar{l}}_{0}}^{-\Phi^{\prime}}-2 \epsilon_{\bar{\ell}_{0}}^{\Phi}\right)}{1-\frac{\epsilon}{\chi^{W}}\left(\delta_{0} \chi^{x}+1\right) \frac{\bar{k}_{0}}{\overline{\bar{c}}_{0}} \frac{1+\phi}{1-\alpha+\chi^{x}}}\right)}+\right.} \\
& \left.\frac{\epsilon}{\chi^{W}}\left(\delta_{0} \chi^{x}+1\right) \frac{\bar{k}_{0}}{\bar{c}_{0}} \frac{1}{1-\alpha+\chi^{x}}\right] \text {, }
\end{aligned}
$$

and then $\frac{\bar{m}_{0}}{\bar{k}_{0}} \frac{d \bar{k}_{0}}{d \bar{m}_{0}}$ implied by (S.18). For $\chi^{W}$ sufficiently large, each will be negative. 
Indeed, in the limit $\chi^{W} \rightarrow \infty$, these imply

$$
\begin{aligned}
& \frac{\bar{m}_{0}}{\bar{\ell}_{0}} \frac{d \bar{\ell}_{0}}{d \bar{m}_{0}}=-\frac{\psi+\frac{\alpha+\left(\delta_{0} \chi^{x}+1\right) \frac{\bar{k}_{0}}{\bar{c}_{0}}}{1-\alpha+\chi^{x}}}{-\psi \epsilon_{\bar{\ell}_{0}}^{\Phi}+\left(\psi+\frac{\alpha+\left(\delta_{0} \chi^{x}+1\right) \frac{\bar{k}_{0}}{\bar{c}_{0}}}{1-\alpha+\chi^{x}}\right)(1+\phi) \alpha}<0, \\
& \frac{\bar{m}_{0}}{\bar{P}_{0}} \frac{d \bar{P}_{0}}{d \bar{m}_{0}}=-\alpha \frac{\psi+\frac{\alpha+\left(\delta_{0} \chi^{x}+1\right) \frac{\overline{\bar{k}}_{0}}{\bar{c}_{0}}}{1-\alpha+\chi^{x}}}{-\psi \epsilon_{\bar{\ell}_{0}}^{\Phi}+\left(\psi+\frac{\alpha+\left(\delta_{0} \chi^{x}+1\right) \frac{\bar{k}_{0}}{\bar{c}_{0}}}{1-\alpha+\chi^{x}}\right)(1+\phi) \alpha}<0 . \\
& \frac{\bar{m}_{0}}{\bar{k}_{0}} \frac{d \bar{k}_{0}}{d \bar{m}_{0}}=-\frac{1}{1-\alpha+\chi^{x}} \frac{-\psi \epsilon_{\bar{\ell}_{0}}^{\Phi}}{-\psi \epsilon_{\bar{\ell}_{0}}^{\Phi}+\left(\psi+\frac{\alpha+\left(\delta_{0} \chi^{x}+1\right) \frac{\bar{k}_{0}}{\bar{c}_{0}}}{1-\alpha+\chi^{x}}\right)(1+\phi) \alpha}
\end{aligned}
$$

Since

$$
\frac{d \bar{\pi}_{0}}{d \bar{m}_{0}}=(1-\alpha) \frac{\bar{\pi}_{0}}{\bar{\ell}_{0}} \frac{d \bar{\ell}_{0}}{d \bar{m}_{0}} \propto \frac{d \bar{\ell}_{0}}{d \bar{m}_{0}}
$$

and

$$
\frac{d \bar{q}_{0}}{d \bar{m}_{0}}=\chi^{x} \frac{1}{\bar{k}_{0}} \frac{d \bar{k}_{0}}{d \bar{m}_{0}} \propto \frac{d \bar{k}_{0}}{d \bar{m}_{0}},
$$

it follows from (S.9) that $\zeta_{m_{0}}>0$.

\section{Proposition 4}

Proof. We first note that, in the general environment featuring portfolio constraints / rules-of-thumb, background risk, and subjective beliefs regarding aggregate TFP, households' limiting portfolios and MPRs are

$$
\begin{aligned}
\frac{\bar{q}_{0} \bar{k}_{0}^{i}}{\bar{a}_{0}^{i}}=\left\{\begin{array}{l}
\omega_{0}^{i} \text { for } i \in C, \\
\left(\frac{\bar{c}_{1}^{i}}{\left(1+\bar{r}_{1}\right) \bar{a}_{0}^{i}}\right) \frac{\gamma}{\gamma^{i}\left(1+\eta^{i}\right) \varsigma^{i}}-\frac{\bar{w}_{1}}{\left(1+\bar{r}_{1}\right) \bar{a}_{0}^{i}} \text { for } i \notin C,
\end{array}\right. \\
\overline{m p r}_{0}^{i}=\left\{\begin{array}{l}
\omega_{0}^{i} \text { for } i \in C, \\
\frac{\gamma}{\gamma^{i}\left(1+\eta^{i}\right) \varsigma^{i}} \text { for } i \notin C,
\end{array}\right.
\end{aligned}
$$

where

$$
\gamma=\left(\int_{i \notin C} \frac{\bar{c}_{1}^{i}}{\int_{i^{\prime} \notin C} \bar{c}_{1}^{i^{\prime}} d i^{\prime}} \frac{1}{\gamma^{i}\left(1+\eta^{i}\right) \varsigma^{i}} d i\right)^{-1}\left(1-\frac{\int_{i \notin C}\left(1+\bar{r}_{1}\right) \bar{b}_{0}^{i} d i}{\int_{i \notin C} \bar{c}_{1}^{i} d i}\right) .
$$


Up to third order in $\left\{\sigma, \hat{z}_{1}, \hat{m}_{0}\right\}$, we obtain (21) with $\gamma$ as in (S.23) and

$$
\zeta_{m_{0}}=\left(\int_{i \notin C} \frac{\bar{c}_{1}^{i}}{\int_{i^{\prime} \notin C} \bar{c}_{1}^{i^{\prime}} d i^{\prime}} \frac{1}{\gamma^{i}\left(1+\eta^{i}\right) \varsigma^{i}} d i\right)^{-1} \int_{0}^{1} \bar{\xi}_{m_{0}}^{i}\left(\overline{m p r}_{0}-\overline{m p r}_{0}^{i}\right) d i
$$

where $\bar{\xi}_{m_{0}}^{i} \equiv \overline{\overline{d\left[\left(1+r_{0}\right) a_{0}^{i} / \int_{0}^{1} c_{1}^{i^{\prime}} d i^{\prime}\right]}}$ for $i \in C$ and $\bar{\xi}_{m_{0}}^{i} \equiv \overline{\frac{\overline{d\left[c_{1}^{i} / \int_{0}^{1} c_{1}^{i^{\prime}} d i^{\prime}\right]}}{d m_{0}}}$ for $i \notin C$, and $\overline{m p r}_{0} \equiv \int_{i \in C} \frac{\left(1+\bar{r}_{1}\right) \bar{a}_{0}^{i}}{\int_{i^{\prime} \in C}\left(1+\bar{r}_{1}\right) \bar{a}_{0}^{i^{\prime}} d i^{\prime}+\int_{i^{\prime} \notin C} \bar{c}_{1}^{i^{\prime}} d i^{\prime}} \overline{m p r}{ }_{0}^{i} d i+\int_{i \notin C} \frac{\bar{c}_{1}^{i}}{\int_{i^{\prime} \in C}\left(1+\bar{r}_{1}\right) \bar{a}_{0}^{i^{\prime}} d i^{\prime}+\int_{i^{\prime} \notin C} \bar{c}_{1}^{i^{\prime}} d i^{\prime}} \overline{m p r} \overline{0}_{0}^{i} d i=1$. The proof of these results combines the proofs in Corollaries A.1-A.3 and we do not repeat it here.

A household's limiting change in future consumption in response to a monetary policy shock $\frac{\overline{d c_{1}^{i}}}{d m_{0}}$ remains characterized by Proposition A.1. Given the limiting period 1 budget constraint

$$
\bar{c}_{1}^{i}=\bar{w}_{1}+\left(1+\bar{r}_{1}\right) \bar{a}_{0}^{i}
$$

a household's limiting change in $\left(1+r_{1}\right) a_{0}^{i}$ in response to a monetary policy shock is characterized by

$$
\overline{\frac{d\left(1+r_{1}\right) a_{0}^{i}}{d m_{0}}}=\overline{\frac{d c_{1}^{i}}{d m_{0}}}-\frac{\overline{d w_{1}}}{d m_{0}} .
$$

Then, under the assumptions that households are identical except for $\left\{\gamma^{i}, \omega_{0}^{i}, \eta^{i}, \varsigma^{i}\right\}$ and whether or not they are constrained, it follows that for unconstrained households $(i \notin C)$

$$
\bar{\xi}_{m_{0}}^{i}=\frac{1}{\bar{c}_{1}}\left(1+\bar{r}_{1}\right) \frac{\overline{\partial a_{0}}}{\partial y_{0}}\left[-\frac{\left(1+i_{-1}\right)}{P_{0}} B_{-1}^{i} \frac{1}{P_{0}} \frac{\overline{d P_{0}}}{d m_{0}}+\left(k_{-1}^{i}-k_{-1}\right)\left(\overline{\frac{d \pi_{0}}{d m_{0}}}+\left(1-\delta_{0}\right) \frac{\overline{d q_{0}}}{d m_{0}}\right)\right] .
$$

as in the baseline case. By (S.21)

$$
\begin{aligned}
k_{-1}^{i}=\bar{k}_{0}^{i} & =\bar{a}_{0}\left[\frac{\bar{c}_{1}}{\left(1+\bar{r}_{1}\right) \bar{a}_{0}} \frac{\gamma}{\gamma^{i}\left(1+\eta^{i}\right) \varsigma^{i}}-\frac{\bar{w}_{1}}{\left(1+\bar{r}_{1}\right) \bar{a}_{0}}\right], \\
& =\frac{\bar{k}_{0}}{\alpha}\left(\frac{\gamma}{\gamma^{i}\left(1+\eta^{i}\right) \varsigma^{i}}-1\right)+\bar{k}_{0}, \\
B_{-1}^{i}=\bar{P}_{0} \bar{b}_{0}^{i} & =\bar{P}_{0}\left[\bar{a}_{0}-\bar{k}_{0}^{i}\right], \\
& =-\bar{P}_{0} \frac{\bar{k}_{0}}{\alpha}\left(\frac{\gamma}{\gamma^{i}\left(1+\eta^{i}\right) \varsigma^{i}}-1\right),
\end{aligned}
$$


where we use $\bar{q}_{0}=1$ and, by (S.23),

$$
\gamma=\left[\int_{i \notin C} \frac{1}{\gamma^{i}\left(1+\eta^{i}\right) \varsigma^{i}} d i\right]^{-1} \frac{\int_{i \notin C}\left[\bar{w}_{1}+\bar{\pi}_{1} \bar{k}_{0}^{i}\right] d i}{\bar{c}_{1}}
$$

It follows that

$$
\begin{aligned}
-\frac{\left(1+i_{-1}\right) B_{-1}^{i}}{P_{0}} & =\left(1+i_{-1}\right) \frac{\bar{k}_{0}}{\alpha}\left(\frac{\gamma}{\gamma^{i}\left(1+\eta^{i}\right) \varsigma^{i}}-1\right) \\
k_{-1}^{i}-k_{-1} & =\frac{\bar{k}_{0}}{\alpha}\left(\frac{\gamma}{\gamma^{i}\left(1+\eta^{i}\right) \varsigma^{i}}-1\right) .
\end{aligned}
$$

Hence,

$$
\begin{aligned}
& \left(\int_{i \notin C} \frac{\bar{c}_{1}^{i}}{\int_{i^{\prime} \notin C} \bar{c}_{1}^{i^{\prime}} d i^{\prime}} \frac{1}{\gamma^{i}\left(1+\eta^{i}\right) \varsigma^{i}} d i\right)^{-1} \int_{i \notin C} \bar{\xi}_{m_{0}}^{i}\left(\overline{m p r}_{0}-\overline{m p r}_{0}^{i}\right) d i, \\
& =\left[\int_{i \notin C} \frac{1}{\gamma^{i}\left(1+\eta^{i}\right) \varsigma^{i}} d i\right]^{-1} \int_{i \notin C} \bar{\xi}_{m_{0}}^{i}\left(1-\frac{\gamma}{\gamma^{i}\left(1+\eta^{i}\right) \varsigma^{i}}\right) d i, \\
& =\left(\int_{i \notin C} \frac{1}{\gamma^{i}\left(1+\eta^{i}\right) \varsigma^{i}} d i\right)^{-1}\left[-\frac{1}{\bar{c}_{1}}\left(1+\bar{r}_{1}\right) \frac{\overline{\partial a_{0}}}{\partial y_{0}} \frac{\bar{k}_{0}}{\alpha} \int_{i \notin C}\left(1-\frac{\gamma}{\gamma^{i}\left(1+\eta^{i}\right) \varsigma^{i}}\right)^{2} d i\right] \times \\
& {\left[\left(1+i_{-1}\right) \bar{q}_{0} \frac{1}{P_{0}} \frac{\overline{d P_{0}}}{d m_{0}}+\overline{\frac{d \pi_{0}}{d m_{0}}}+\left(1-\delta_{0}\right) \frac{\overline{d q_{0}}}{d m_{0}}\right],}
\end{aligned}
$$

where the second equality uses (S.22) and the third equality uses the above results. 
For constrained households $(i \in C)$,

$$
\begin{aligned}
\bar{\xi}_{m_{0}}^{i}= & \frac{1}{\bar{c}_{1}}\left[\frac{\overline{d\left(1+r_{1}\right) a_{0}^{i}}}{d m_{0}}-\frac{\left(1+\bar{r}_{1}\right) \bar{a}_{0}}{\bar{c}_{1}} \int_{0}^{1} \frac{\overline{d c_{1}^{i}}}{d m_{0}} d i\right], \\
= & \frac{1}{\bar{c}_{1}}\left[\frac{\overline{d\left(1+r_{1}\right) a_{0}^{i}}}{d m_{0}}-\int_{0}^{1} \frac{\overline{d c_{1}^{i}}}{d m_{0}} d i\right]+\frac{1}{\bar{c}_{1}} \frac{\bar{w}_{1}}{\bar{c}_{1}} \int_{0}^{1} \frac{\overline{d c_{1}^{i}}}{d m_{0}} d i, \overline{\overline{d a_{0}}}\left[-\frac{\left(1+i_{-1}\right)}{P_{0}} B_{-1}^{i} \frac{1}{P_{0}} \frac{\overline{d P_{0}}}{d m_{0}}+\left(k_{-1}^{i}-k_{-1}\right)\left(\overline{\frac{d \pi_{0}}{d m_{0}}}+\left(1-\delta_{0}\right) \frac{\overline{d q_{0}}}{d m_{0}}\right)\right]- \\
= & \left.\frac{1}{\bar{c}_{1}}\left(1+\bar{r}_{1}\right) \frac{1}{\partial y_{0}}\left[\overline{\frac{d \pi_{0}}{d m_{0}}}+\left(1-\delta_{0}\right) \frac{\overline{d q_{0}}}{d m_{0}}\right)\right]+ \\
& \frac{1}{\bar{c}_{1}} \frac{d w_{1}}{d m_{0}}+\frac{1}{\bar{c}_{1}} \frac{\bar{w}_{1}}{\bar{c}_{1}} \int_{0}^{1} \frac{\frac{d c_{1}^{i}}{d m_{0}} d i}{=} \frac{1}{\bar{c}_{1}}\left(1+\bar{r}_{1}\right) \frac{\partial a_{0}}{\partial y_{0}}\left[-\frac{\left(1+i_{-1}\right)}{P_{0}} B_{-1}^{i} \frac{1}{P_{0}} \frac{\overline{d P_{0}}}{d m_{0}}+\left(k_{-1}^{i}-k_{-1}\right)\right. \\
& \frac{\bar{w}_{1}}{\bar{c}_{1}}\left[\frac{1}{\bar{c}_{1}} \int_{0}^{1} \frac{d c_{1}^{i}}{d m_{0}} d i-\frac{1}{\bar{w}_{1}} \frac{d w_{1}}{d m_{0}}\right],
\end{aligned}
$$

where the second equality uses (S.25) and the third equality uses (S.26) as well as Proposition A.1. By (S.21)

$$
\begin{aligned}
k_{-1}^{i}=\bar{k}_{0}^{i} & =\frac{\bar{a}_{0} \omega_{0}^{i}}{\bar{q}_{0}}, \\
& =\bar{k}_{0}\left(\omega_{0}^{i}-1\right)+\bar{k}_{0}, \\
B_{-1}^{i}=\bar{P}_{0} \bar{b}_{0}^{i} & =\bar{P}_{0} \bar{a}_{0}\left(1-\omega_{0}^{i}\right), \\
& =-\bar{P}_{0} \bar{k}_{0}\left(\omega_{0}^{i}-1\right) .
\end{aligned}
$$

It follows that

$$
\begin{aligned}
-\frac{\left(1+i_{-1}\right) B_{-1}^{i}}{\bar{P}_{0}} & =\left(1+i_{-1}\right) \bar{k}_{0}\left(\omega_{0}^{i}-1\right), \\
k_{-1}^{i}-k_{-1} & =\bar{k}_{0}\left(\omega_{0}^{i}-1\right) .
\end{aligned}
$$


Hence,

$$
\begin{aligned}
& \left(\int_{i \notin C} \frac{\bar{c}_{1}^{i}}{\int_{i^{\prime} \notin C} \bar{c}_{1}^{i^{\prime}} d i^{\prime}} \frac{1}{\gamma^{i}\left(1+\eta^{i}\right) \varsigma^{i}} d i\right)^{-1} \int_{i \in C} \bar{\xi}_{m_{0}}^{i}\left(\overline{m p r}_{0}-\overline{m p r}_{0}^{i}\right) d i \\
= & \left(\int_{i \notin C} \frac{1}{\gamma^{i}\left(1+\eta^{i}\right) \varsigma^{i}} d i\right)^{-1} \int_{i \in C} \bar{\xi}_{m_{0}}^{i}\left(1-\omega_{0}^{i}\right) d i \\
= & \left(\int_{i \notin C} \frac{1}{\gamma^{i}\left(1+\eta^{i}\right) \varsigma^{i}} d i\right)^{-1} \times \\
& \left(\left[-\frac{1}{\bar{c}_{1}}\left(1+\bar{r}_{1}\right) \frac{\partial a_{0}}{\partial y_{0}} \bar{k}_{0} \int_{i \in C}\left(1-\omega_{0}^{i}\right)^{2} d i\right]\left[\left(1+i \bar{l}_{-1}\right) \bar{q}_{0} \frac{1}{P_{0}} \frac{\overline{d P_{0}}}{d m_{0}}+\frac{\overline{d \pi_{0}}}{d m_{0}}+\left(1-\delta_{0}\right) \frac{\overline{d q_{0}}}{d m_{0}}\right]+\right. \\
& \left.\left(\int_{i \in C}\left(1-\omega_{0}^{i}\right) d i\right) \frac{\bar{w}_{1}}{\bar{c}_{1}}\left[\frac{1}{\bar{c}_{1}} \int_{0}^{1} \frac{\left.\mathrm{S}_{0} .28\right)}{d c_{1}^{i}} d i-\frac{1}{\bar{w}_{1}} \frac{\overline{d w_{1}}}{d m_{0}}\right]\right) .
\end{aligned}
$$

Now note that the characterization of $\frac{\overline{d P_{0}}}{d m_{0}}, \frac{\overline{d \pi_{0}}}{d m_{0}}$, and $\overline{\frac{d q_{0}}{d m_{0}}}$ is unchanged from the proof of Proposition 3. Furthermore, since limiting goods market clearing in period 1

$$
\int_{0}^{1} \bar{c}_{1}^{i} d i=\bar{z}_{1} \bar{k}_{0}^{\alpha}
$$

implies

$$
\frac{1}{\bar{c}_{1}} \int_{0}^{1} \frac{d \bar{c}_{1}^{i}}{d \bar{m}_{0}} d i=\alpha \frac{1}{\bar{k}_{0}} \frac{d \bar{k}_{0}}{d \bar{m}_{0}},
$$

while limiting labor demand in period 1

$$
\bar{w}_{1}=(1-\alpha) \bar{z}_{1} \bar{k}_{0}^{\alpha}
$$

implies

$$
\frac{1}{\bar{w}_{1}} \frac{d \bar{w}_{1}}{d \bar{m}_{0}}=\alpha \frac{1}{\bar{k}_{0}} \frac{d \bar{k}_{0}}{d \bar{m}_{0}}
$$

we have that

$$
\left[\frac{1}{\bar{c}_{1}} \int_{0}^{1} \frac{\overline{d c_{1}^{i}}}{d m_{0}} d i-\frac{1}{\bar{w}_{1}} \frac{\overline{d w_{1}}}{d m_{0}}\right]=0
$$


Hence, combining (S.27) and (S.28) in (S.24) implies

$$
\begin{aligned}
\zeta_{m_{0}} & =\left(\int_{i \notin C} \frac{\bar{c}_{1}^{i}}{\int_{i^{\prime} \notin C} \bar{c}_{1}^{i^{\prime}} d i^{\prime}} \frac{1}{\gamma^{i}\left(1+\eta^{i}\right) \varsigma^{i}} d i\right)^{-1} \int_{0}^{1} \bar{\xi}_{m_{0}}^{i}\left(1-\overline{m p r}_{0}^{i}\right) d i \\
& \propto-\left(1+i_{-1}\right) \frac{1}{P_{0}} \frac{\overline{d P_{0}}}{d m_{0}}-\frac{\overline{d \pi_{0}}}{d m_{0}}-\left(1-\delta_{0}\right) \frac{\overline{d q_{0}}}{d m_{0}}, \\
& >0
\end{aligned}
$$

for $\chi^{W}$ sufficiently large.

\section{Proposition 5}

Proof. Recall that the monetary policy rule (10) and $P_{1}=\bar{P}_{1}$ implies a real interest rate

$$
1+r_{1}=\frac{(1+\bar{i})}{P_{-1}^{\phi}} \frac{\left(P_{0}\right)^{1+\phi}}{\bar{P}_{1}} m_{0},
$$

which then implies the exact log-linear relationship

$$
\hat{r}_{1}=(1+\phi) \hat{P}_{0}+\hat{m}_{0}
$$

When $\phi=-1$, it follows that

$$
\hat{r}_{1}=\hat{m}_{0}
$$

Given the expansion in state variables

$$
\hat{r}_{1}^{k}=\delta_{m_{0}}^{r_{1}} \hat{m}_{0}+\hat{z}_{1}+\frac{1}{2} \delta_{\sigma^{2}}^{r_{1}^{k}} \sigma^{2}+\frac{1}{2} \delta_{z_{1}^{2}}^{r_{1}^{k}} z_{1}^{2}+\frac{1}{2} \delta_{m_{0} \sigma^{2}}^{r_{1}^{k}} \hat{m}_{0} \sigma^{2}+\frac{1}{2} \delta_{m_{0} z_{1}^{2}}^{r_{1}^{k}} \hat{m}_{0} z_{1}^{2}+o\left(\|\cdot\|^{4}\right)
$$

it follows from Proposition 2 that

$$
\frac{1}{2} \delta_{m_{0} \sigma^{2}}^{r_{1}^{k}}+\frac{1}{2} \delta_{m_{0} z_{1}^{2}}^{r_{1}^{k}}=\zeta_{m_{0}}
$$

Now by the definition of the return on capital, we have the exact log-linear relationship

$$
\hat{r}_{1}^{k}=\hat{z}_{1}-\left(1-\alpha+\chi^{x}\right) \hat{k}_{0}
$$


as derived in the main text. It follows by the method of undetermined coefficients

$$
\begin{aligned}
& \frac{1}{2} \delta_{m_{0} \sigma^{2}}^{r_{k}^{k}}=-\left(1-\alpha+\chi^{x}\right) \frac{1}{2} \delta_{m_{0} \sigma^{2}}^{k_{0}}, \\
& \frac{1}{2} \delta_{m_{0} z_{1}^{2}}^{r_{1}^{k}}=0 .
\end{aligned}
$$

Hence, the above results imply

$$
\frac{1}{2} \delta_{m_{0} \sigma^{2}}^{r_{1}^{k}}=-\frac{1}{1-\alpha+\chi^{x}} \zeta_{m_{0}}
$$

proving the claim.

\section{Proposition 6}

Proof. Given $\psi^{i}=1$, each household's first order condition for saving in each asset given the problem (16) is

$$
\begin{aligned}
& \left(c_{0}^{i}\right)^{-1}=\frac{\beta^{i}}{1-\beta^{i}}\left(c e_{0}^{i}\right)^{\gamma^{i}-1} \mathbb{E}_{0}\left(c_{1}^{i}\right)^{-\gamma^{i}}\left(1+r_{1}^{k}\right), \\
& \left(c_{0}^{i}\right)^{-1}=\frac{\beta^{i}}{1-\beta^{i}}\left(c e_{0}^{i}\right)^{\gamma^{i}-1} \mathbb{E}_{0}\left(c_{1}^{i}\right)^{-\gamma^{i}}\left(1+r_{1}\right),
\end{aligned}
$$

where $c e_{0}^{i} \equiv\left(\mathbb{E}_{0}\left[\left(c_{1}^{i}\right)^{1-\gamma^{i}}\right]\right)^{\frac{1}{1-\gamma^{i}}}$ is the certainty equivalent of future consumption. In equilibrium, recall that

$$
\begin{aligned}
w_{1} & =(1-\alpha) z_{1} k_{0}^{\alpha}, \\
1+r_{1}^{k} & =\frac{\alpha z_{1} k_{0}^{\alpha-1}}{q_{0}},
\end{aligned}
$$

so the period 1 resource constraint can be written

$$
c_{1}^{i}=\left(q_{0} k_{0}^{i}+\frac{1-\alpha}{\alpha} q_{0} k_{0}\right)\left(1+r_{1}^{k}\right)+b_{0}^{i}\left(1+r_{1}\right) .
$$

Hence, multiplying (S.29) by $\left(q_{0} k_{0}^{i}+\frac{1-\alpha}{\alpha} q_{0} k_{0}\right)$ and (S.30) by $b_{0}^{i}$, and then adding them, we obtain

$$
\left(a_{0}^{i}+\frac{1-\alpha}{\alpha} q_{0} k_{0}\right)\left(c_{0}^{i}\right)^{-1}=\frac{\beta^{i}}{1-\beta^{i}}\left(c e_{0}^{i}\right)^{\gamma^{i}-1} \mathbb{E}_{0}\left(c_{1}^{i}\right)^{1-\gamma^{i}}
$$


given total savings $a_{0}^{i} \equiv b_{0}^{i}+q_{0} k_{0}^{i}$. Given the definition of the certainty equivalent, this simplifies to

$$
\left(a_{0}^{i}+\frac{1-\alpha}{\alpha} q_{0} k_{0}\right)\left(c_{0}^{i}\right)^{-1}=\frac{\beta^{i}}{1-\beta^{i}} .
$$

Solving this for $a_{0}^{i}$ and substituting this into the period 0 resource constraint implies

$$
c_{0}^{i}=\left(1-\beta^{i}\right)\left[y_{0}^{i}\left(w_{0} \ell_{0}^{i}, P_{0}, \pi_{0}, q_{0}\right)+\frac{1-\alpha}{\alpha} q_{0} k_{0}\right] .
$$

As described in the main text, the additional assumption $\beta^{i}=\beta$, together with goods market clearing (11), implies that

$$
c_{0}=\frac{1-\beta}{\beta} \frac{1}{\alpha} q_{0} k_{0}=\frac{1-\beta}{\beta} \frac{1}{\alpha}\left(\frac{k_{0}}{k_{-1}}\right)^{\chi^{x}} k_{0} .
$$

It follows that we have the exact log-linear relationship

$$
\hat{c}_{0}=\left(\chi^{x}+1\right) \hat{k}_{0}
$$

The claim immediately follows.

We now demonstrate that the same result holds in the more general environment featuring portfolio constraints / rules-of-thumb, background risk, and subjective beliefs regarding aggregate TFP. In this environment, each household's problem (16) generalizes to

$$
\begin{array}{r}
\max \left(\left(1-\beta^{i}\right)\left(c_{0}^{i} \Phi^{i}\left(\ell_{0}^{i}\right)\right)^{1-1 / \psi^{i}}+\beta^{i}\left(\mathbb{E}_{0}^{i}\left[\left(c_{1}^{i}\right)^{1-\gamma^{i}}\right]\right)^{\frac{1-1 / \psi^{i}}{1-\gamma^{i}}}\right)^{\frac{1}{1-1 / \psi^{i}}} \text { s.t. } \\
c_{0}^{i}+b_{0}^{i}+q_{0} k_{0}^{i}=y_{0}^{i}\left(w_{0} \ell_{0}^{i}, P_{0}, \pi_{0}, q_{0}\right) \\
c_{1}^{i}=\epsilon_{1}^{i} w_{1}+\left(1+r_{1}\right) b_{0}^{i}+\epsilon_{1}^{i} \pi_{1} k_{0}^{i}
\end{array}
$$

where $\mathbb{E}_{0}^{i}$ is the household's expectation given their subjective belief regarding TFP, $\epsilon_{1}^{i}$ is the household's idiosyncratic labor productivity and capital quality shock, and if $i \in C$ the household faces the additional constraint $q_{0} k_{0}^{i}=\omega_{0}^{i}\left(b_{0}^{i}+q_{0} k_{0}^{i}\right)$. For this claim we assume a particular form of the constraint among such agents, $\omega_{0}^{i}=1$. 
Then each household's first order condition for saving in each asset is

$$
\begin{aligned}
& \left(c_{0}^{i}\right)^{-1}=\frac{\beta^{i}}{1-\beta^{i}}\left(c e_{0}^{i}\right)^{\gamma^{i}-1} \mathbb{E}_{0}^{i}\left(c_{1}^{i}\right)^{-\gamma^{i}}\left(1+r_{1}^{k}\right)-\nu^{i}\left(\omega_{0}^{i}-1\right), \\
& \left(c_{0}^{i}\right)^{-1}=\frac{\beta^{i}}{1-\beta^{i}}\left(c e_{0}^{i}\right)^{\gamma^{i}-1} \mathbb{E}_{0}^{i}\left(c_{1}^{i}\right)^{-\gamma^{i}}\left(1+r_{1}\right)-\nu^{i} \omega_{0}^{i},
\end{aligned}
$$

where $\nu^{i}$ is the (scaled) multiplier on the portfolio constraint, equaling zero for $i \notin C$, and $c e_{0}^{i} \equiv\left(\mathbb{E}_{0}^{i}\left[\left(c_{1}^{i}\right)^{1-\gamma^{i}}\right]\right)^{\frac{1}{1-\gamma^{i}}}$ is the certainty equivalent. The equilibrium relationship between $w_{1}$ and $1+r_{1}^{k}$ remains unchanged from above, so that the period 1 resource constraint can be written

$$
c_{1}^{i}=\epsilon_{1}^{i}\left(q_{0} k_{0}^{i}+\frac{1-\alpha}{\alpha} q_{0} k_{0}\right)\left(1+r_{1}^{k}\right)+b_{0}^{i}\left(1+r_{1}\right) .
$$

Hence, multiplying (S.33) by $\left(q_{0} k_{0}^{i}+\frac{1-\alpha}{\alpha} q_{0} k_{0}\right)$ and (S.30) by $b_{0}^{i}$, and then adding them, we obtain

$$
\left(a_{0}^{i}+\frac{1-\alpha}{\alpha} q_{0} k_{0}\right)\left(c_{0}^{i}\right)^{-1}=\frac{\beta^{i}}{1-\beta^{i}}\left(c e_{0}^{i}\right)^{\gamma^{i}-1} \mathbb{E}_{0}^{i}\left(c_{1}^{i}\right)^{1-\gamma^{i}},
$$

where we have used the assumption that for constrained households, $\omega_{0}^{i}=1$. Given the definition of the certainty equivalent, this simplifies to

$$
\left(a_{0}^{i}+\frac{1-\alpha}{\alpha} q_{0} k_{0}\right)\left(c_{0}^{i}\right)^{-1}=\frac{\beta^{i}}{1-\beta^{i}}
$$

as in (S.31). The remainder of the proof proceeds as in the baseline environment.

\section{Proposition A.1}

Proof. Assuming that $\frac{d c_{1}^{i}}{d m_{0}}$ is continuous in $\sigma$, it is equivalent to characterize $\frac{d c_{1}^{i}}{d m_{0}}$ and then evaluate its limit at the deterministic steady-state $(\sigma=0)$ or simply compute $\frac{d \bar{c}_{1}^{i}}{d \bar{m}_{0}}$ at this limit. It is expositionally simpler to do the latter, so we do that here.

Re-consider households' micro-level optimization problem (16) given $\sigma=0$ :

$$
\begin{array}{r}
\max \left(\left(1-\beta^{i}\right)\left(\bar{c}_{0}^{i} \Phi^{i}\left(\bar{\ell}_{0}^{i}\right)\right)^{1-\frac{1}{\psi^{i}}}+\beta^{i}\left(\bar{c}_{1}^{i}\right)^{1-\frac{1}{\psi^{i}}}\right)^{\frac{1}{1-\frac{1}{\psi^{i}}}} \text { s.t. } \\
\bar{c}_{0}^{i}+\bar{a}_{0}^{i}=\bar{y}_{0}^{i}\left(\bar{w}_{0} \bar{\ell}_{0}^{i}, \bar{P}_{0}, \bar{\pi}_{0}, \bar{q}_{0}\right), \\
\bar{c}_{1}^{i}=\bar{w}_{1}+\left(1+\bar{r}_{1}\right) \bar{a}_{0}^{i},
\end{array}
$$


defining policy functions

$$
\bar{c}_{1}^{i}\left(\bar{y}_{0}^{i}\left(\bar{w}_{0} \bar{\ell}_{0}^{i}, \bar{P}_{0}, \bar{\pi}_{0}, \bar{q}_{0}\right), \bar{\ell}_{0}^{i}, 1+\bar{r}_{1}, \bar{w}_{1}\right)
$$

where recall that

$$
\bar{y}_{0}^{i}\left(\bar{w}_{0} \bar{\ell}_{0}^{i}, \bar{P}_{0}, \bar{\pi}_{0}, \bar{q}_{0}\right)=\bar{w}_{0} \bar{\ell}_{0}^{i}+\frac{1}{\bar{P}_{0}}\left(1+i_{-1}\right) B_{-1}^{i}+\left(\bar{\pi}_{0}+\left(1-\delta_{0}\right) \bar{q}_{0}\right) k_{-1}^{i}
$$

It follows that

$$
\begin{aligned}
\frac{d \bar{c}_{1}^{i}}{d \bar{m}_{0}}=\frac{\partial \bar{c}_{1}^{i}}{\partial \bar{y}_{0}^{i}}\left[-\frac{1}{\bar{P}_{0}} B_{-1}^{i} \frac{1}{\bar{P}_{0}} \frac{d \bar{P}_{0}}{d \bar{m}_{0}}+k_{-1}^{i}\right. & \left.\left(\frac{d \bar{\pi}_{0}}{d \bar{m}_{0}}+\left(1-\delta_{0}\right) \frac{d \bar{q}_{0}}{d \bar{m}_{0}}\right)+\frac{d \bar{w}_{0} \bar{\ell}_{0}^{i}}{d m_{0}}\right] \\
& +\frac{\partial \bar{c}_{1}^{i}}{\partial \bar{\ell}_{0}^{i}} \frac{d \bar{\ell}_{0}^{i}}{d \bar{m}_{0}}+\frac{\partial \bar{c}_{1}^{i}}{\partial\left(1+\bar{r}_{1}\right)} \frac{d \bar{r}_{1}}{d \bar{m}_{0}}+\frac{\partial \bar{c}_{1}^{i}}{\partial \bar{w}_{1}} \frac{d \bar{w}_{1}}{d \bar{m}_{0}}
\end{aligned}
$$

where each of the partial derivatives is evaluated with respect to the policy function above. We now characterize each of these partial derivatives in turn.

First note that it is clearly the case that

$$
\frac{\partial \bar{c}_{1}^{i}}{\partial \bar{w}_{1}}=\frac{1}{1+\bar{r}_{1}} \frac{\partial \bar{c}_{1}^{i}}{\partial \bar{y}_{0}^{i}} .
$$

Then define the expenditure minimization problem dual to the utility maximization problem above

$$
\begin{array}{r}
\min \bar{c}_{0}^{i, h}+\bar{a}_{0}^{i, h} \text { s.t. } \\
\left(\left(1-\beta^{i}\right)\left(\bar{c}_{0}^{i, h} \Phi^{i}\left(\bar{\ell}_{0}^{i, h}\right)\right)^{1-\frac{1}{\psi^{i}}}+\beta^{i}\left(\bar{c}_{1}^{i, h}\right)^{1-\frac{1}{\psi^{i}}}\right)^{\frac{1}{1-\frac{1}{\psi^{i}}}} \geq \bar{u}^{i} \\
\bar{c}_{1}^{i, h}=\bar{w}_{1}+\left(1+\bar{r}_{1}\right) \bar{a}_{0}^{i, h},
\end{array}
$$

where we use $h$ superscripts to denote compensated (Hicksian) policies. Letting

$$
\bar{e}_{0}^{i}\left(\bar{u}^{i}, \bar{\ell}_{0}^{i}, 1+\bar{r}_{1}, \bar{w}_{1}\right)
$$

denote the level of period 0 expenditure solving this problem, duality implies

$$
\bar{c}_{1}^{i}\left(\bar{e}_{0}^{i}\left(\bar{u}^{i}, \bar{\ell}_{0}^{i}, 1+\bar{r}_{1}, \bar{w}_{1}\right), \bar{\ell}_{0}^{i}, 1+\bar{r}_{1}, \bar{w}_{1}\right)=\bar{c}_{1}^{i, h}\left(\bar{u}^{i}, \bar{\ell}_{0}^{i}, 1+\bar{r}_{1}, \bar{w}_{1}\right) .
$$


This leads to Slutsky identities

$$
\begin{aligned}
\frac{\partial \bar{c}_{1}^{i}}{\partial \bar{\ell}_{0}^{i}} & =\frac{\partial \bar{c}_{1}^{i, h}}{\partial \bar{\ell}_{0}^{i}}-\frac{\partial \bar{c}_{1}^{i}}{\partial \bar{y}_{0}^{i}} \frac{\partial \bar{e}_{0}^{i}}{\partial \bar{\ell}_{0}^{i}}, \\
\frac{\partial \bar{c}_{1}^{i}}{\partial\left(1+\bar{r}_{1}\right)} & =\frac{\partial \bar{c}_{1}^{i, h}}{\partial\left(1+\bar{r}_{1}\right)}-\frac{\partial \bar{c}_{1}^{i}}{\partial \bar{y}_{0}^{i}} \frac{\partial \bar{e}_{0}^{i}}{\partial\left(1+\bar{r}_{1}\right)} .
\end{aligned}
$$

By the Envelope Theorem,

$$
\begin{aligned}
\frac{\partial \bar{e}_{0}^{i}}{\partial \bar{\ell}_{0}^{i}} & =-\bar{c}_{0}^{i, h} \frac{\Phi^{i^{\prime}}\left(\bar{l}_{0}^{i}\right)}{\Phi^{i}\left(\bar{l}_{0}^{i}\right)}, \\
\frac{\partial \bar{e}_{0}^{i}}{\partial\left(1+\bar{r}_{1}\right)} & =-\frac{1}{1+\bar{r}_{1}} \bar{a}_{0}^{i, h},
\end{aligned}
$$

so that we may further write the above identities as

$$
\begin{aligned}
\frac{\partial \bar{c}_{1}^{i}}{\partial \bar{\ell}_{0}^{i}} & =\frac{\partial \bar{c}_{1}^{i, h}}{\partial \bar{\ell}_{0}^{i}}+\frac{\partial \bar{c}_{1}^{i}}{\partial \bar{y}_{0}^{i}}\left(\bar{c}_{0}^{i, h} \frac{\Phi^{i^{\prime}}\left(\bar{l}_{0}^{i}\right)}{\Phi^{i}\left(\bar{l}_{0}^{i}\right)}\right), \\
\frac{\partial \bar{c}_{1}^{i}}{\partial\left(1+\bar{r}_{1}\right)} & =\frac{\partial \bar{c}_{1}^{i, h}}{\partial\left(1+\bar{r}_{1}\right)}+\frac{\partial \bar{c}_{1}^{i}}{\partial \bar{y}_{0}^{i}} \frac{1}{1+\bar{r}_{1}} \bar{a}_{0}^{i, h} .
\end{aligned}
$$

Substituting the above results into (S.35), using $\bar{c}_{0}^{i, h}=\bar{c}_{0}^{i}$ and $\bar{a}_{0}^{i, h}=\bar{a}_{0}^{i}$ implied by duality, and collecting terms, we obtain

$$
\begin{aligned}
\frac{d \bar{c}_{1}^{i}}{d \bar{m}_{0}}=\frac{\partial \bar{c}_{1}^{i}}{\partial \bar{y}_{0}^{i}}[ & -\frac{1}{\bar{P}_{0}} B_{-1}^{i} \frac{1}{\bar{P}_{0}} \frac{d \bar{P}_{0}}{d \bar{m}_{0}}+k_{-1}^{i}\left(\frac{d \bar{\pi}_{0}}{d \bar{m}_{0}}+\left(1-\delta_{0}\right) \frac{d \bar{q}_{0}}{d \bar{m}_{0}}\right)+\frac{d \bar{w}_{0} \bar{\ell}_{0}^{i}}{d \bar{m}_{0}}+\frac{1}{1+\bar{r}_{1}} \frac{d \bar{w}_{1}}{d \bar{m}_{0}} \\
& \left.+\frac{1}{1+\bar{r}_{1}} \bar{a}_{0}^{i} \frac{d \bar{r}_{1}}{d \bar{m}_{0}}+\bar{c}_{0}^{i} \frac{\Phi^{i^{\prime}}\left(\bar{l}_{0}^{i}\right)}{\Phi^{i}\left(\bar{l}_{0}^{i}\right)} \frac{d \bar{\ell}_{0}^{i}}{d \bar{m}_{0}}\right]+\frac{\partial \bar{c}_{1}^{i, h}}{\partial \bar{l}_{0}^{i}} \frac{d \bar{l}_{0}^{i}}{d \bar{m}_{0}}+\frac{\partial \bar{c}_{1}^{i, h}}{\partial\left(1+\bar{r}_{1}\right)} \frac{d \bar{r}_{1}}{d \bar{m}_{0}} .
\end{aligned}
$$

We next characterize the compensated derivatives $\frac{\partial \bar{c}_{1}^{i, h}}{\partial l_{0}^{i}}$ and $\frac{\partial \bar{c}_{1}^{i, h}}{\partial\left(1+\bar{r}_{1}\right)}$. The compensated policies solve the system

$$
\begin{gathered}
\left(1-\beta^{i}\right)\left(\Phi^{i}\left(\bar{l}_{0}^{i}\right)\right)^{1-\frac{1}{\psi^{i}}}\left(\bar{c}_{0}^{i, h}\right)^{-\frac{1}{\psi^{i}}}=\beta^{i}\left(\bar{c}_{1}^{i, h}\right)^{-\frac{1}{\psi^{i}}}\left(1+\bar{r}_{1}\right) \\
\left(\left(1-\beta^{i}\right)\left(\bar{c}_{0}^{i, h} \Phi^{i}\left(\bar{\ell}_{0}^{i, h}\right)\right)^{1-\frac{1}{\psi^{i}}}+\beta^{i}\left(\bar{c}_{1}^{i, h}\right)^{1-\frac{1}{\psi^{i}}}\right)^{\frac{1}{1-\frac{1}{\psi^{i}}}}=\bar{u}^{i} \\
\bar{c}_{1}^{i, h}=\bar{w}_{1}+\left(1+\bar{r}_{1}\right) \bar{a}_{0}^{i, h}
\end{gathered}
$$


Straightforward differentiation of this system yields

$$
\begin{aligned}
& \frac{\partial \bar{c}_{1}^{i, h}}{\partial \bar{l}_{0}^{i}}=\frac{-\frac{\Phi^{i^{\prime}}\left(\bar{l}_{0}^{i}\right)}{\Phi^{i}\left(l_{0}^{2}\right)}}{\frac{1}{\psi^{i}} \frac{1}{\bar{c}_{0}^{i, h}} \frac{1}{1+\bar{r}_{1}}+\frac{1}{\psi^{i}} \frac{1}{\bar{c}_{1}^{i, h}}}, \\
& \frac{\partial \bar{c}_{1}^{i, h}}{\partial \bar{r}_{0}}=\frac{\frac{1}{1+\bar{r}_{1}}}{\frac{1}{\psi^{i}} \frac{1}{\bar{c}_{0}^{i, h}} \frac{1}{1+\bar{r}_{1}}+\frac{1}{\psi^{i}} \frac{1}{\bar{c}_{1}^{i, h}}} .
\end{aligned}
$$

Differentiating the system defining uncompensated policies

$$
\begin{gathered}
\left(1-\beta^{i}\right)\left(\Phi^{i}\left(\bar{l}_{0}^{i}\right)\right)^{1-\frac{1}{\psi^{i}}}\left(\bar{c}_{0}^{i, h}\right)^{-\frac{1}{\psi^{i}}}=\beta^{i}\left(\bar{c}_{1}^{i, h}\right)^{-\frac{1}{\psi^{i}}}\left(1+\bar{r}_{1}\right), \\
\bar{c}_{0}^{i}+\bar{a}_{0}^{i}=\bar{y}_{0}^{i} \\
\bar{c}_{1}^{i}=\bar{w}_{1}+\left(1+\bar{r}_{1}\right) \bar{a}_{0}^{i},
\end{gathered}
$$

implies that

$$
\frac{\partial \bar{c}_{1}^{i}}{\partial \bar{y}_{0}^{i}}=\frac{\frac{1}{\psi^{i}} \frac{1}{\bar{c}_{0}^{i}}}{\frac{1}{\psi^{i}} \frac{1}{\bar{c}_{0}^{i}} \frac{1}{1+\bar{r}_{1}}+\frac{1}{\psi^{i}} \frac{1}{\bar{c}_{1}^{i}}} .
$$

Hence, making use of duality $\left(\bar{c}_{0}^{i}=\bar{c}_{0}^{i, h}\right.$ and so on), we can more succinctly write

$$
\begin{aligned}
\frac{\partial \bar{c}_{1}^{i, h}}{\partial \bar{l}_{0}^{i}} & =\frac{\partial \bar{c}_{1}^{i}}{\partial \bar{y}_{0}^{i}}\left(-\psi^{i} \bar{c}_{0}^{i} \frac{\Phi^{i^{\prime}}\left(\bar{l}_{0}^{i}\right)}{\Phi^{i}\left(\bar{l}_{0}^{i}\right)}\right), \\
\frac{\partial \bar{c}_{1}^{i, h}}{\partial \bar{r}_{0}} & =\frac{\partial \bar{c}_{1}^{i}}{\partial \bar{y}_{0}^{i}}\left(\psi^{i} \bar{c}_{0}^{i} \frac{1}{1+\bar{r}_{1}}\right) .
\end{aligned}
$$

Combining the prior results and using

$$
\frac{\partial \bar{c}_{1}^{i}}{\partial \bar{y}_{0}^{i}}=\left(1+\bar{r}_{0}\right) \frac{\partial \bar{a}_{0}^{i}}{\partial \bar{y}_{0}^{i}}
$$

and the definition of the static labor wedge in this environment

$$
\bar{\tau}^{\ell_{0}^{i}}=1-\frac{-\bar{c}_{0}^{i} \Phi^{i^{\prime}}\left(\bar{l}_{0}^{i}\right) / \Phi^{i}\left(\bar{l}_{0}^{i}\right)}{\bar{w}_{0}}
$$

yields the stated result in the claim. 


\section{Corollary A.1}

Proof. First consider the case of a household $i$ facing a binding leverage constraint or rule-of-thumb $(i \in C)$. If the household maintains

$$
q_{0} k_{0}^{i}=\omega_{0}^{i} a_{0}^{i}
$$

in response to a marginal change in income, clearly

$$
q_{0} \frac{\partial k_{0}^{i}}{\partial y_{0}^{i}}=\omega_{0}^{i} \frac{\partial a_{0}^{i}}{\partial y_{0}^{i}}
$$

and so

$$
m p r_{0}^{i} \equiv \frac{q_{0} \frac{\partial k_{0}^{i}}{\partial y_{0}^{i}}}{\frac{\partial a_{0}^{i}}{\partial y_{0}^{i}}}=\omega_{0}^{i} .
$$

Provided the household remains constrained in the limit of zero aggregate risk, it follows that

$$
\begin{gathered}
\frac{\bar{q}_{0} \bar{k}_{0}^{i}}{\bar{a}_{0}^{i}}=\omega_{0}^{i}, \\
\overline{m p r}_{0}^{i}=\omega_{0}^{i} .
\end{gathered}
$$

Now consider a household $i$ at an interior optimum in portfolio choice $(i \notin C)$. Optimal portfolio choice remains

$$
\mathbb{E}_{0}\left(c_{1}^{i}\right)^{-\gamma^{i}}\left(r_{1}^{k}-r_{1}\right)=0
$$

As in the proof of Propositions 1 and 2, we successively consider higher-order approximations and repeatedly make use of the method of undetermined coefficients and market clearing.

The first- and second-order approximations imply (S.1) as in the proof of Proposition 1. As before,

$$
\delta_{z_{1}}^{c_{1}^{i}}=\frac{\bar{w}_{1}+\bar{\pi}_{1} \bar{k}_{0}^{i}}{\bar{c}_{1}^{i}} .
$$

Multiplying both sides of (S.1) by $\frac{\bar{c}_{1}^{i}}{\gamma^{i}}$ but now integrating only over households $i^{\prime} \notin C$ 
and dividing by $\int_{i \notin C}\left[\bar{w}_{1}+\bar{\pi}_{1} \bar{k}_{0}^{i}\right] d i$ yields

$$
\mathbb{E}_{0} \hat{r}_{1}^{k}-\hat{r}_{1}+\frac{1}{2} \mathbb{E}_{0} \sigma^{2}=\gamma \sigma^{2}+o\left(\|\cdot\|^{3}\right)
$$

for $\gamma$ as defined in the claim, noting that

$$
\frac{\int_{i \notin C}\left[\bar{w}_{1}+\bar{\pi}_{1} \bar{k}_{0}^{i}\right] d i}{\int_{i \notin C} \bar{c}_{1}^{i} d i}=1-\frac{\int_{i \notin C}\left(1+\bar{r}_{1}\right) \bar{b}_{1}^{i} d i}{\int_{i \notin C} \bar{c}_{1}^{i} d i} .
$$

Moreover, by (S.1) we obtain (S.2) for $i \notin C$. It follows then that, as in the proof of Proposition 1, we obtain

$$
\begin{aligned}
\frac{\bar{q}_{0} \bar{k}_{0}^{i}}{\bar{a}_{0}^{i}} & =\left(\frac{\bar{c}_{1}^{i}}{\left(1+\bar{r}_{1}\right) \bar{a}_{0}^{i}}\right) \frac{\gamma}{\gamma^{i}}-\frac{\bar{w}_{1}}{\left(1+\bar{r}_{1}\right) \bar{a}_{0}^{i}}, \\
\overline{m p r}_{0}^{i} & =\frac{\gamma}{\gamma^{i}}
\end{aligned}
$$

for $i \notin C$.

A third-order approximation implies (S.6) as in the proof of Proposition 2. Using the same steps outlined therein yields (S.7). Multiplying both sides by $\frac{\bar{c}_{1}^{i}}{\gamma^{i}}$ but now again integrating only over households $i \notin C$ and dividing by $\int_{i \notin C}\left[\bar{w}_{1}+\bar{\pi}_{1} \bar{k}_{0}^{i}\right] d i$ yields

$$
\mathbb{E}_{0} \hat{r}_{1}^{k}-\hat{r}_{0}+\frac{1}{2} \sigma^{2}=\gamma \sigma^{2}+\frac{\gamma}{\int_{i \notin C}\left[\bar{w}_{1}+\bar{\pi}_{1} \bar{k}_{0}^{i}\right] d i}\left(\int_{i \notin C} \bar{c}_{1}^{i} \delta_{m_{0} z_{1}}^{c_{1}^{i}} d i\right) \hat{m}_{0} \sigma^{2}+o\left(\|\cdot\|^{4}\right)
$$

By the period 1 resource constraint and equilibrium wages and profits, we again obtain 
(S.8). Integrating again only over households $i \notin C$ yields

$$
\begin{aligned}
\int_{i \notin C} \bar{c}_{1}^{i} \delta_{m_{0} z_{1}}^{c_{1}^{i}} d i= & -\int_{i \notin C} \bar{c}_{1}^{i} \delta_{m_{0}}^{c_{1}^{i}} \delta_{z_{1}}^{c_{1}^{i}} d i+\int_{i \notin C}\left[\alpha \bar{w}_{1} \delta_{m_{0}}^{k_{0}}+\bar{\pi}_{1} \delta_{m_{0}}^{k_{0}^{i}}-(1-\alpha) \bar{\pi}_{1} \bar{k}_{0}^{i} \delta_{m_{0}}^{k_{0}}\right] d i \\
= & \int_{i \notin C} \bar{c}_{1}^{i} \delta_{m_{0}}^{c_{1}^{i}}\left(1-\delta_{z_{1}}^{c_{1}^{i}}\right) d i+ \\
& \int_{i \notin C}\left[\alpha \bar{w}_{1} \delta_{m_{0}}^{k_{0}}+\bar{\pi}_{1} \delta_{m_{0}}^{k_{0}^{i}}-(1-\alpha) \bar{\pi}_{1} \bar{k}_{0}^{i} \delta_{m_{0}}^{k_{0}}-\bar{c}_{1}^{i} \delta_{m_{0}}^{c_{1}^{i}}\right] d i \\
= & \int_{i \notin C} \bar{c}_{1}^{i} \delta_{m_{0}}^{c_{1}^{i}}\left(1-\delta_{z_{1}}^{c_{1}^{i}}\right) d i+ \\
& \int_{i \notin C}\left[\alpha \bar{w}_{1} \delta_{m_{0}}^{k_{0}}+\bar{\pi}_{1} \delta_{m_{0}}^{k_{0}^{i}}-(1-\alpha) \bar{\pi}_{1} \bar{k}_{0}^{i} \delta_{m_{0}}^{k_{0}}-\right. \\
= & \int_{i \notin C} \bar{c}_{1}^{i} \delta_{m_{0}}^{c_{1}^{i}}\left(1-\delta_{z_{1}}^{c_{1}^{i}}\right) d i-\int_{i \notin C}\left[\left(1+\bar{r}_{1}\right) \delta_{m_{0}}^{b_{0}^{i}}+\bar{b}_{0}^{i} \delta_{m_{0}}^{r_{1}}\right] d i \\
= & \int_{i \notin C} \bar{c}_{1}^{i} \delta_{m_{0}}^{c_{1}^{i}}\left(1-\delta_{z_{1}}^{c_{1}}\right) d i+\int_{i \in C}\left[\left(1+\bar{r}_{1}\right) \delta_{m_{0}}^{b_{0}^{i}}+\bar{b}_{0}^{i} \delta_{m_{0}}^{r_{1}}\right] d i \\
= & \left.\int_{i \notin C} \bar{c}_{1}^{i} \delta_{m_{0}}^{c_{1}^{i}}\left(1-\delta_{z_{1}}^{c_{1}^{i}}\right) d i+\int_{i \in C}\left[\left(1+\bar{r}_{1}\right) \delta_{m_{0}}^{a_{0}^{i}}+\bar{a}_{0}^{i} \delta_{m_{0}}^{r_{1}}\right]\left(1-\bar{b}_{0}^{i} \delta_{m_{0}}^{r_{1}}+\bar{\pi}_{1} \delta_{m_{0}}^{k_{0}^{i}}-(1-\alpha) \bar{\pi}_{1} \bar{k}_{0}^{i} \delta_{m_{0}}^{k_{0}}\right)\right] d i
\end{aligned}
$$

where the third equality substitutes in for $\bar{c}_{1}^{i} \delta_{m_{0}}^{c_{1}^{i}}$ implied by the period 1 resource constraint and equilibrium wages and profits; the fifth equality uses bond market clearing $\int_{0}^{1} b_{0}^{i} d i=0$ both at the point of approximation and up to first order; and the final equality uses $b_{0}^{i}=\left(1-\omega_{0}^{i}\right) a_{0}^{i}$ both at the point of approximation and up to first order among constrained households. Using (S.2) and the expression for $\gamma$ as defined in the claim, then note that

$$
\begin{aligned}
& \int_{i \notin C} \bar{c}_{1}^{i} \delta_{m_{0}}^{c_{1}^{i}}\left(1-\delta_{z_{1}}^{c_{1}^{i}}\right) d i= \\
& \int_{i \notin C}\left(\bar{c}_{1}^{i} \delta_{m_{0}}^{c_{1}^{i}}-\frac{\bar{c}_{1}^{i}}{\int_{0}^{1} \bar{c}_{1}^{i^{\prime}} d i^{\prime}} \int_{0}^{1} \bar{c}_{1}^{i^{\prime}} \delta_{m_{0}}^{c_{1}^{\prime}} d i^{\prime}\right)\left(1-\frac{\gamma}{\gamma^{i}}\right)+ \\
&\left(\int_{0}^{1} \bar{c}_{1}^{i^{\prime}} \delta_{m_{0}}^{c_{1}^{\prime}} d i^{\prime}\right)\left(\frac{\int_{i^{\prime} \notin C} \bar{c}_{1}^{i^{\prime}} d i^{\prime}}{\int_{0}^{1} \bar{c}_{1}^{i^{\prime}} d i^{\prime}}-\frac{\int_{i^{\prime} \notin C}\left[\bar{w}_{1}+\bar{\pi}_{1} \bar{k}_{0}^{i^{\prime}}\right] d i^{\prime}}{\int_{0}^{1} \bar{c}_{1}^{i^{\prime}} d i^{\prime}}\right) .
\end{aligned}
$$


Furthermore,

$$
\begin{aligned}
& \int_{i \in C}\left[\left(1+\bar{r}_{1}\right) \delta_{m_{0}}^{a_{0}^{i}}+\bar{a}_{0}^{i} \delta_{m_{0}}^{r_{1}}\right]\left(1-\omega_{0}^{i}\right) d i= \\
& \int_{i \in C}\left[\left(1+\bar{r}_{1}\right) \delta_{m_{0}}^{a_{0}^{i}}+\bar{a}_{0}^{i} \delta_{m_{0}}^{r_{1}}-\frac{\left(1+\bar{r}_{1}\right) \bar{a}_{0}^{i}}{\int_{0}^{1} \bar{c}_{1}^{i^{\prime}} d i^{\prime}} \int_{0}^{1} \bar{c}_{1}^{i^{\prime}} \delta_{m_{0}}^{i_{1}^{\prime}} d i^{\prime}\right]\left(1-\omega_{0}^{i}\right)+ \\
&\left(\int_{0}^{1} \bar{c}_{1}^{i^{\prime}} \delta_{m_{0}}^{i_{1}^{\prime}} d i^{\prime}\right)\left(\frac{\left(1+\bar{r}_{1}\right) \int_{i^{\prime} \in C} \bar{a}_{0}^{i^{\prime}}\left(1-\omega_{0}^{i^{\prime}}\right) d i^{\prime}}{\int_{0}^{1} \bar{c}_{1}^{i^{\prime}} d i^{\prime}}\right) .
\end{aligned}
$$

Since bond market clearing implies

$$
\frac{\int_{i^{\prime} \notin C} \bar{c}_{1}^{i^{\prime}} d i^{\prime}}{\int_{0}^{1} \bar{c}_{1}^{i^{\prime}} d i^{\prime}}-\frac{\int_{i^{\prime} \notin C}\left[\bar{w}_{1}+\bar{\pi}_{1} \bar{k}_{0}^{i^{\prime}}\right] d i^{\prime}}{\int_{0}^{1} \bar{c}_{1}^{i^{\prime}} d i^{\prime}}+\frac{\left(1+\bar{r}_{1}\right) \int_{i^{\prime} \in C} \bar{a}_{0}^{i^{\prime}}\left(1-\omega_{0}^{i^{\prime}}\right) d i^{\prime}}{\int_{0}^{1} \bar{c}_{1}^{i^{\prime}} d i^{\prime}}=0,
$$

it follows that

$$
\begin{aligned}
& \int_{i \notin C} \bar{c}_{1}^{i} \delta_{m_{0}}^{c_{1}^{i}}\left(1-\delta_{z_{1}}^{c_{1}^{i}}\right) d i \int_{i \in C}\left[\left(1+\bar{r}_{1}\right) \delta_{m_{0}}^{a_{0}^{i}}+\bar{a}_{0}^{i} \delta_{m_{0}}^{r_{1}}\right]\left(1-\omega_{0}^{i}\right) d i= \\
& \int_{i \notin C}\left(\bar{c}_{1}^{i} \delta_{m_{0}}^{c_{1}^{i}}-\frac{\bar{c}_{1}^{i}}{\int_{0}^{1} \bar{c}_{1}^{i^{\prime}} d i^{\prime}} \int_{0}^{1} \bar{c}_{1}^{i^{\prime}} \delta_{m_{0}}^{c_{1}^{i^{\prime}}} d i^{\prime}\right)\left(1-\frac{\gamma}{\gamma^{i}}\right)+ \\
& \int_{i \in C}\left[\left(1+\bar{r}_{1}\right) \delta_{m_{0}}^{a_{0}^{i}}+\bar{a}_{0}^{i} \delta_{m_{0}}^{r_{1}}-\frac{\left(1+\bar{r}_{1}\right) \bar{a}_{0}^{i}}{\int_{0}^{1} \bar{c}_{1}^{i^{\prime}} d i^{\prime}} \int_{0}^{1} \bar{c}_{1}^{i^{\prime}} \delta_{m_{0}}^{c^{i^{\prime}}} d i^{\prime}\right]\left(1-\omega_{0}^{i}\right) .
\end{aligned}
$$

Furthermore note that using the definition of $\gamma$ given in the claim and bond market clearing,

$$
\begin{aligned}
1 & =\int_{i \notin C} \frac{\bar{c}_{1}^{i}}{\int_{i^{\prime} \notin C} \bar{c}_{1}^{i^{\prime}} d i^{\prime}+\int_{i^{\prime} \in C}\left(1+\bar{r}_{1}\right) \bar{a}_{0}^{i^{\prime}} d i^{\prime}} \overline{m p r}{ }_{0}^{i} d i+\int_{i \in C} \frac{\left(1+\bar{r}_{1}\right) \bar{a}_{0}^{i}}{\int_{i^{\prime} \notin C} \bar{c}_{1}^{i^{\prime}} d i^{\prime}+\int_{i^{\prime} \in C}\left(1+\bar{r}_{1}\right) \bar{a}_{0}^{i^{\prime}} d i^{\prime}} \overline{m p r}{ }_{0}^{i} d i, \\
& =\overline{m p r}_{0} .
\end{aligned}
$$

Finally, since

$$
\begin{aligned}
& \frac{\overline{d\left[c_{1}^{i} / \int_{0}^{1} c_{1}^{i^{\prime}}\right]}}{d m_{0}}=\frac{1}{\int_{0}^{1} \bar{c}_{1}^{i^{\prime}} d i^{\prime}}\left(\overline{\frac{d c_{1}^{i}}{d m_{0}}}-\frac{\bar{c}_{1}^{i}}{\int_{0}^{1} \bar{c}_{1}^{i^{\prime}} d i^{\prime}} \int_{0}^{1} \overline{\frac{d c_{1}^{i^{\prime}}}{d m_{0}}} d i^{\prime}\right), \\
& =\frac{1}{\int_{0}^{1} \bar{c}_{1}^{i^{\prime}} d i^{\prime}}\left(\bar{c}_{1}^{i} \delta_{m_{0}}^{c_{1}^{i}}-\frac{\bar{c}_{1}^{i}}{\int_{0}^{1} \bar{c}_{1}^{i^{\prime}} d i^{\prime}} \int_{0}^{1} \bar{c}_{1}^{i^{\prime}} \delta_{m_{0}}^{i_{1}^{\prime}} d i^{\prime}\right)
\end{aligned}
$$


and

$$
\begin{aligned}
\overline{\frac{d\left[\left(1+r_{1}\right) a_{0}^{i} / \int_{0}^{1} c_{1}^{\left.i^{\prime}\right]}\right]}{d m_{0}}} & =\frac{1}{\int_{0}^{1} \bar{c}_{1}^{i^{\prime}} d i^{\prime}}\left(\overline{\frac{d\left(1+r_{1}\right) a_{0}^{i}}{d m_{0}}}-\frac{\left(1+r_{1}\right) a_{0}^{i}}{\int_{0}^{1} \bar{c}_{1}^{i^{\prime}} d i^{\prime}} \int_{0}^{1} \overline{\frac{d c_{1}^{i^{\prime}}}{d m_{0}}} d i^{\prime}\right) \\
& =\frac{1}{\int_{0}^{1} \bar{c}_{1}^{i^{\prime}} d i^{\prime}}\left(\left(1+\bar{r}_{1}\right) \delta_{m_{0}}^{a_{i}^{i}}+\bar{a}_{0}^{i} \delta_{m_{0}}^{r_{1}}-\frac{\left(1+\bar{r}_{1}\right) \bar{a}_{0}^{i}}{\int_{0}^{1} \bar{c}_{1}^{i^{\prime}} d i^{\prime}} \int_{0}^{1} \bar{c}_{1}^{i^{\prime}} \delta_{m_{0}}^{c_{1}^{\prime}} d i^{\prime}\right)
\end{aligned}
$$

we can combine all of the previous results to write

$\frac{\gamma}{\int_{i \notin C}\left[\bar{w}_{1}+\bar{\pi}_{1} \bar{k}_{0}^{i}\right] d i}\left(\int_{i \notin C} \bar{c}_{1}^{i} \delta_{m_{0} z_{1}}^{c_{1}^{i}} d i\right)=\gamma \frac{\int_{0}^{1} \bar{c}_{1}^{i} d i}{\int_{i \notin C}\left[\bar{w}_{1}+\bar{\pi}_{1} \bar{k}_{0}^{i}\right] d i} \int_{0}^{1} \bar{\xi}_{m_{0}}^{i}\left(\overline{m p r}_{0}-\overline{m p r}_{0}^{i}\right) d i$

for $\bar{\xi}_{m_{0}}^{i}=\overline{\frac{\overline{d\left[c_{1}^{i} / \int_{0}^{1} c_{1}^{i^{\prime}}\right]}}{d m_{0}}}$ for $i \notin C$ and $\bar{\xi}_{m_{0}}^{i}=\frac{\overline{d\left[\left(1+r_{1}\right) a_{0}^{i} / \int_{0}^{1} c_{1}^{i^{\prime}}\right]}}{d m_{0}}$ for $i \in C$. Again noting that

$$
\frac{\int_{0}^{1} \bar{c}_{1}^{i} d i}{\int_{i \notin C}\left[\bar{w}_{1}+\bar{\pi}_{1} \bar{k}_{0}^{i}\right] d i}=\left(1-\frac{\int_{i \notin C}\left(1+\bar{r}_{1}\right) \bar{b}_{0}^{i} d i}{\int_{i \notin C} \bar{c}_{1}^{i} d i}\right)^{-1} \frac{\int_{0}^{1} \bar{c}_{1}^{i} d i}{\int_{i \notin C} \bar{c}_{1}^{i} d i} .
$$

yields the expression for $\zeta_{m_{0}}$ given in the claim.

\section{Corollary A.2}

Proof. The period 1 consumption of each household $i$ is now

$$
c_{1}^{i}=w_{1} \epsilon_{1}^{i}+\left(1+r_{1}\right) b_{0}^{i}+\pi_{1} \epsilon_{1}^{i} k_{0}^{i},
$$

where the real wage and real profits per unit of capital remain

$$
\begin{aligned}
& w_{1}=(1-\alpha) z_{1} k_{0}^{\alpha}, \\
& \pi_{1}=\alpha z_{1} k_{0}^{\alpha-1}
\end{aligned}
$$

since, by the law of large numbers, the aggregate efficiency units of labor supplied remains 1 and aggregate capital among households of type $i$ remains $k_{0}^{i}{ }^{2}$ Define the

\footnotetext{
${ }^{2}$ Recall that we are assuming a double continuum of households now, where the continuum of households of type $i$ are each subject to a distinct shock $\epsilon_{1}^{i}$ which is $i i d$ within and across $i$.
} 
capital return facing each household $i$

$$
1+r_{1}^{k, i} \equiv \frac{\pi_{1} \epsilon_{1}^{i}}{q_{0}}
$$

distinct from the return on capital aggregating over idiosyncratic risk

$$
1+r_{1}^{k} \equiv \frac{\pi_{1}}{q_{0}}
$$

Then household $i$ 's optimal portfolio choice is now

$$
\mathbb{E}_{0}\left(c_{1}^{i}\right)^{-\gamma^{i}}\left(r_{1}^{k, i}-r_{1}\right)=0 .
$$

Using approximations up to first and second order as in the proof of Proposition 1 yields the analog to (S.1) in this environment,

$$
\mathbb{E}_{0} \hat{r}_{1}^{k, i}-\hat{r}_{1}+\frac{1}{2}\left(1+\eta^{i}\right) \sigma^{2}=\gamma^{i}\left(\delta_{z_{1}}^{c_{1}^{i}}+\eta^{i} \delta_{\epsilon_{1}^{i}}^{c_{1}^{i}}\right) \sigma^{2}+o\left(\|\cdot\|^{3}\right) .
$$

Given the definitions of the idiosyncratic and aggregate capital returns,

$$
\hat{r}_{1}^{k, i}=\hat{\epsilon}_{1}^{i}+\hat{r}_{1}^{k}
$$

By assumption,

$$
\mathbb{E}_{0} \hat{\epsilon}_{1}^{i}=-\frac{1}{2} \eta^{i} \sigma^{2}
$$

It follows that

$$
\mathbb{E}_{0} \hat{r}_{1}^{k, i}=-\frac{1}{2} \eta^{i} \sigma^{2}+\mathbb{E}_{0} \hat{r}_{1}^{k},
$$

so that (S.37) implies for the aggregate capital claim

$$
\mathbb{E}_{0} \hat{r}_{1}^{k}-\hat{r}_{1}+\frac{1}{2} \sigma^{2}=\gamma^{i}\left(\delta_{z_{1}}^{c_{1}^{i}}+\eta^{i} \delta_{\epsilon_{1}^{i}}^{c_{1}^{i}}\right) \sigma^{2}+o\left(\|\cdot\|^{3}\right) .
$$

By the period 1 resource constraint and equilibrium wages and profits,

$$
\delta_{z_{1}}^{c_{1}^{i}}=\frac{\bar{w}_{1}+\bar{\pi}_{1} \bar{k}_{0}^{i}}{\bar{c}_{1}^{i}}
$$


as in the baseline environment and

$$
\delta_{\epsilon_{1}^{i}}^{c_{1}^{i}}=\frac{\bar{w}_{1}+\bar{\pi}_{1} \bar{k}_{0}^{i}}{\bar{c}_{1}^{i}}=\delta_{z_{1}}^{c_{1}^{i}} .
$$

Hence, (S.38) implies

$$
\mathbb{E}_{0} \hat{r}_{1}^{k}-\hat{r}_{1}+\frac{1}{2} \sigma^{2}=\gamma^{i}\left(1+\eta^{i}\right) \delta_{z_{1}}^{c_{1}^{i}} \sigma^{2}+o\left(\|\cdot\|^{3}\right) .
$$

Multiplying both sides by $\frac{\bar{c}_{1}^{i}}{\gamma^{2}\left(1+\eta^{2}\right)}$, integrating over all households $i$, and making use of the market clearing conditions, we obtain

$$
\mathbb{E}_{0} \hat{r}_{1}^{k}-\hat{r}_{1}+\frac{1}{2} \sigma^{2}=\gamma \sigma^{2}+o\left(\|\cdot\|^{3}\right)
$$

for $\gamma$ as defined in the claim. Furthermore, it follows from (S.39) that we generalize (S.2) to

$$
\delta_{z_{1}}^{c_{1}^{i}}=\frac{\gamma}{\gamma^{i}\left(1+\eta^{i}\right)}
$$

which implies

$$
\frac{\bar{w}_{1}+\bar{\pi}_{1} \bar{k}_{0}^{i}}{\bar{c}_{1}^{i}}=\frac{\gamma}{\gamma^{i}\left(1+\eta^{i}\right)}
$$

and thus the expression for $\frac{\bar{q}_{0} \bar{k}_{0}^{i}}{\bar{a}_{0}^{i}}$ given in the claim.

Differentiating each household's optimality conditions and resource constraints generalizes (S.3) to

$$
0=\mathbb{E}_{0} m_{0,1}^{i} \frac{\gamma^{i}}{c_{1}^{i}}\left(r_{1}^{k, i}-r_{1}\right)\left(\left(1+r_{1}\right) \frac{\partial b_{0}^{i}}{\partial y_{0}^{i}}+\pi_{1} \epsilon_{1}^{i} \frac{\partial k_{0}^{i}}{\partial y_{0}^{i}}\right)
$$

A second-order approximation then generalizes (S.4) to

$$
\begin{gathered}
0=\left(\left(1+\bar{r}_{1}\right) \frac{\overline{\partial b_{0}^{i}}}{\partial y_{0}^{i}}+\bar{\pi}_{1} \frac{\overline{\partial k_{0}^{i}}}{\partial y_{0}^{i}}\right)\left(\mathbb{E}_{0} \hat{r}_{1}^{k, i}-\hat{r}_{1}+\frac{1}{2}\left(1+\eta^{i}\right) \sigma^{2}\right) \\
-\left(\left(1+\bar{r}_{1}\right) \frac{\overline{\partial b_{0}^{i}}}{\partial y_{0}^{i}}+\bar{\pi}_{1} \frac{\overline{\partial k_{0}^{i}}}{\partial y_{0}^{i}}\right) \frac{\gamma^{i}+1}{\bar{c}_{1}^{i}}\left(\bar{w}_{1}+\bar{\pi}_{1} \bar{k}_{0}^{i}\right)\left(1+\eta^{i}\right) \sigma^{2}+\bar{\pi}_{1} \frac{\overline{\partial k_{0}^{i}}}{\partial y_{0}^{i}}\left(1+\eta^{i}\right) \sigma^{2}+o\left(\|\cdot\|^{3}\right) .
\end{gathered}
$$


Using the above results, this implies

$$
\bar{q}_{0} \frac{\overline{\partial k_{0}^{i}}}{\partial y_{0}^{i}}=\frac{\gamma}{\gamma^{i}\left(1+\eta^{i}\right)} \frac{\overline{\partial a_{0}^{i}}}{\partial y_{0}^{i}},
$$

from which the expression for $\overline{m p r}_{0}^{i}$ in the claim follows.

Finally, optimal portfolio choice up to third order, the above results, and steps analogous to those used in the proof of Proposition 2 yields the analog of (S.7)

$$
\mathbb{E}_{0} \hat{r}_{1}^{k}-\hat{r}_{1}+\frac{1}{2} \sigma^{2}=\gamma^{i}\left(\delta_{z_{1}}^{c_{1}^{i}}+\delta_{\epsilon_{1}^{i}}^{c_{1}^{i}} \eta^{i}\right) \sigma^{2}+\gamma^{i}\left(\delta_{m_{0} z_{1}}^{c_{1}^{i}}+\delta_{m_{0} \epsilon_{1}^{i}}^{c^{i}} \eta^{i}\right) \hat{m}_{0} \sigma^{2}+o\left(\|\cdot\|^{4}\right) .
$$

A second order expansion of the period 1 resource constraint implies

$$
\begin{aligned}
\bar{c}_{1}^{i} \delta_{m_{0} z_{1}}^{c_{1}}+\bar{c}_{1}^{i} \delta_{m_{0}}^{c_{1}^{i}} \delta_{z_{1}}^{c_{1}^{i}} & =\alpha \bar{w}_{1} \delta_{m_{0}}^{k_{0}}+\bar{\pi}_{1} \delta_{m_{0}}^{k_{0}^{i}}-(1-\alpha) \bar{\pi}_{1} \bar{k}_{0}^{i} \delta_{m_{0}}^{k_{0}} \\
& =\bar{c}_{1}^{i} \delta_{m_{0} \epsilon_{1}^{i}}^{c_{i}^{i}}+\bar{c}_{1}^{i} \delta_{m_{0}}^{c_{1}^{i}} \delta_{\epsilon_{1}^{i}}^{c_{i}^{i}}
\end{aligned}
$$

from which we can conclude

$$
\delta_{m_{0} z_{1}}^{c_{1}^{i}}=\delta_{m_{0} \epsilon_{1}^{i}}^{c^{i}}
$$

since $\delta_{\epsilon_{1}^{i}}^{c_{1}^{i}}=\delta_{z_{1}}^{c_{1}^{i}}$ as argued above. It follows from (S.40) that

$$
\mathbb{E}_{0} \hat{r}_{1}^{k}-\hat{r}_{1}+\frac{1}{2} \sigma^{2}=\gamma^{i}\left(1+\eta^{i}\right) \delta_{z_{1}}^{c_{1}^{i}} \sigma^{2}+\gamma^{i}\left(1+\eta^{i}\right) \delta_{m_{0} z_{1}}^{c_{1}^{i}} \hat{m}_{0} \sigma^{2}+o\left(\|\cdot\|^{4}\right) .
$$

Then multiplying both sides by $\frac{\bar{c}_{1}^{i}}{\gamma^{i}\left(1+\eta^{i}\right)}$, integrating over all households $i$, and making use of the market clearing conditions, we obtain

$$
\mathbb{E}_{0} \hat{r}_{1}^{k}-\hat{r}_{1}+\frac{1}{2} \sigma^{2}=\gamma \sigma^{2}+\frac{\gamma}{\int_{0}^{1} \bar{c}_{1}^{i} d i}\left(\int_{0}^{1} \bar{c}_{1}^{i} \delta_{m_{0} z_{1}}^{c_{1}^{i}} d i\right) \hat{m}_{0} \sigma^{2}+o\left(\|\cdot\|^{4}\right) .
$$

Then following similar steps as in the proof of Proposition 2, using

$$
\delta_{z_{1}}^{c_{1}^{i}}=\frac{\gamma}{\gamma^{i}\left(1+\eta^{i}\right)}=\overline{m p r}_{0}^{i}
$$

implied by the above results, yields the expression for $\zeta_{m_{0}}$ given in the claim. 


\section{Corollary A.3}

Proof. Denote with $\mathbb{E}_{0}^{i}$ the expectation under household $i$ 's subjective beliefs, and $\mathbb{E}_{0}$ that under the objective (true) probability distribution. Household $i$ 's optimal portfolio choice is then characterized by

$$
\mathbb{E}_{0}^{i}\left(c_{1}^{i}\right)^{-\gamma^{i}}\left(r_{1}^{k}-r_{1}\right)=0
$$

Using approximations up to first and second order as in the proof of Proposition 1 yields the analog to (S.1) in this environment,

$$
\mathbb{E}_{0}^{i} \hat{r}_{1}^{k}-\hat{r}_{1}+\frac{1}{2} \varsigma^{i} \sigma^{2}=\gamma^{i} \delta_{z_{1}}^{c_{1}^{i}} \varsigma^{i} \sigma^{2}+o\left(\|\cdot\|^{3}\right)
$$

By the definition of returns,

$$
\hat{r}_{1}^{k}=\hat{z}_{1}+(\alpha-1) \hat{k}_{0}-\hat{q}_{0}
$$

where there is no uncertainty over $\hat{k}_{0}$ or $\hat{q}_{0}$ as of period 0 . Hence,

$$
\mathbb{E}_{0}^{i} \hat{r}_{1}^{k}+\frac{1}{2} \varsigma^{i} \sigma^{2}=\mathbb{E}_{0} \hat{r}_{1}^{k}+\frac{1}{2} \sigma^{2}
$$

Hence, (S.41) implies

$$
\mathbb{E}_{0} \hat{r}_{1}^{k}-\hat{r}_{1}+\frac{1}{2} \sigma^{2}=\gamma^{i} \delta_{z_{1}}^{c_{1}^{i}} \varsigma^{i} \sigma^{2}+o\left(\|\cdot\|^{3}\right)
$$

By the period 1 resource constraint and equilibrium wages and profits,

$$
\delta_{z_{1}}^{c_{1}^{i}}=\frac{\bar{w}_{1}+\bar{\pi}_{1} \bar{k}_{0}^{i}}{\bar{c}_{1}^{i}}
$$

as in the baseline environment. Multiplying both sides by $\frac{\bar{c}_{1}^{i}}{\gamma^{i} \varsigma^{i}}$, integrating over all households $i$, and making use of the market clearing conditions, we obtain

$$
\mathbb{E}_{0} \hat{r}_{1}^{k}-\hat{r}_{1}+\frac{1}{2} \sigma^{2}=\gamma \sigma^{2}+o\left(\|\cdot\|^{3}\right)
$$


for $\gamma$ as defined in the claim. Furthermore, it follows from (S.42) that we generalize (S.2) to

$$
\delta_{z_{1}}^{c_{1}^{i}}=\frac{\gamma}{\gamma^{i} \varsigma^{i}}
$$

which implies

$$
\frac{\bar{w}_{1}+\bar{\pi}_{1} \bar{k}_{0}^{i}}{\bar{c}_{1}^{i}}=\frac{\gamma}{\gamma^{i} \varsigma^{i}}
$$

and thus the expression for $\frac{\bar{q}_{0} \bar{k}_{0}^{i}}{\bar{a}_{0}^{i}}$ given in the claim.

Differentiating each household's optimality conditions and resource constraints generalizes (S.3) to

$$
0=\mathbb{E}_{0}^{i} m_{0,1}^{i} \frac{\gamma^{i}}{c_{1}^{i}}\left(r_{1}^{k}-r_{1}\right)\left(\left(1+r_{1}\right) \frac{\partial b_{0}^{i}}{\partial y_{0}^{i}}+\pi_{1} \frac{\partial k_{0}^{i}}{\partial y_{0}^{i}}\right)
$$

A second-order approximation then generalizes (S.4) to

$$
\begin{aligned}
0= & \left.\left(1+\bar{r}_{1}\right) \frac{\overline{\partial b_{0}^{i}}}{\partial y_{0}^{i}}+\bar{\pi}_{1} \frac{\overline{\partial k_{0}^{i}}}{\partial y_{0}^{i}}\right)\left(\mathbb{E}_{0}^{i} \hat{r}_{1}^{k}-\hat{r}_{1}+\frac{1}{2} \varsigma^{i} \sigma^{2}\right) \\
& -\left(\left(1+\bar{r}_{1}\right) \frac{\overline{\partial b_{0}^{i}}}{\partial y_{0}^{i}}+\bar{\pi}_{1} \frac{\overline{\partial k_{0}^{i}}}{\partial y_{0}^{i}}\right) \frac{\gamma^{i}+1}{\bar{c}_{1}^{i}}\left(\bar{w}_{1}+\bar{\pi}_{1} \bar{k}_{0}^{i}\right) \varsigma^{i} \sigma^{2}+\bar{\pi}_{1} \frac{\overline{\partial k_{0}^{i}}}{\partial y_{0}^{i}} \varsigma^{i} \sigma^{2}+o\left(\|\cdot\|^{3}\right) .
\end{aligned}
$$

Using the above results, this implies

$$
\bar{q}_{0} \frac{\overline{\partial k_{0}^{i}}}{\partial y_{0}^{i}}=\frac{\gamma}{\gamma^{i} \varsigma^{i}} \frac{\overline{\partial a_{0}^{i}}}{\partial y_{0}^{i}}
$$

from which the expression for $\overline{m p r}_{0}^{i}$ in the claim follows.

Finally, optimal portfolio choice up to third order, the above results, and steps analogous to those used in the proof of Proposition 2 yields the analog of (S.7)

$$
\mathbb{E}_{0} \hat{r}_{1}^{k}-\hat{r}_{1}+\frac{1}{2} \sigma^{2}=\gamma^{i} \delta_{z_{1}}^{c_{1}^{i}} \varsigma^{i} \sigma^{2}+\gamma^{i} \delta_{m_{0} z_{1}}^{c_{1}^{i}} \varsigma^{i} \hat{m}_{0} \sigma^{2}+o\left(\|\cdot\|^{4}\right)
$$

Multiplying both sides by $\frac{\bar{c}_{1}^{i}}{\gamma^{i} \varsigma^{i}}$, integrating over all households $i$, and making use of the market clearing conditions, we obtain

$$
\mathbb{E}_{0} \hat{r}_{1}^{k}-\hat{r}_{1}+\frac{1}{2} \sigma^{2}=\gamma \sigma^{2}+\frac{\gamma}{\int_{0}^{1} \bar{c}_{1}^{i} d i}\left(\int_{0}^{1} \bar{c}_{1}^{i} \delta_{m_{0} z_{1}}^{c_{1}^{i}} d i\right) \hat{m}_{0} \sigma^{2}+o\left(\|\cdot\|^{4}\right)
$$


Then following similar steps as in the proof of Proposition 2, using

$$
\delta_{z_{1}}^{c_{1}^{i}}=\frac{\gamma}{\gamma^{i} \varsigma^{i}}=\overline{m p r}_{0}^{i}
$$

implied by the above results, yields the expression for $\zeta_{m_{0}}$ given in the claim.

\section{B Solution algorithm in infinite horizon}

In this section we characterize our solution algorithm for the infinite horizon environment studied in section 3 and described in further detail in appendix C.

\section{B.1 First-order conditions}

We first outline households' and firms' optimality conditions.

Households Defining the realized real interest rate and real return on capital

$$
\begin{aligned}
1+r_{t+1} & \equiv\left(1+i_{t}\right) \frac{P_{t}}{P_{t+1}}, \\
1+r_{t+1}^{k} & =\equiv \frac{\left(\Pi_{t+1}+(1-\delta) Q_{t+1}\right) \exp \left(\varphi_{t+1}\right)}{Q_{t}} \frac{P_{t}}{P_{t+1}}
\end{aligned}
$$

the representative household $i$ 's optimal consumption and savings decisions are characterized by

$$
\begin{aligned}
1 & =\mathbb{E}_{t} m_{t, t+1}^{i}\left(1+r_{t+1}\right), \\
1-\kappa_{t}^{i} & =\mathbb{E}_{t} m_{t, t+1}^{i}\left(1+r_{t+1}^{k}\right), \\
\kappa_{t}^{i}\left(k_{t}^{i}-\underline{k} z_{t}\right) & =0, \\
k_{t}^{i} & \geq \underline{k} z_{t}, \\
\kappa_{t}^{i} & \geq 0,
\end{aligned}
$$

given the real stochastic discount factor

$$
m_{t, t+1}^{i}=\beta\left(c e_{t}^{i}\right)^{\gamma^{i}-1 / \psi}\left(v_{t+1}^{i}\right)^{1 / \psi-\gamma^{i}} \frac{\left(c_{t+1}^{i}\right)^{-\frac{1}{\psi}} \Phi\left(\ell_{t+1}\right)^{1-\frac{1}{\psi}}}{\left(c_{t}^{i}\right)^{-\frac{1}{\psi}} \Phi\left(\ell_{t}\right)^{1-\frac{1}{\psi}}},
$$


certainty equivalent $c e_{t}^{i}=\mathbb{E}_{t}\left[\left(v_{t+1}^{i}\right)^{1-\gamma^{i}}\right]^{\frac{1}{1-\gamma^{i}}}$, and multiplier on the constraint (29) $\kappa_{t}^{i} Q_{t}$.

Unions Defining the real wage $w_{t} \equiv \frac{W_{t}}{P_{t}}$, the representative union sets

$$
\begin{aligned}
\sum_{i} \lambda^{i}\left(v_{t}^{i}\right)^{\frac{1}{\psi}}\left(c_{t}^{i}\right)^{-\frac{1}{\psi}}\left[w_{t}+c_{t}^{i} \frac{\Phi^{\prime}\left(\ell_{t}\right)}{\Phi\left(\ell_{t}\right)}\right. & \\
& +w_{t} \frac{\chi^{W}}{\epsilon}\left[\frac{w_{t}}{w_{t-1} \exp \left(\varphi_{t}\right)} \frac{P_{t}}{P_{t-1}}\left(\frac{w_{t}}{w_{t-1} \exp \left(\varphi_{t}\right)} \frac{P_{t}}{P_{t-1}}-1\right)\right. \\
& \left.\left.-\mathbb{E}_{t} m_{t, t+1}^{i}\left(\frac{w_{t+1}}{w_{t} \exp \left(\varphi_{t+1}\right)}\right)^{2} \frac{P_{t+1}}{P_{t}} \frac{\ell_{t+1}}{\ell_{t}}\left(\frac{w_{t+1}}{w_{t} \exp \left(\varphi_{t+1}\right)} \frac{P_{t+1}}{P_{t}}-1\right)\right]\right]=0
\end{aligned}
$$

Producers Defining the real price of capital $q_{t} \equiv \frac{Q_{t}}{P_{t}}$, the representative producer follows

$$
\begin{aligned}
w_{t} & =(1-\alpha) z_{t}^{1-\alpha} \ell_{t}^{-\alpha}\left(k_{t-1} \exp \left(\varphi_{t}\right)\right)^{\alpha}, \\
q_{t} & =\left(\frac{k_{t}}{k_{t-1} \exp \left(\varphi_{t}\right)}\right)^{\chi^{x}} .
\end{aligned}
$$

\section{B.2 Re-scaled economy}

We now characterize the equilibrium conditions of an equivalent, stationary economy obtained by dividing households' resource constraints and market clearing conditions by the price level $P_{t}$, and further scaling these conditions as well as the first-order conditions in the prior subsection by $z_{t}$. We denote real variables in lower-case (except for the nominal rate $i_{t}$ ) and further defined the re-scaled variables

$$
\begin{gathered}
\tilde{c}_{t}^{i} \equiv \frac{c_{t}^{i}}{z_{t}}, \quad \tilde{c} e_{t}^{i} \equiv \frac{c e_{t}^{i}}{z_{t}}, \quad \tilde{b}_{t}^{i} \equiv \frac{b_{t}^{i}+\nu^{i} b^{g}}{z_{t}}, \quad \tilde{k}_{t}^{i} \equiv \frac{k_{t}^{i}}{z_{t}}, \quad \tilde{k}_{t} \equiv \frac{k_{t}}{z_{t}}, \quad \tilde{w}_{t} \equiv \frac{w_{t}}{z_{t}} \\
\tilde{m}_{t, t+1}^{i} \equiv m_{t, t+1}^{i}\left(\frac{z_{t+1}}{z_{t}}\right)^{-\gamma}, \\
\tilde{k}_{t-1}^{i} \equiv \frac{k_{t-1}^{i}}{\exp \left(\sigma \epsilon_{t}^{z}\right)}, \quad \tilde{k}_{t-1} \equiv \frac{k_{t-1}}{\exp \left(\sigma \epsilon_{t}^{z}\right)}, \quad \tilde{w}_{t-1} \equiv \frac{w_{t-1}}{\exp \left(\sigma \epsilon_{t}^{z}\right)} .
\end{gathered}
$$

We note that $\tilde{b}_{t}^{i}$ is the productivity-adjusted bond position of household $i$ accounting for the implicit position that household also has through the government. 
Then the household's optimality conditions and constraints are equivalent to:

$$
\begin{aligned}
& 1=\mathbb{E}_{t} \tilde{m}_{t, t+1}^{i} \exp \left(\gamma^{i}\left[\sigma \epsilon_{t+1}^{z}+\varphi_{t+1}\right]\right)\left(1+r_{t+1}\right), \\
& 1-\kappa_{t}=\mathbb{E}_{t} \tilde{m}_{t, t+1}^{i} \exp \left(\gamma^{i}\left[\sigma \epsilon_{t+1}^{z}+\varphi_{t+1}\right]\right)\left(1+r_{t+1}^{k}\right), \\
& \kappa_{t}^{i}\left(\tilde{k}_{t}^{i}-\underline{k}\right)=0, \\
& \tilde{k}_{t}^{i} \geq \underline{k}, \\
& \kappa_{t}^{i} \geq 0, \\
& \tilde{m}_{t, t+1}^{i}=\beta\left(\tilde{c}_{t}^{i}\right)^{\gamma^{i}-1 / \psi}\left(\tilde{v}_{t+1}^{i}\right)^{1 / \psi-\gamma^{i}} \frac{\left(\tilde{c}_{t+1}^{i}\right)^{-\frac{1}{\psi}} \Phi\left(\ell_{t+1}\right)^{1-\frac{1}{\psi}}}{\left(\tilde{c}_{t}^{i}\right)^{-\frac{1}{\psi}} \Phi\left(\ell_{t}\right)^{1-\frac{1}{\psi}}}, \\
& \tilde{c}_{t}^{i}=\mathbb{E}_{t}\left[\exp \left(\left(1-\gamma^{i}\right)\left[\sigma \epsilon_{t+1}^{z}+\varphi_{t+1}\right]\right)\left(\tilde{v}_{t+1}^{i}\right)^{1-\gamma^{i}}\right]^{\frac{1}{1-\gamma^{i}}}, \\
& \tilde{c}_{t}^{i}+\tilde{b}_{t}^{i}+q_{t} \tilde{k}_{t}^{i}=\tilde{w}_{t} \ell_{t}^{i}+\tilde{n}_{t-1}^{i},
\end{aligned}
$$

where financial wealth inclusive of taxes and transfers, accounting for government budget balance, is

$$
\tilde{n}_{t-1}^{i}=\frac{1}{\lambda^{i}} s_{t}^{i}\left(\pi_{t}+(1-\delta) q_{t}\right) \tilde{k}_{t-1} .
$$

The representative union's optimality condition is equivalent to:

$$
\begin{aligned}
& \sum_{i} \lambda^{i}\left(\tilde{v}_{t}^{i}\right)^{\frac{1}{\psi}}\left(\tilde{c}_{t}^{i}\right)^{-\frac{1}{\psi}}\left[\tilde{w}_{t}+\tilde{c}_{t}^{i} \frac{\Phi^{\prime}\left(\ell_{t}\right)}{\Phi\left(\ell_{t}\right)}\right. \\
& +\tilde{w}_{t} \frac{\chi^{W}}{\epsilon}\left[\frac{\tilde{w}_{t}}{\tilde{w}_{t-1}} \frac{P_{t}}{P_{t-1}}\left(\frac{\tilde{w}_{t}}{\tilde{w}_{t-1}} \frac{P_{t}}{P_{t-1}}-1\right)\right. \\
& \left.\left.\quad-\mathbb{E}_{t} \tilde{m}_{t, t+1}^{i} \exp \left(\gamma^{i}\left[\sigma \epsilon_{t+1}^{z}+\varphi_{t+1}\right]\right)\left(\frac{\tilde{w}_{t+1}}{\tilde{w}_{t}}\right)^{2} \frac{P_{t+1}}{P_{t}} \frac{\ell_{t+1}}{\ell_{t}}\left(\frac{\tilde{w}_{t+1}}{\tilde{w}_{t}} \frac{P_{t+1}}{P_{t}}-1\right)\right]\right]=0 .
\end{aligned}
$$

The representative producer's optimality condition and flow of funds are equivalent 
to:

$$
\begin{aligned}
& \tilde{w}_{t}=(1-\alpha) \ell_{t}^{-\alpha} \tilde{k}_{t-1}^{\alpha}, \\
& q_{t}=\left(\frac{\tilde{k}_{t}}{\tilde{k}_{t-1}}\right)^{\chi^{x}} \\
& \pi_{t} \tilde{k}_{t-1}=\alpha \ell_{t}^{1-\alpha} \tilde{k}_{t-1}^{\alpha} .
\end{aligned}
$$

The specifications of fiscal and monetary policy imply:

$$
\begin{aligned}
& s_{t+1}^{i}=\lambda^{i}\left(1-\tau_{t+1}^{i}\right) \frac{\left(1+r_{t+1}\right) \tilde{b}_{t}+\left(\pi_{t+1}+(1-\delta) q_{t+1}\right) \tilde{k}_{t}^{i} \exp \left(\varphi_{t+1}\right)}{\left(\pi_{t+1}+(1-\delta) q_{t+1}\right) \tilde{k}_{t} \exp \left(\varphi_{t+1}\right)} \\
& 1+i_{t}=(1+\bar{i})\left(\frac{P_{t}}{P_{t-1}}\right)^{\phi} m_{t}
\end{aligned}
$$

The definitions of real returns remain:

$$
\begin{aligned}
1+r_{t+1} & \equiv\left(1+i_{t}\right) \frac{P_{t}}{P_{t+1}} \\
1+r_{t+1}^{k} & =\equiv \frac{\left(\pi_{t+1}+(1-\delta) q_{t+1}\right) \exp \left(\varphi_{t+1}\right)}{q_{t}}
\end{aligned}
$$

The market clearing conditions are equivalent to:

$$
\begin{aligned}
& \sum_{i} \lambda^{i} \tilde{c}_{t}^{i}+\left(\frac{\tilde{k}_{t}}{\tilde{k}_{t-1}}\right)^{\chi^{x}} \tilde{x}_{t}=\ell_{t}^{1-\alpha} \tilde{k}_{t-1}^{\alpha} \\
& \sum_{i} \lambda^{i} \tilde{k}_{t-1}^{i}=\tilde{k}_{t-1} \\
& (1-\delta) \sum_{i} \lambda^{i} \tilde{k}_{t-1}^{i}+\tilde{x}_{t}=\sum_{i} \lambda^{i} \tilde{k}_{t}^{i} \\
& \sum_{i} \lambda^{i} \tilde{b}_{t}^{i}=0
\end{aligned}
$$

Finally, the evolution of exogenous state variables is:

$$
\log m_{t+1}=\rho^{m} \log m_{t}+\sigma^{m} \epsilon_{t+1}^{m} .
$$

After solving this transformed economy, we can simulate prices and quantities in the original economy by reversing the re-scaling in (S.44)-(S.46), where $z_{t}$ follows (30) 
and $P_{t}$ follows $P_{t}=P_{-1} \prod_{t^{\prime}=0}^{t} \Pi_{t^{\prime}}^{P}$ where $\Pi_{t^{\prime}}^{P} \equiv \frac{P_{t^{\prime}}}{P_{t^{\prime}-1}}$.

\section{B.3 Global solution algorithm}

We now outline the computational algorithm used to solve the transformed economy.

Grids The model is solved over a discretized grid of aggregate states $S$. Each node is defined by the current monetary policy shock $m(S)$ and probability of disaster $p(S)$, the wealth shares $s^{a}(S)$ and $s^{c}(S)$ of groups $a$ and $c$, the scaled capital chosen in the previous period $\tilde{k}_{-1}(S)$ as chosen in the previous period, as well as the scaled real wage $\tilde{w}_{-1}(S)$ set in the previous period. In the transformed, stationary economy, productivity shocks inclusive of disasters only govern the transition across states. The grid over states is given by a mesh grid over vectors of each state variable. In each dimension except the two-state disaster probability $p(S)$ we choose a vector length of at least five nodes. We verify that the model solutions are robust to grid boundaries and size for the chosen values.

Expectations and interpolation When forming expectations, we use Gauss-Hermite quadrature for integration. Expectations over future states will typically not lie on the grid, and we use linear interpolation over aggregate states to find variable values for those states. The value functions of the representative household in each group are solved over a vector of individual wealth inclusive of transfers $n_{-1}^{i}$, so that households can entertain a range of portfolio and savings choices when optimizing. We use cubic splines to interpolate over the idiosyncratic wealth levels, which also enables us to calculate value function derivatives.

Solution algorithm We look for a stationary solution to the model and use backward iteration until all equilibrium objects converge. We assume that convergence is satisfactory when relative period-to-period changes are smaller than $10^{-6}$. For each state $S$, the solution objects are the price of capital $q(S)$, the nominal rate $i(S)$, the chosen real wage $w(S)$, the inflation rate $\Pi^{P}(S)$, labor supply $\ell(S)$, capital choices of each household group $k^{i}(S)$, real bond choices of each group $b^{i}(S)$, and the value functions of each group over a vector of wealth $v^{i}\left(n_{-1}^{i}, S\right)$.

The solution algorithm starts from an initial guess for $v^{i}\left(n_{-1}^{i}, S\right), q(S), i(S), w(S)$, $\Pi^{P}(S)$, and $\ell(S)$ and proceeds as follows. 
1. With this guess at hand we can solve each representative household's savings and portfolio choice problem (S.47)-(S.54) given its current wealth inclusive of transfers implied by (S.55), the interest rates implied by (S.59), (S.62), (S.63), and the evolution of state variables implied by (S.60), (S.65), and (S.68).

2. Observing the excess demand for bonds relative to the market clearing condition (S.67), we adjust $i(S)$ to lower the absolute value of the excess demand, returning to step 1, until excess bond demand relative to the aggregate capital stock is smaller than $10^{-12}$.

3. The resulting choice of individual capital holdings, together with the market clearing condition (S.65), allows us to update the price of capital $q(S)$ according to $(\mathrm{S} .58)$.

4. We use the union's first-order condition (S.56) to update the wage choice $w(S)$, given labor demand for the representative producer (S.57).

5. Given the equilibrium nominal rate, we use the Taylor rule (S.61) to update $\Pi^{P}(S)$.

6. Finally, we update the value functions $v^{i}\left(n_{-1}^{i}, S\right)$ by solving the optimization problem (S.47)-(S.54) of all representative households for wealth away from the current state.

7. Using the updated equilibrium objects, we define new guesses $v^{i}\left(n_{-1}^{i}, S\right), q(S)$, $i(S), w(S), \Pi^{P}(S)$, and $\ell(S)$ and return to step 1. For numerical stability we dampen the updating of most equilibrium objects.

At the end of the algorithm, $x(S)$ is implied by the capital accumulation condition (S.66), and goods market clearing (S.64) is satisfied by Walras' Law.

The solution code is written in Fortran and parallelized using OpenMP. Convergence can be achieved in less than one hour on a computing system with 16 cores.

\section{Supplemental quantitative results}

In this section we provide supplementary quantitative results accompanying section 3. 


\section{C.1 Model versus RANK without recalibrating $\epsilon_{0}^{m}$}

In the main text, we compared impulse responses to a monetary shock in our model to those of a counterfactual RANK economy where $\epsilon_{0}^{m}$ was re-calibrated to match the same initial $22 b p$ decline in the 1-year nominal yield. Here we instead compare impulse responses to the same monetary shock $\epsilon_{0}^{m}$. Figure S.1 summarizes the variables of interest. Notably, the 1-year nominal yield falls by much less in our model than in the representative agent economy - even on impact - owing to the endogenous tightening of monetary policy in response to the stimulative effects operating through the lower risk premium. For that reason, the impulse responses of quantities are little different between the model relative to RANK.

\section{C.2 Impulse responses to a productivity shock}

We now characterize the impulse responses to a productivity shock instead of a monetary shock. We compare in Figure S.2 the impulse responses of the model with heterogeneity to the RANK economy, with the same primitive one standard deviation shock in productivity.

The first row again reports the change in the 1-year nominal bond yield, expected real returns, and expected excess returns. The first panel demonstrates that the central bank following a standard Taylor rule will cut the nominal interest rate in response to the price deflation induced by this shock. The second and third panels demonstrate that the expected real interest rate and the expected excess returns on capital decline following the shock. The decline in the former is a standard real business cycle response to the shock and also reflects the endogenous monetary easing in this New Keynesian setting. The decline in the latter demonstrates that productivity shocks induce a countercylical risk premium.

The second and third rows demonstrate that redistribution drives the decline in the risk premium following the shock. The first panel of the second row demonstrates that, as in the case of a negative monetary policy shock, realized excess returns on capital are substantially positive on impact and followed by small negative returns in the quarters which follow. The substantially positive excess returns on impact endogenously redistribute to the high MPR $a$ households who hold levered claims on capital, evidenced in the financial wealth share of $a$ households in the second panel in this row. As described in appendix A, however, the mechanisms are more nuanced 

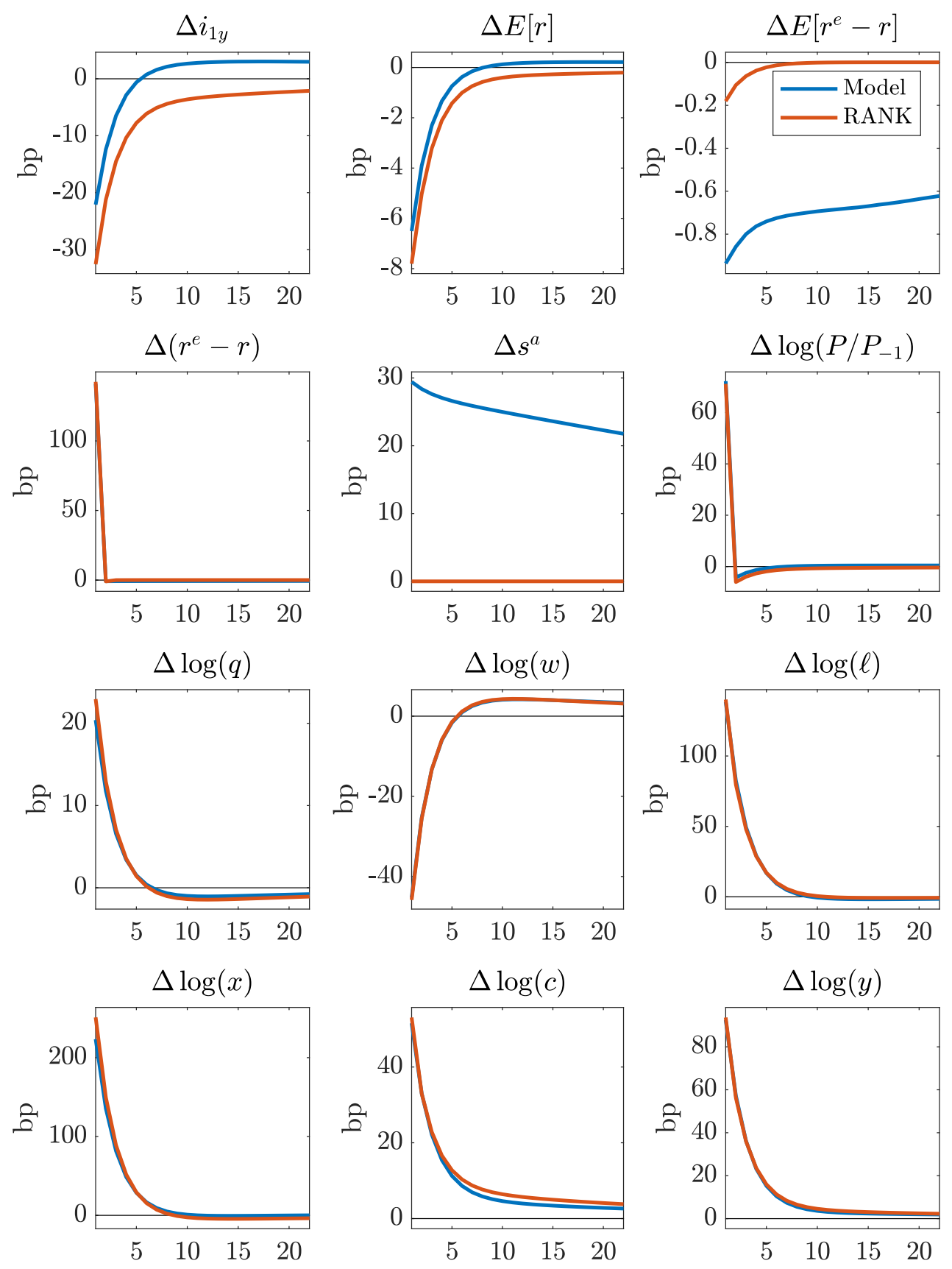

Figure S.1: effects of negative monetary policy shock without recalibrating $\epsilon_{0}^{m}$

Notes: series are quarterly (non-annualized) measures, except for the 1-year nominal bond yield $\Delta i_{1 y}$. Impulse responses are the average response (relative to no shock) starting at 1,000 different points drawn from the ergodic distribution of the state space, itself approximated using a sample path over 50,000 quarters after a burn-in period of 5,000 quarters. $b p$ denotes basis points $(0.01 \%)$. 

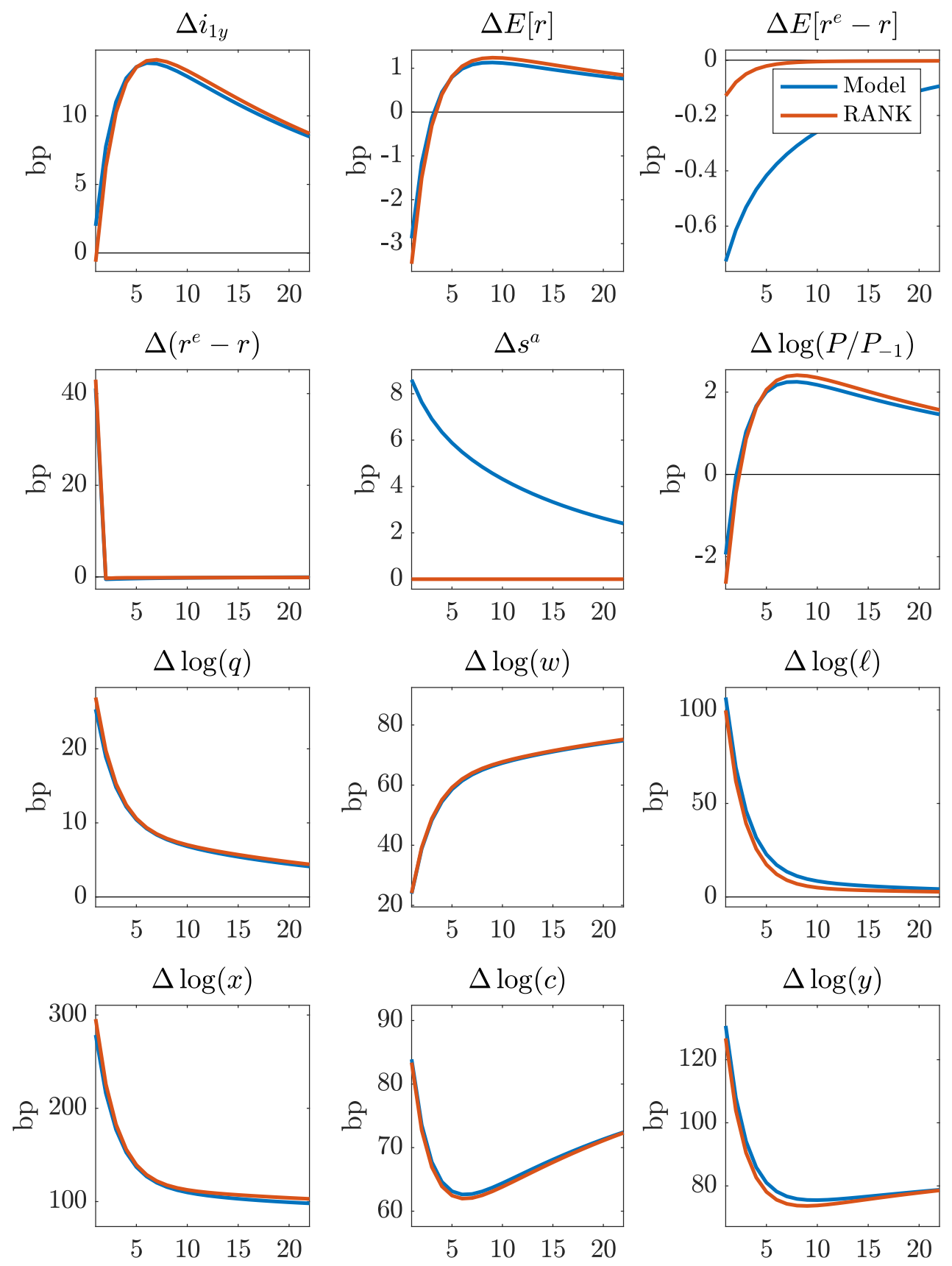

Figure S.2: impulse responses to positive productivity shock

Notes: series are quarterly (non-annualized) measures, except for the 1-year nominal bond yield $\Delta i_{1 y}$. Impulse responses are the average response (relative to no shock) starting at 1,000 different points drawn from the ergodic distribution of the state space, itself approximated using a sample path over 50,000 quarters after a burn-in period of 5,000 quarters. $b p$ denotes basis points $(0.01 \%)$. 
than in the case of a monetary shock. On the one hand, unexpected deflation raises the real interest rate, shown in the third panel. On the other hand, the increase in the price of capital raises the return on capital, shown in the first panel of the third row. The effect on profits reflects the competing effects of a higher real wage and higher employment. On balance, the return to capital increases and outweighs the higher realized real interest rate, and wealth redistributes to the high-MPR $a$ households, lowering the risk premium.

The fourth row examines the consequences for real transmission. Comparing the responses in the model to the RANK case, we find rather small differences in investment, consumption, and output. Consistent with the responses to the same monetary policy shock described in the last subsection, this arises from the endogenous tightening of monetary policy in the model in response to the stimulus from lower risk premia.

\section{C.3 Impulse responses to a disaster probability shock}

We now characterize the impulse responses to a shock to the disaster probability. We

consider a change in $p_{t}$ from $p-\frac{1}{2} \sigma^{p}$ to $p+\frac{1}{2} \sigma^{p}$. We again compare in Figure S.3 the impulse responses in the model with heterogeneity to the RANK economy.

The first row again reports the change in the expected returns. The first panel demonstrates that the central bank following a standard Taylor rule will cut the nominal interest rate in response to the price deflation induced by this shock. The second panel demonstrates that the expected real interest rate declines following the shock, reflecting the increase in precautionary saving associated with the increase in disaster probability. The third panel demonstrates that expected excess returns rise following the shock, reflecting both the persistent increase in the quantity of risk and transitory redistribution of wealth away from the relatively risk tolerant. The latter is absent in the RANK economy.

The second and third rows rationalize the dynamics of the wealth distribution in the model with heterogeneity. The first panel of the second row demonstrates that realized excess returns on capital are substantially negative on impact and positive in the quarters which follow. As with (contractionary) monetary and productivity shocks, the substantially negative excess returns on impact endogenously redistribute away from the high MPR a households who hold levered claims on capital. However, the substantially higher excess returns in the medium/long-term (as compensation for the higher quantity of risk) mean that a households recoup these losses and eventually 

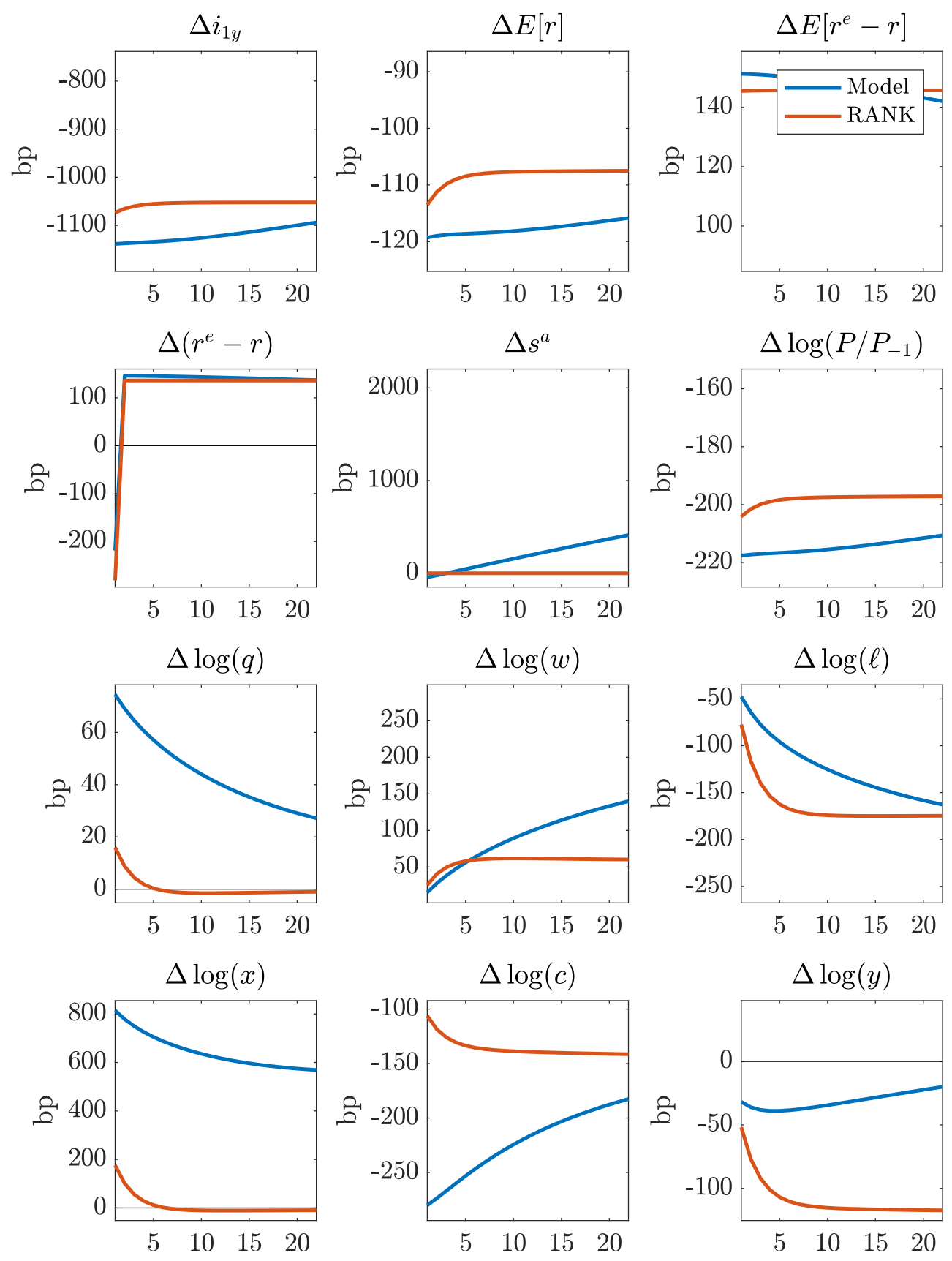

Figure S.3: impulse responses to disaster probability shock from $p-\frac{1}{2} \sigma^{p}$ to $p+\frac{1}{2} \sigma^{p}$

Notes: series are quarterly (non-annualized) measures, except for the 1-year nominal bond yield $\Delta i_{1 y}$. Impulse responses are the average response (relative to no shock) starting at 1,000 different points drawn from the ergodic distribution of the state space, itself approximated using a sample path over 50,000 quarters after a burn-in period of 5,000 quarters. $b p$ denotes basis points $(0.01 \%)$. 
hold a greater fraction of wealth than they did before the shock.

The fourth row summarizes the quantity effects of the increase in disaster risk. The increase in precautionary saving is associated with a large increase in investment but a large decrease in consumption. On balance, output falls despite the fact that the households' intertemporal elasticity of substitution is less than one. This is consistent with the effects of uncertainty shocks in New Keynesian environments as in Fernandez-Villaverde, Guerron-Quintana, Kuester, and Rubio-Ramirez (2015) and Basu and Bundick (2017). It is for this reason that the model-implied equity premium is countercyclical, as reported in the main text. As is evident, the model with heterogeneity features larger precautionary responses to the disaster shock, but the sign of the output response and thus the countercyclicality of the equity premium remain the same across models. ${ }^{3}$ What does affect the sign is the presence of nominal rigidity: with sufficiently low nominal wage rigidity (not shown), in both models the effect on output and thus the cyclicality of the equity premium are reversed.

\section{C.4 Ergodic distribution and sample path of $s^{a}$}

As discussed in the main text, the changes in the wealth share of relatively risk tolerant $a$ households $\left(s^{a}\right)$ plays a key role in determining the effects of monetary shocks. Here we provide the ergodic distribution of this variable as well as a sample path, in both cases conditional on the assumption of no disasters actually being realized. Figure S.4 depicts the ergodic distribution over 50,000 quarters simulated after a burn-in period of 5,000 quarters. Figure S.5 provides the sample path of the first 1,200 quarters after the burn-in period. As is evident, the lower frequency movements in the wealth distribution are much larger than the higher frequency movements, and these are driven by tiemvarying disaster risk. In blue, we highlight quarters in which the disaster probability is at its higher level. Consistent with the impulse responses in Figure S.3, these periods are associated with an initial reduction followed by sustained rise in the wealth share of $a$ households. The opposite is true when the disaster probability is at its lower level.

\footnotetext{
${ }^{3}$ We find that the precautionary responses are larger in the model with heterogeneity primarily because of the binding capital constraint on workers (29). The increase in disaster risk raises the riskiness of their capital claim. To reduce this capital claim as a share of their wealth, they save more and work more (the latter evident in the third row, last panel).
} 


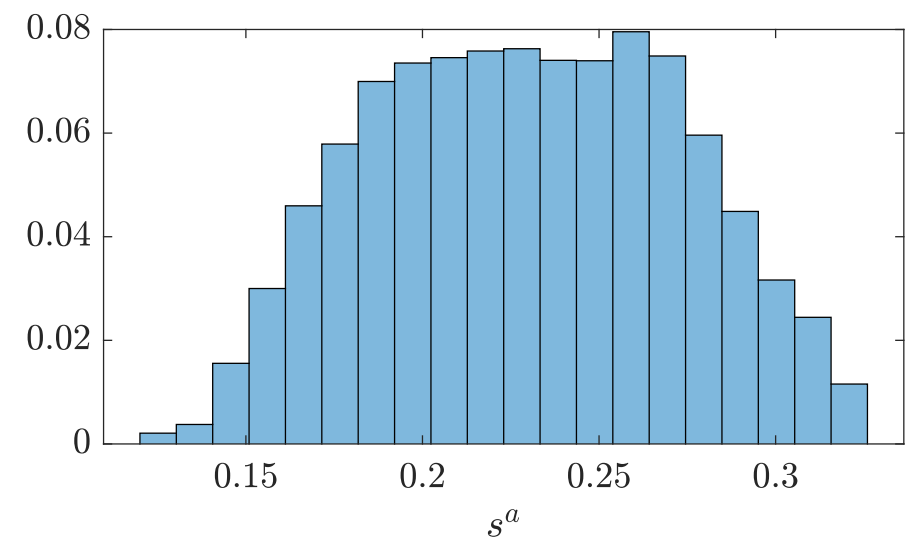

Figure S.4: ergodic distribution of wealth share of $a$ households

Notes: distribution estimated using a sample path over 50,000 quarters after a burn-in period of 5,000 quarters, with no disasters ever realized.
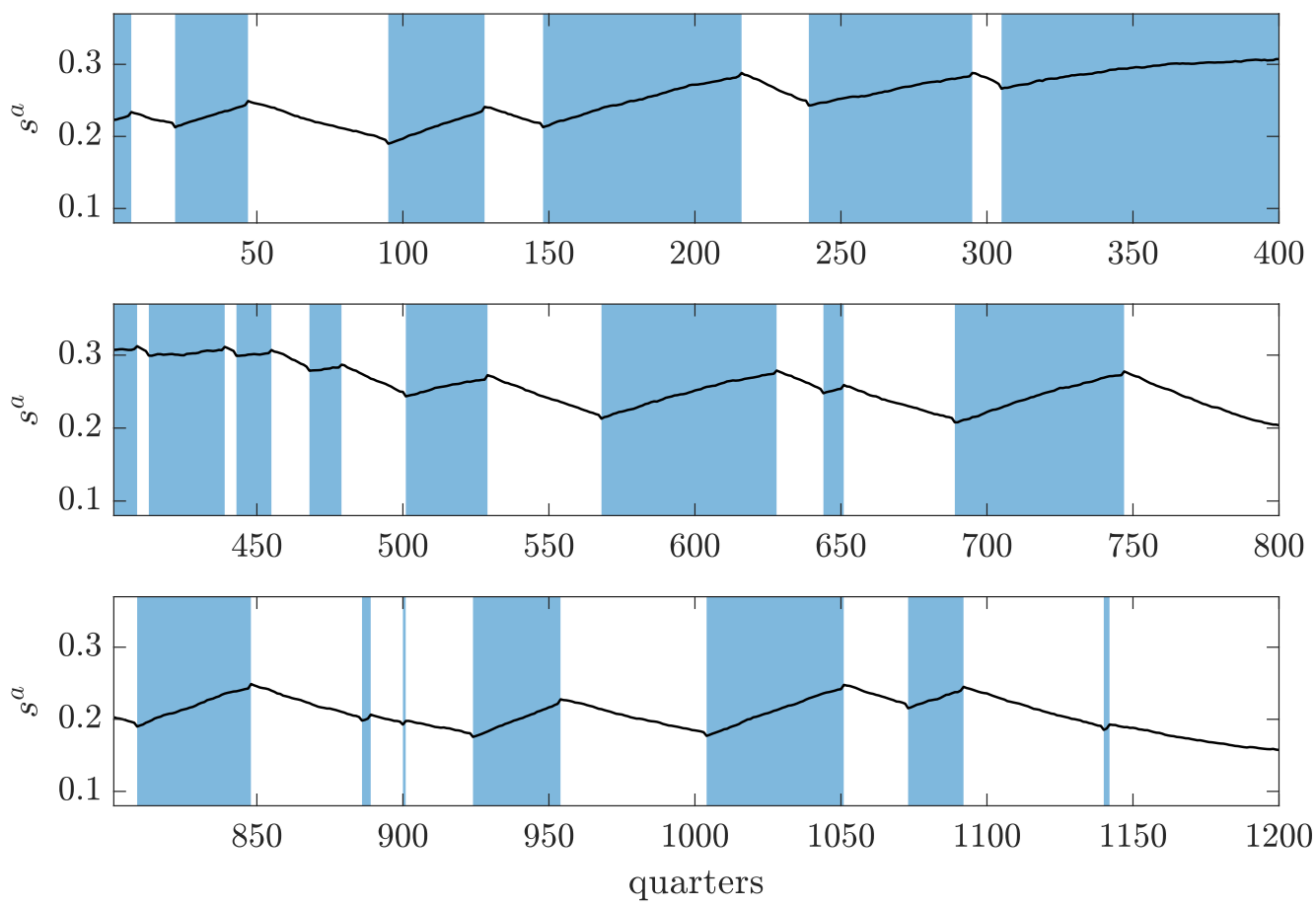

Figure S.5: sample path of wealth share of $a$ households

Notes: sample path shown after a burn-in period of 5,000 quarters, with no disasters ever realized. Highlighted areas denote quarters in which the disaster probability is at its higher level. 


\section{References}

BAsu, S. AND B. Bundick (2017): "Uncertainty shocks in a model of effective demand," Econometrica, 85, 937-958.

Fernandez-Villaverde, J., P. Guerron-Quintana, K. Kuester, And J. Rubio-RAmirez (2015): "Fiscal volatility shocks and economic activity," American Economic Review, 105, 3352-3384. 